FERNANDA DE ASSIS BUENO AULER

\title{
Associação da radiografia, tomografia computadorizada e rinoscopia no auxílio diagnóstico das afecções em cavidade nasal e seios paranasais de cães
}

Dissertação apresentada ao programa de Pós-Graduação em Clínica Cirúrgica Veterinária da Faculdade de Medicina Veterinária e Zootecnia da Universidade de São Paulo para obtenção do título de Mestre em Ciências

Departamento:

Cirurgia

Área de Concentração:

Clínica Cirúrgica Veterinária Orientador:

Prof. Dr. Angelo João Stopiglia

São Paulo 
Autorizo a reprodução parcial ou total desta obra, para fins acadêmicos, desde que citada a fonte.

DADOS INTERNACIONAIS DE CATALOGAÇÃO-NA-PUBLICAÇÃO

(Biblioteca Virginie Buff D’Ápice da Faculdade de Medicina Veterinária e Zootecnia da Universidade de São Paulo)

Auler, Fernanda de Assis Bueno

Associação da radiografia, tomografia computadorizada e rinoscopia no auxílio diagnóstico das afecções em cavidade nasal e seios paranasais de cães / Fernanda de Assis Bueno Auler. -- 2010

$98 \mathrm{f}$ : : il.

Dissertação (Mestrado) - Universidade de São Paulo. Faculdade de Medicina Veterinária e Zootecnia. Departamento de Cirurgia, São Paulo, 2010.

Programa de Pós-Graduação: Clínica Cirúrgica Veterinária.

Área de concentração: Clínica Cirúrgica Veterinária.

Orientador: Prof. Dr. Angelo João Stopiglia.

1. Rinoscopia. 2. Afecções nasais. 3. Sinonasal. 4. Rinite 5. Tomografia computadorizada. 6. Radiografia I. Título. 


\section{ERRATA}

\begin{tabular}{cccll}
\hline Página & Parágrafo & Linha & Onde se lê & Leia-se \\
\hline 9 & 1 & 5 & Dissertação. $98 \mathrm{f.}$ & $98 \mathrm{f}$. Dissertação \\
11 & 1 & 5 & Dissertação. $98 \mathrm{f.}$ & $98 \mathrm{f}$. Dissertação \\
13 & 1 & 1 & Ausente & A Ausente \\
13 & 2 & 2 & Cm & cm \\
\hline
\end{tabular}




\section{Comissão de Ética no uso de animais}

\section{CERTIFICADO}

Certificamos que o Projeto intitulado "Associação da rinoscopia e tomografia nas principais afecções em seios paranasais e cavidade nasal de cães: contribuição diagnóstica", protocolado sob o no 1495/2008, utilizando cães com sintomas referentes a afecções nasais e sinonasais atendidos pelo HOVET-USP, sob a responsabilidade do Prof. Dr. Angelo João Stopiglia, está de acordo com os princípios éticos de experimentação animal da "Comissão de Ética no uso de animais" da Faculdade de Medicina Veterinária e Zootecnia da Universidade de São Paulo e foi aprovado em reunião de 01/10/2008.

We certify that the Research "Association rhinoscopy and tomography in major diseases in the paranasal sinuses and nasal cavity of dogs: diagnostic contribution", protocol number 1495/2008, under the responsibility Prof. Dr. Angelo João Stopiglia, agree with Ethical Principles in Animal Research adopted by "Ethic Committee in the use of animals" of the School of Veterinary Medicine and Animal Science of University of São Paulo and was approved in the meeting of day $10 / 01 / 2008$.

São Paulo, 28 de maio de 2010

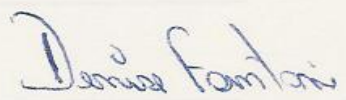

Profa. Dra. Denise Tabacchi Fantoni

Presidente

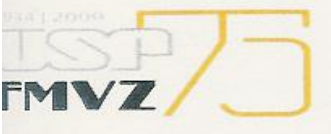




\section{FOLHA DE AVALIAÇÃO}

Nome: AULER, Fernanda de Assis Bueno

Título: Associação da radiografia, tomografia computadorizada e rinoscopia no auxílio diagnóstico das afecções em cavidade nasal e seios paranasais de cães

Dissertação apresentada ao programa de Pós-Graduação em Clínica Cirúrgica Veterinária da Faculdade de Medicina Veterinária e Zootecnia da Universidade de São Paulo para obtenção do título de Mestre em Ciências

Data:

Banca Examinadora

Prof. Dr.

Assinatura:

Prof. Dr.

Assinatura:

Prof. Dr.

Assinatura:
Instituição:

Julgamento:

Instituição:

Julgamento:

Instituição:

Julgamento: 
Agradeço a Deus por sempre iluminar meu caminho e por todas as coisas boas da minha vida. 


\section{DEDICATÓRIA}

À minha mãe Olivia Teresa, por tudo que sou, pela sua dedicação, força, apoio, amor incondicional e por estar ao meu lado em todas as horas.

Ao André, por seu amor, carinho, companheirismo, paciência, incentivo, compreensão e dedicação.

Aos meus filhos Pedro e Guilherme, os amores da minha vida, por seu amor, paciência e compreensão com meu trabalho.

À Rafaella, minha amada filha do coração.

Ao meu pai José Otávio, por seu amor, orientação e apoio à minha formação.

As minhas irmãs, Daniela e Manuela.

A toda a minha família e amigos pela amizade, alegrias, boas risadas e estarem sempre ao meu lado. 


\section{AGRADECIMENTOS}

Ao Profo. Dr. Angelo João Stopiglia, por sua confiança, orientação, oportunidade e amizade. Tenho grande admiração.

À Profa Dra. Denise Fantoni, por seu incentivo, amizade e conselhos que foram muito importantes para a realização deste trabalho.

Ao Franz Yoshitoshi, por ser um grande mestre e pelos seus ensinamentos sobre endoscopia, seu incentivo, oportunidade, confiança e amizade.

À amiga Leda Marques de Oliveira por sua amizade, companheirismo, apoio, incentivo e colaboração para a realização deste trabalho.

À Profa Dra. Ana Carolina Brandão de Campos Fonseca Pinto, pela amizade, dedicação, auxílio, conselhos e sua colaboração fundamental na realização deste trabalho.

À Médica Veterinária Silvana Unruh, pela amizade, dedicação, por sua colaboração e grande contribuição na avaliação das radiografias para este trabalho.

Aos amigos e pós- graduandos Carina Outi Baroni, Gabriela Paola Banon e Lenin Arturo Villamizar Martinez pela amizade e por toda a ajuda, da qual, foi fundamental para a realização deste trabalho.

Aos Professores, Dr. Luis Cláudio Lopes da Silva e Dr. André Zoppa, pelo incentivo, confiança e ensinamentos sobre endoscopia.

À Prof ${ }^{a}$ Dra. Silvia Cortopassi pela dedicação e paciência durante as anestesias.

À Profa Dra. Júlia Matera pela confiança e ensinamentos.

À Profa Dra. Denise Schwartz, pela amizade, confiança e encaminhamento de casos. Às Médicas Veterinárias contratadas do Serviço de Cirurgia do HOVET-FMVZ/USP Viviane Sanchez Galeazzi, Patricia Ferreira de Castro, Andressa Gianotti Campos, 
Sandra Aparecida Rosner e Tatiana Soares, pela amizade, confiança, ensinamentos e encaminhamento dos casos. Sua colaboração foi fundamental para este trabalho.

Às Médicas Veterinárias Patrícia Flor e Geni Patricio, pela amizade, anestesias e paciência durante os procedimentos, e por dividirem seus conhecimentos.

Aos muito especiais funcionários dos Serviços de Cirurgia de Pequenos e Grandes Animais do HOVET- FMVZ/USP Jesus dos Anjos Vieira, Otávio Rodrigues dos Santos, Clédson Lélis dos Santos, José Miron Oliveira da Silva, Henrique Fragoso e Cícero da Silva, por sempre estarem dispostos a ajudar.

Às Médicas Veterinárias contratadas do Serviço de Clínica Médica do HOVETFMVZ/USP Denise Simões, Bruna Coelho, Paula Rumi, Vera Wirthl e Khadine Kanayama pela confiança e encaminhamento dos casos.

Aos amigos da pós-graduação Carolina Scarpa, Thaís Casagrande, Luiz Felipe de Oliveira Barros, Diogo Gorayeb, Ayne Hayashi, Ewaldo de Mattos Junior, Vanessa Ferraz, Marcos Della Nina, Tatiana Mariani, Daniela Izquierdo, Olicies da Cunha, Rodrigo Marúcio, Adalberto Monteiro Filho, Lourenço Cotes.

A todos os Residentes do HOVET- FMVZ/USP, pelos casos encaminhados. Aos secretários Belarmino Ney Pereira e Alessandra Souza pela atenção, paciência e ajuda em todas as horas.

À Dra. Ludhmila Hajjar pela amizade, conselhos e ajuda na confecção desta tese. À Júlia Fushikuma pela ajuda na realização da análise estatística deste trabalho. A todas bibliotecárias, em especial, Sandra Toledo e Elena Tanganini. A todos os funcionários do Serviço de Imagem do HOVET-FMVZ/USP, pela ajuda e paciência.

À Pretinha, Zoya, Spike e Tara meus queridos e fiéis companheiros. 
Ao Conselho Nacional de Desenvolvimento Científico e Tecnológico - CNPq - Brasil pelo apoio financeiro durante a realização de mestrado.

A todos os animais, muito obrigada, e aos proprietários pela confiança e respeito.

A todas as pessoas que de alguma forma contribuíram para a realização deste trabalho.

Muito Obrigada!! 


\section{RESUMO}

AULER, F.A.B. Associação da radiografia, tomografia computadorizada e rinoscopia no auxílio diagnóstico das afecções em cavidade nasal e seios paranasais de cães. [Association of radiography, computed tomography and rhinoscopy in aid diagnosis of disorders in the nasal cavity and paranasal sinuses of dogs]. 2010. 98 f. Dissertação. (Mestrado em Ciências) - Faculdade de Medicina Veterinária e Zootecnia da Universidade de São Paulo, São Paulo, 2010.

Introdução: As afecções nasais e sinonasais em cães possuem causas variadas, e algumas vezes cursam com sinusites, sendo raros os casos que não há doença nasal pré-existente. O diagnóstico presuntivo é baseado nas manifestações clínicas como secreção nasal uni ou bilateral anormais, esternutações, esternutações reversas paroxísticas, respiração estertorosa, engasgos, halitose, epistaxes, rinorragia, tosse, distrição respiratória, dor e deformação facial. Para concluir o diagnóstico, são indicados exames de imagem, rinoscopia, culturas, citologia e histopatológico. Objetivo: O presente estudo observacional teve como objetivo avaliar a contribuição ao diagnóstico das afecções da cavidade nasal e seios paranasais de cães, da radiografia, tomografia computadorizada e rinoscopia, realizando-se a comparação dos métodos diagnósticos mediante ao escore comparativo idealizado para este fim. Materiais e métodos: Foram utilizados 20 cães atendidos do Hospital Veterinário da Faculdade de Medicina Veterinária e Zootecnia da Universidade de São Paulo, com manifestações clínicas compatíveis com afecção nasal e submetidos a exame radiográfico, tomográfico e rinoscópico. A biópsia foi realizada, em 18 cães, por meio da rinoscopia, nos casos em que visibilizou-se proliferação tecidual, úlcera ou alteração na mucosa nasal sendo encaminhadas para estudo histológico. Resultados: Foram observados resultados estatisticamente significativos, baseados pelo escore, a radiografia em conjunto com a tomografia computadorizada, a rinoscopia associada à tomografia computadorizada e, também, a rinoscopia isoladamente, como métodos diagnósticos mais específicos na diferenciação de lesão maligna. A rinoscopia demonstrou como vantagem a visibilização direta diferenciando a presença ou não de inflamação ou proliferação tecidual, alteração anatômica, corpo estranho e placa fúngica. Conclusão: Os resultados do presente estudo indicam que embora possuam especifidade diferentes a utilização da radiografia, tomografia computadorizada e rinoscopia se complementaram como métodos diagnósticos nas afecções nasais e sinonasais dos cães avaliados. Nos casos de proliferação tecidual 
o estudo histológico demonstrou ser mais útil para conclusão diagnóstica em comparação aos exames de imagem e a rinoscopia.

Palavras-chave: Rinoscopia. Afecções nasais. Sinonasal. Rinite. Tomografia computadorizada. Radiografia. 


\section{ABSTRACT}

AULER, F. A. B. Association of radiography, computed tomography and rhinoscopy in aid diagnosis of disorders in the nasal cavity and paranasal sinuses of dogs [Associação da radiografia, tomografia computadorizada e rinoscopia no auxílio diagnóstico das afecções em cavidade nasal e seios paranasais de cães]. 2010. 98 f. Dissertação. (Mestrado em Ciências) - Faculdade de Medicina Veterinária e Zootecnia da Universidade de São Paulo, São Paulo, 2010.

Introduction: The nasal and sinus disorders in dogs have various causes, and sometimes go with sinusitis that there is no pre-existing nasal disease. The presumptive diagnosis is based on clinical manifestations as nasal discharge, sneezing, reverse sneezing, gagging, stertor, halitosis, epistaxis, cough, open-mouth breathing, pain and facial deformation. To complete the diagnosis, image examinations, rhinoscopy, cultures, cytology and histopathological fidings. Objectives: This observational study aimed to evaluate the contribution to the diagnosis of disorders of the nasal cavity and paranasal in dogs, radiography, computed tomography and rhinoscopy, performing comparison of diagnostic methods through the comparative score conceived for this purpose. Materials and methods: This study used 20 dogs of Veterinary Hospital of the Faculty of Veterinary Medicine and Zootechny of the University of São Paulo, with clinical signs compatible with nasal disorder and undergone radiographic examination, computed tomography and rhinoscopy. The biopsy was performed on 18 dogs through rhinoscopy, where is tissue proliferation, ulcer or change in the nasal mucosa histology study being forwarded to. Results: Significant results were observed by the score with radiography, computed tomography, rhinoscopy associated with computed tomography, and also, separately, as rhinoscopy diagnostic methods more specific differentiation of malignant lesion. The rhinoscopy demonstrated how advantage to visualize directly differentiating presence or not of inflammation or tissue proliferation, alteration, foreign body and fungal plaques. Conclusion: The results of this study indicate that although having different specific utilization, radiography, computed tomography and rhinoscopy as diagnostic methods arranged in nasal disorders of dogs and evaluated. In cases of tissue proliferation, histological study proved most useful in final diagnostic compared to the image exams and rhinoscopy. 
Keywords: Rhinoscopy. Nasal disorders. Sinus. Rhinitis. Computed tomography. Radiography. 
LISTA DE ABREVIATURAS E SIGLAS

A

$\mathrm{cm}$

F

FMVZ/USP

kV

$\mathrm{Kg}$

M

$\mathrm{mA}$

$\mathrm{mg}$

$\mathrm{ml}$

$\mathrm{mm}$

NA

NR

PB

PD

PE

RM

$\mathrm{RX}$

SP

SRD

TCC
Ausente

Centímetros

Fêmea

Faculdade de Medicina Veterinária

e Zootecnia da Universidade de

São Paulo

Quilovoltagem

Quilograma

Macho

Miliámperes

Miligramas

Mililitros

Milimetros

Não Avaliado

Não Realizado

Presente Bilateral

Presente Direito

Presente Esquerdo

Ressonância Magnética

Radiografia

São Paulo

Sem Raça Definida

Tomografia Computadorizada de Crânio 
Tomografia Computadorizada

TVT

Tumor Venéreo Transmissível 


\section{LISTA DE SÍMBOLOS}




\section{LISTA DE TABELAS}

Tabela 01 - Descrição das raças, sexo e idade dos animais incluídos no presente estudo e submetidos ao estudo radiográfico digital, tomografia e rinoscopia, e suas manifestações clinicas presentes.

Tabela 02 - Descrição das alterações visibilizadas por meio do exame radiográfico digital do crânio

Tabela 03 - Descrição das alterações visibilizadas por meio do exame tomográfico do crânio dos cães inclusos no presente estudo

Tabela 04 - Descrição das regiões selecionadas e as alterações visibilizada através do exame radiográfico e tomográfico do crânio dos cães inclusos no presente estudo.

Tabela 05 - Classificação das rinites, sugeridas pelas alterações visibilizadas por meio do exame radiográfico e tomográfico do crânio dos cães inclusos no presente estudo.

Tabela 06 - Descrição das alterações em cavidade nasal e nasofaringe, visibilizadas por meio da rinoscopia.

Tabela 07 - Descrição dos resultados do estudo histopatológico do material coletado por meio da rinoscopia.

Tabela 08 - Distribuição dos cães segundo a presença de lesão pela radiografia.

Tabela 09 - Distribuição dos cães segundo a extensão de lesão pela radiografia.

Tabela 10 - Distribuição dos cães segundo a suspeita diagnóstica de lesão pela radiografia.

Tabela 11 - Distribuição dos cães segundo a presença de lesão pela tomografia computadorizada.

Tabela 12 - Distribuição dos cães segundo a extensão de lesão pela tomografia computadorizada.

Tabela 13 - Distribuição dos cães segundo a suspeita diagnóstica de lesão pela tomografia computadorizada.

Tabela 14 - Distribuição dos cães segundo a presença de lesão pela rinoscopia.

Tabela 15 - Distribuição dos cães segundo a extensão de lesão pela rinoscopia. 
Tabela 16 - Distribuição dos cães segundo a suspeita diagnóstica de lesão pela rinoscopia.

Tabela 17 - Distribuição dos cães segundo os resultados do estudo histopatológico.

Tabela 18 - Distribuição dos cães segundo o tipo de lesão

Tabela 19 - Distribuição dos cães segundo a rinite pelo exame radiográfico

Tabela 20 - Distribuição dos cães segundo a rinite pelo exame tomográfico.

Tabela 21 - Distribuição dos cães segundo os escores e o tipo de lesão.

Tabela 22 - Distribuição dos cães segundo os escores de rinite e o tipo de lesão.

Tabela 23 - Média e desvio padrão das somas de escores por tipo de lesão.

Tabela 24 - Média e desvio padrão das somas de escores por tipo de lesão e alterações visibilizadas por meio dos exames de imagem.

Tabela 25 - Resultados modelo regressão logística multivariada.

Tabela 26 - Escore exame radiográfico.

Tabela 27 - Escore exame tomográfico. .96

Tabela 28 - Escore rinoscopia. 


\section{LISTA DE FIGURAS}

Figura 01 - Posicionamento em decúbito lateral do paciente durante a realização da radiografia na projeção latero lateral..

Figura 02 - Posicionamento em decúbito dorsal durante a realização de radiografia na projeção dorsoventral.

Figura 03 - Posicionamento em decúbito ventral durante a realização de radiografia na projeção ventro-dorsal com a boca aberta

Figura 04 - Posicionamento em decúbito ventral durante a realização de radiografia na projeção ventro-dorsal com a boca aberta.

Figura 05 - Posicionamento em decúbito esternal durante a realização da tomografia computadorizada.

Figura 06 - Posicionamento em decúbito esternal durante a realização da tomografia computadorizada.

Figura 07 - Inspeção das coanas, pela técnica de retroflexão, por meio da rinoscopia posterior com endoscópio flexível, em cadáver de cão.

Figura 08 - Imagem da nasofaringe de cão e das coanas normais visibilizadas pela técnica de retroflexão, por meio da rinoscopia posterior com endoscópio flexível.

Figura 09 - Cavidade nasal anterior de cão normal, visibilizada por meio da rinoscopia com endoscópio rígido.

Figura 10 - Cavidade nasal anterior de cão normal, visibilizada por meio da rinoscopia com endoscópio rígido.

Figura 11 - Imagem de cão com secreção nasal muco-purulenta. .57

Figura 12 - Imagem de cão com deformação facial

Figura 13 - (A) Imagem radiográfica digital de crânio de cão, Golden Retriver macho, dez anos de idade, em projeção dorso-ventral com diagnóstico conclusivo de carcinoma.(B) Imagem radiográfica digital de crânio, do mesmo animal, em projeção latero-lateral. 
Figura 14 - Imagem radiográfica digital de crânio de cão, SRD,macho,cinco anos de idade, em projeção dorso-ventral e diagnóstico de aspergilose nasal.

Figura 15 - (A) Imagem radiográfica digital de crânio de cão, SRD, fêmea, oito anos de idade, em projeção ventro-dorsal com a boca aberta e diagnóstico conclusivo de rinite linfoplasmocitária (B) Imagem radiográfica digital de crânio, do mesmo animal, em projeção latero-lateral.

Figura 16 - (A) Imagem tomográfica digitalizada de crânio de cão Golden Retriver, macho, dez anos de idade a nível de cavidades nasais e seio frontal com diagnóstico conclusivo de carcinoma. (B) Imagem tomográfica digitalizada de crânio do mesmo animal a nível de cavidades nasais e seio frontal.

Figura 17 - (A) Imagem tomográfica digitalizada de crânio de cão, SRD, macho,cinco anos de idade a nível de cavidades nasais com diagnóstico conclusivo de aspergilose nasal. (B) Imagem tomográfica digitalizada de crânio domesmo animal a nivel de seio frontal.

Figura 18 - (A) Imagem tomográfica digitalizada de crânio de cão, SRD, fêmea, oito anos de idade a nível de cavidades nasais com diagnóstico conclusivo de rinite linfoplasmocitária. (B) Imagem tomográfica digitalizada de crânio do mesmo animal a nível de seio frontal.

Figura 19 - Imagem digitalizada de cavidade nasal direita durante a rinoscopia anterior de cão, Golden Retriver, macho, dez anos de idade com diagnóstico conclusivo de carcinoma

Figura 20 - Imagem digitalizada de nasofaringe durante a rinoscopia posterior de cão Golden Retriver, macho, dez anos de idade com diagnóstico conclusivo de carcinoma.

Figura 21 - Imagem digitalizada de cavidade nasal esquerda durante a rinoscopia anterior de cão, SRD, fêmea, oito anos de idade com diagnóstico conclusivo de rinite linfoplasmocitária

Figura 22 - Imagem digitalizada de nasofaringe durante a rinoscopia posterior cão, SRD, fêmea, oito anos de idade com diagnóstico conclusivo de rinite linfoplasmocitária. 
Figura 23 e 24 - Imagem digitalizada de cavidade nasal direita durante a rinoscopia anterior de cão, SRD, macho, cinco anos de idade com diagnóstico conclusivo de aspergilose nasal. 


\section{LISTA DE GRÁFICOS}

Gráfico 01 - Probabilidade de neoplasia maligna segundo o escore. 


\section{SUMÁRIO}

1. INTRODUÇÃO

2. REVISÃO DE LITERATURA

2.1. Anatomia do nariz e narinas. .27

2.2. Anatomia da cavidade nasal 27

2.3. Anatomia dos seios paranasais ............................................................... 28

2.4 Afecções nasais e sinonasais ................................................................29

2.4.1 Rinite inflamatória .29

2.4.2 Rinite bacteriana 30

2.4.3 Rinite fúngica. 30

2.4.4 Neoplasia 32

2.4.5 Corpo estranho nasal 34

2.4.6 Trauma 35

2.4.7 Rinite parasitária 36

2.4.8 Rinite secundária à afecção dental 36

2.5 Abordagens diagnósticas para as principais doenças nasais e sinonasais

2.5.1 Exame radiográfico 38

2.5.2 Tomografia Computadorizada 40

2.5.3 Rinoscopia.

2.5.4 Sinoscopia.

2.5.5 Cultura bacteriana e fúngica

2.5.6 Citologia

2.5.7 Biópsia

3. OBJETIVO

4. MATERIAL E MÉTODO.

4.1 Animais

4.2 Critérios de inclusão 
4.4 Anestesia

4.5 Tomografia Computadorizada..............................................................50

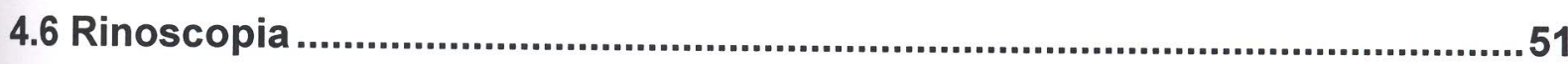

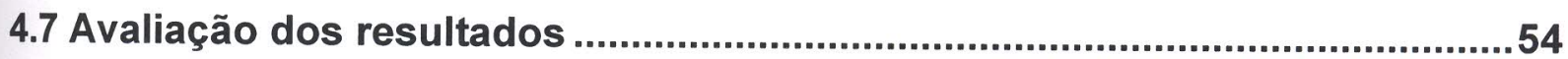

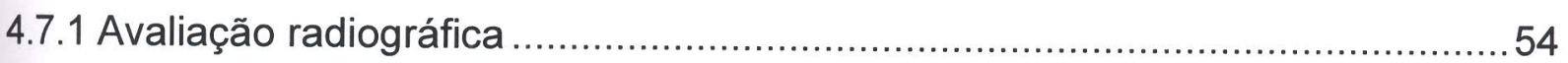

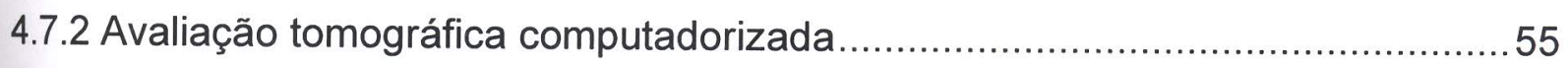

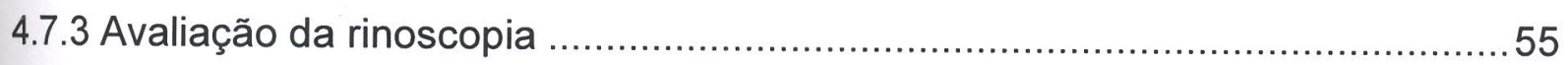

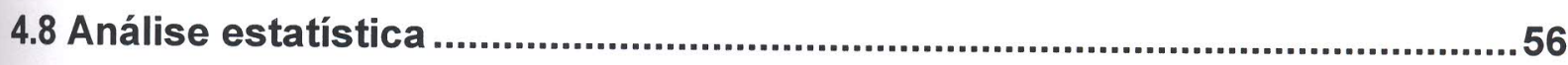

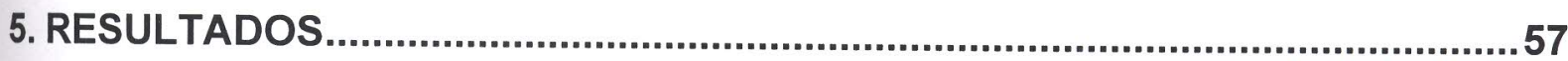

5.1 Descrição do exame radiográfico .........................................................58

5.2 Descrição do exame tomográfico computadorizado ...................................59

5.3 Descrição dos exames radiográficos e tomográficos ..................................61

5.4 Descrição da rinoscopia ....................................................................62

5.5 Descrição do estudo histopatológico ......................................................64

5.6 Avaliação estatística dos resultados........................................................65

5.6.1 Avaliação do escore da radiografia .................................................... 65

5.6.2 Avaliação escore da tomografia computadorizada ...................................66

5.6.3 Avaliação escore da rinoscopia........................................................67

5.6.4 Avaliação distribuição resultado histopatológico .......................................68

5.6.5 Classificação das rinites por meio do exame radiográfico ............................69

5.6.6 Classificação das rinites por meio do exame tomográfico............................70

5.6.7 Avaliação comparativa dos escores e o tipo de lesão ..................................70

5.6.8 Avaliação segundo a classificação de rinite e o tipo de lesão .........................72

5.6.8 Avaliação da média e desvio padrão...................................................73

5.6.9 Avaliação comparativa das alterações e o tipo de lesão .............................73

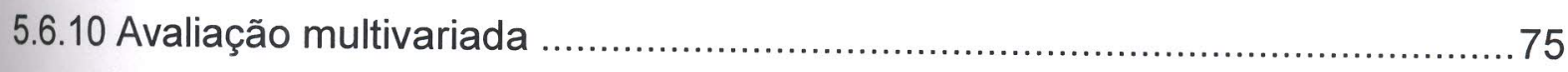

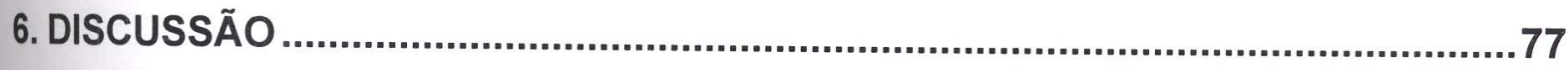

6.1 Limitações do estudo ............................................................................ 88

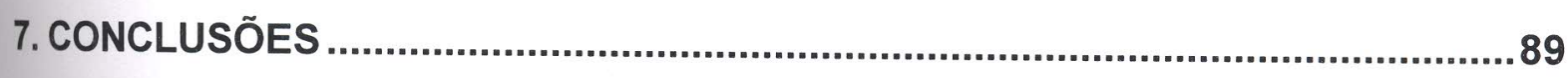

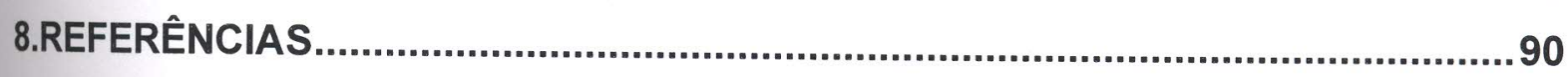

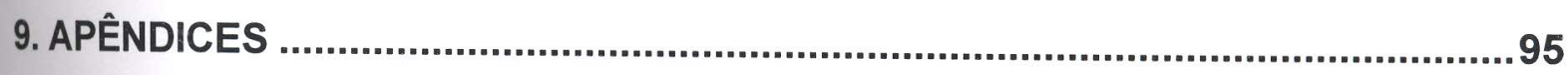

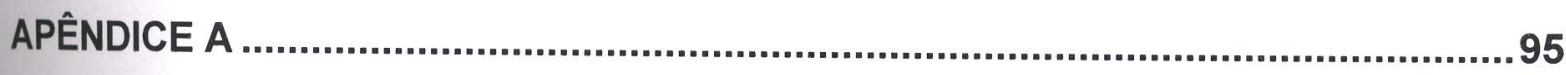

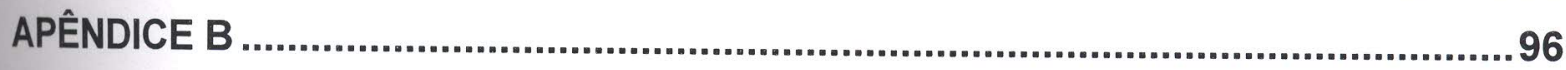


APÊNDICE C

.97

ANEXOS. 


\section{INTRODUÇÃO}

As afecções nasais e ou sinonasais em cães possuem causas variadas, podem ser classificadas como rinites primárias quando há causas alérgicas, bacterianas, fúngicas e neoplásicas, ou secundárias em casos de traumatismos, corpos estranhos, parasitas e afecções dentárias. Geralmente cursam com sinusites, sendo raros os casos em que não há doença nasal pré-existente (McCARTHY; McDEIRMAN, 1990; KING, 1997; FORRESTER; NOFTSINGER, 2002; DAVIDSON et al., 2004). O diagnóstico presuntivo é baseado na anamnese, exame físico e nas manifestações clínicas como secreção nasal uni ou bilateral, esternutações, esternutações reversas paroxísticas, respiração estertorosa, engasgos, halitose, epistaxes, rinorragia, tosse, distrição respiratória, dor e deformação facial (McCARTHY; McDEIRMAN, 1990; BURK, 1992 a; TASKER, 1999; FORRESTER; NOFTSINGER, 2002; DAVIDSON et al., 2004). Contudo, para concluir o diagnóstico, são ainda necessários exames mais específicos como radiografia simples de crânio, tomografia computadorizada (TC), e ou ressonância magnética (RM), rinoscopia, culturas, citologia e histopatológico. O exame radiográfico simples de crânio é o primeiro a ser indicado nestes casos, mas nem sempre permite visibilizar com precisão a extensão e o envolvimento das estruturas relacionadas com a afecção presente, devido a sobreposição de imagens (DAVIDSON et al., 2004; LEFEBVRE; KUEHN; WORTINGER, 2005). A tomografia computadorizada de crânio (TCC) apresenta vantagens em relação a radiografia convencional, pois permite por meio de cortes transversais, avaliar detalhadamente a cavidade nasal, os seios paranasais e as estruturas anatômicas envolvidas com melhor definição que a radiografia (THRALL et al., 1989; WITHROW, 1989; BURK, 1992 a; BURK, 1992 b; DAVIDSON et al., 2004; LEFEBVRE; KUEHN; WORTINGER, 2005; JOHNSON; WISNER, 2007). De acordo com a literatura de estudos realizados, a utilização de exames de imagem de grande acurácia, não descartam a indicação da rinoscopia nas afecções nasais, da qual possibilita a avaliação das cavidades nasais de forma direta e minimamente invasiva, auxiliando o diagnóstico. Sua contribuição se estende ainda na coleta de material para exame citológico, exame histopatológico e 
cultura, coletados sob orientação visual (McCARTHY; McDEIRMAN, 1990; DAVIDSON et al., 2004; VENKERVAN HAAGEN, 2005; PIETRA, et al., 2010). No entanto, a rinoscopia pode não trazer informações quanto à extensão da lesão. Outra limitação, inerente a este exame, seria devido a presença de secreção mucopurulenta espessa ou sanguinolenta e hemorragia nasal durante o procedimento, que prejudicam a visibilização adequada das cavidades nasais (NOONE, 2001; FORRESTER; JONES, 2002; McCARTHY, 2005).

Existem poucos estudos presentes na literatura, comparando estes métodos diagnósticos em afecções nasais em um mesmo trabalho, razão pela qual se realizou a presente pesquisa, a fim de subsidiar a literatura no sentido de observarse, quando associados, quão poderiam auxiliar, de forma mais precisa, o diagnóstico das afecções nasais e sinonasais em cães. 


\section{REVISÃO DE LITERATURA}

\subsection{Anatomia do nariz e narinas}

O nariz é considerado a porção rostral do sistema respiratório e compreende a parte externa do nariz, ossos, cartilagens móveis e a cavidade nasal (VENKERVAN HAAGEN, 2005).

\subsection{Anatomia da cavidade nasal}

A cavidade nasal é estreita e alongada, porém, no cão o comprimento desta é relativo e depende, em grande parte, se o tipo de crânio é braquiocefálico, mesaticefálico ou dolicocefálico (HARE, 1986). Divide-se longitudinalmente na linha mediana em dois lados simétricos, sem comunicação entre si, por um septo, sendo cartilaginoso rostralmente e ósseo caudalmente, tendo como limite anterior o orifício nasal que estende-se até o meato nasofaríngeo (EVANS, 1993; DAVIDSON et al., 2004). A parte cartilaginosa do septo nasal se estende rostralmente da placa perpendicular do etmóide aos ossos incisivos e a parte óssea do septo nasal é formada pela placa perpendicular do etmóide e pelo vômer (HARE, 1986). Cada cavidade é ocupada, em sua maioria, por estruturas denominadas conchas que se projetam da parede lateral e quase atingem o septo nasal (HARE, 1986). São formadas por cartilagem ou estruturas alongadas finamente ossificadas, recobertas por mucosa e divididas em concha dorsal, concha ventral e concha etmoidal (EVANS, 1993). As conchas dorsais e ventrais estão localizadas rostralmente e podem ser denominadas respectivamente de nasoturbinados e maxiloturbinados. As conchas etmoidais estão localizadas caudalmente, e podem ser denominadas de etmoturbinados (EVANS, 1993; DAVIDSON et al., 2004). A concha nasal dorsal tem formato espiralado e alongado ligada ao osso etmoidal e ao osso nasal, formando o meato nasal dorsal. A concha nasal ventral apresenta uma série de espirais pregueadas a ela, e se estende do primeiro ao terceiro pré-molar, e o meato nasal médio é o espaço que se forma entre as conchas dorsal e ventral (HARE, 1986; EVANS, 1993). O meato nasal ventral é maior que os outros dois e se estende ao 
meato nasofaríngeo, penetrando na nasofaringe através das coanas (HARE, 1986). Os meatos nasais são câmaras longitudinalmente posicionadas e formadas pelo espaço entre as conchas nasais. Próximo ao septo nasal localiza-se o meato nasal comum, conectado aos outros três meatos e orientado verticalmente (HARE, 1986; BEDFORD, 1997; DAVIDSON et al., 2004). A placa cribriforme é um dos quatro componentes do osso etmoide, que separa a cavidade nasal da craniana, de aparência fenestrada e apresenta em sua composição fibras do nervo olfatório (DAVIDSON et al., 2004; POWDER; ROSE; CRAWFORD, 2006). As cavidades nasais são amplamente circundadas e protegidas por ossos, que incluem o osso frontal, a maxila, ossos nasais, ossos incisivos, o vômer e os ossos palatinos (HARE, 1986; DAVIDSON et al., 2004).

\subsection{Anatomia dos seios paranasais}

Os seios paranasais são estruturas ocas da cavidade nasal, conectados com as passagens respiratórias e descritos como parte do aparelho respiratório. Constituem os seios paranasais, o recesso maxilar, os seios frontais e esfenoidais (BEDFORD, 1997). O recesso maxilar comunica-se livremente com a cavidade nasal, o que o torna mais apropriadamente um recesso do que um verdadeiro seio (HARE, 1986) e encontra-se presente na superfície nasal da maxila, dorsal às raízes a partir do dente quarto pré-molar superior (DAVIDSON et al., 2004). Os seios frontais estão situados primariamente entre as tábuas externa (dorsal) e interna (ventral) dos ossos frontais. No cão, os seios frontais são divididos sem comunicação entre si, em um pequeno seio medial e um seio lateral maior abrindo-se no meato etmoidal dorsal (HARE, 1986; DAVIDSON et al., 2004). Podem ser muito pequenos ou ausentes nos braquiocefálicos e de maior tamanho nos mesaticefálicos e dolicocefálicos (HARE, 1986; DAVIDSON et al., 2004). Revestidos por membrana mucosa ciliada completam a drenagem por meio de óstios separados (ductos nasofrontais) (DAVIDSON et al., 2004). O seio esfenóide no cão encontra-se no interior do osso pré-esfenóide, ocupado pelas partes ventrocaudais dos etmoturbinados (HARE, 1986; BEDFORD,1997). Nos casos de doenças sinunosais em cães, são os seios 
frontais que possuem significado clínico. Seu envolvimento pode estar relacionado apenas com a drenagem deficiente, ou pela extensão da lesão por toxina fúngica ou formação tumoral (BEDFORD,1997; DAVIDSON et al., 2004).

\subsection{Afecções nasais e sinonasais}

O trato respiratório nos cães é a maior porta de entrada para agentes infecciosos, bem como, sujeito a entrada de corpo estranho, trauma, e também, ao desenvolvimento de neoplasias (FORD, 1990).

\subsubsection{Rinite inflamatória}

A rinite inflamatória na maioria dos casos está relacionada a pacientes que apresentam doença nasal crônica, e geralmente há presença de infiltrados linfoplasmocitários na mucosa nasal característicos de processo inflamatório (DAVIDSON et al., 2004; WINDSOR; JOHNSON, 2006). A patogênese da rinite linfoplasmocitária é desconhecida, embora tenha sido descrita como doença imunomediada (BURGENER; SLOCOMBER; ZERBE, 1987). Infecção e alergia também podem estar associadas a esta afecção, e é comum não haver melhora clínica e resposta adequada à antibioticoterapia, corticóides e anti-histaminicos (WINDSOR; JOHNSON, 2006). Agentes alérgicos e ou substâncias irritativas também podem induzir inflamação em alguns animais (WINDSOR; JOHNSON, 2006). Em seres humanos a rinite alérgica possui importância para a saúde pública. Sua incidência na população é alta, e sua prevalência só é menos significativa que as rinites virais. A rinite alérgica representa, hoje, problema de extensão mundial, com tendência a se agravar cada vez mais, em virtude do progresso industrial, com o surgimento crescente de novas substâncias alergênicas, aumento das grandes concentrações urbanas e da poluição ambiental (BAGATIN; ANDRADE DA COSTA, 2006). Em cães a rinite alérgica tem sido considerada doença, porém, ainda pouco estabelecida (WINDSOR; JOHNSON, 2006). A rinite inflamatória pode ser caracterizada por meio da imagem radiográfica por opacificação e lesões multifocais. A imagem tomográfica, nestes casos, pode indicar acúmulo de fluído nas passagens aéreas, opacificação de tecidos moles, destruição de turbinados de pouca 
severidade (RUSSO; LAMB; JAKOVLJEVIC, 2000; WINDSOR et al., 2004, LEFEBVRE; KUEHN; WORTINGER, 2005, et al., 2005). Na rinoscopia secreção mucosa ou muco-purulenta podem estar presentes, além de hiperemia, edema, erosões, friabilidade na mucosa acompanhada ou não de atrofia ou de destruição de turbinados (WINDSOR et al., 2004).

\subsubsection{Rinite bacteriana}

Rinite por infecção bacteriana primária em cães é raro, enquanto que as infecções secundárias são comuns, mas o tratamento com antibióticos acaba sendo responsivo positivamente, devido à presença de algumas bactérias, como a Chamydophila, Mycoplasma, ou Bartonella das quais também podem estar presentes na patogênese da rinite linfoplasmocitária (DAVIDSON et al., 2004; McCARTHY, 2005; VENKERVAN HAAGEN, 2005; WINDSOR; JOHNSON, 2006). A cultura bacteriana indica o crescimento de bactérias da flora bacteriana nasal incluindo Staphylococcus, Streptococcus, Escherichia coli, Proteus, Pasteurella, Corynebacterium, Bordetella e Pseudomonas (WINDSOR et al., 2004).

As manifestações clínicas envolvidas na rinite bacteriana são semelhantes à rinite inflamatória, assim como as imagens radiográficas e tomográficas, além do aspecto das cavidades nasais visibilizadas pela rinoscopia (DAVIDSON et al., , 2004; WINDSOR et al., 2004).

\subsubsection{Rinite fúngica}

Nos casos de rinite fúngica, a cultura para os fungos Aspergillus e Penicillium spp. da cavidade nasal de cães pode ser positiva mesmo não sendo estes os agentes causadores. No entanto, por ser oportunista e estar presente na flora da cavidade nasal, o Aspergillus spp. é responsável pelas principais rinites fúngicas e descarga nasal crônica em cães (BENITAH, 2006). A aspergilose nasal pode ser resultado da instalação do fungo associado a presença de corpo estranho nasal, afecções nasais pré-existentes, trauma ou em casos de imunossupressão (JOHNSON et al., 2006). O progresso da doença nos animais afetados inicia-se na cavidade nasal e como regra estende-se para os seios frontais, se tornando afecção 
sinonasal decorrente da endotoxina produzida pelo fungo, responsável, também, pela necrose e destruição dos turbinados e etmoturbinados, sendo o $A$. fumigatus a espécie mais comum envolvida nestes casos (BENITAH, 2006). Esta rinite é relativamente comum nos cães e as manifestações clínicas são secreção nasal profusa serosa a hemorrágica, uni ou bilateral, com períodos alternados de epistaxe, crostas, ulceração nas narinas acompanhadas ou não de despigmentação. Por meio do exame radiográfico é comum visibilizar aumento da densidade de tecidos moles e lise óssea (SAUNDERS; VAN BREE, 2003; VENKERVAN HAAGEN, 2005; JOHNSON et al., 2006; BENITAH, 2006).

O estudo, realizado por Saunders et al. (2004), teve como objetivo comparar por meio da radiografia de crânio, TCC, ressonância magnética e da rinoscopia, alterações encontradas nos 15 casos de cães com aspergilose nasal. De acordo com os autores, a ressonância magnética e a TCC apresentaram imagens sugestivas de rinite fúngica, com maior frequência do que as imagens radiográficas. A visibilização quanto à extensão das lesões e o grau de destruição óssea, por meio da radiografia foi inferior, em relação aos outros exames de imagem estudados. As imagens visibilizadas pela TCC apresentaram alterações significantemente maior quando comparada com as imagens radiográficas, porém, semelhantes as imagens da ressonância magnética. Pela rinoscopia, foi possível confirmar a doença visibilizando a colônia fúngica e tecido proliferativo, mas não foi útil como a TCC e a ressonância magnética em determinar a extensão da lesão e o acometimento de outras estruturas ósseas.

Em geral, nos casos de rinite fúngica, a rinoscopia colabora com a visibilização da destruição ou ausência de maxiloturbinados e etmoturbinados, permitindo acesso ao seio frontal, além da presença de necrose tecidual e placas fúngicas que podem ser de coloração esbranquiçada, amareladas ou esverdeadas presentes na cavidade nasal ou no seio frontal. O diagnóstico é concluído com a cultura destas placas e o estudo histopatológico da biópsia, que podem ser coletadas pela rinoscopia (BENITAH, 2006). Candida, Trichosporum e Cladosporidium são outros agentes que já foram isolados, principalmente em cães com rinite linfoplasmocitária (WINDSOR et al., 2004; WINDSOR; JOHNSON, 2006). 


\subsubsection{Neoplasia}

As neoplasias intranasais e sinonasais representam cerca de 59\% a $82 \%$ dos casos de neoplasia no trato respiratório e cerca de $1 \%$ a $2 \%$ de todos os casos de doenças neoplásicas em cães. A cavidade nasal é mais afetada do que seios paranasais e $80 \%$ são de caráter maligno com prognóstico reservado a ruim. Carcinomas, adenocarcinomas, carcinoma de células escamosas, compreendem cerca de dois terços dos tipos de neoplasia encontradas nestes casos. No entanto, tardam em metastatizar e sem tratamento a eutanásia é a escolha do proprietário poucos meses depois da progressão da doença, pois comumente, possuem crescimento rápido e agressivo (SHARP, et al., 1991; LANA; WITHROW, 2001; ELLIOT; MAYER, 2009).

Os cães dolicocefálicos e raças que possuem nariz mais longo estão entre os mais afetados, e são mais suscetíveis aqueles que vivem em locais urbanizados e com poluição aérea (LANA; WITHROW, 2001). Os cães braquiocefálicos possuem menos chances de desenvolver neoplasia intranasal (ELLIOT; MAYER, 2009). Os cães machos com idade média de 10 anos são mais acometidos e as raças de porte médio a grande, tem maior risco de desenvolver esta afecção (LANA; WITHROW, 2001).

Em estudo comparativo entre a radiografia de crânio e a TCC realizados por Park, Beck e Le Couteurs et al. (1992) houve superioridade na imagem tomográfica em relação a imagem radiográfica. As alterações associadas à neoplasia nasal foram avaliadas em 18 regiões anatômicas de 21 cães com suspeita de neoplasia nasal. A imagem da TCC demonstrou superioridade detectando alterações em 14 destas 18 regiões, e a imagem radiográfica em 10 regiões. Lise óssea e opacificação no seio esfeinoidal, em seios paranasais e a presença de obliteração em meato nasofaríngeo, entre outras, não foram bem definidas pelo exame radiográfico em comparação com a imagem tomográfica. Neste estudo a imagem radiográfica demonstrou menor sensibilidade, nestes casos, que a imagem tomográfica. As neoplasias dos 21 cães foram confirmadas pelo estudo histológico. Outros estudos realizados posteriormente por Burk (1992) b e Schwarz (1995) 
corroboraram com o resultado sobre a superioridade, especificidade e sensibilidade da TCC em relação à radiografia.

Em outro estudo retrospectivo, Miles et al.(2008), realizaram com 78 cães portadores de doenças nasais, a comparação entre imagens visibilizadas pela ressonância magnética o resultado do estudo histopatológico das amostras coletadas por meio da rinoscopia e rinotomia (três animais). Os 78 animais foram submetidos à RM seguida de rinoscopia para coleta de biópsia. Nas imagens adquiridas por meio da ressonância magnética onde visibilizou-se destruição de turbinados, envolvimento dos seios frontais e recesso maxilar, não foram significativas suficientemente para confirmar lesão neoplásica, porém nos cães com imagens contendo lise em placa cribriforme, vômer, invasão de seio esfenoidal e nasofaringe, sugeriu-se neoplasia intransal, das quais foram confirmadas pelo estudo histológico. Dentre as neoplasias nasais diagnosticadas a maior incidência foi de carcinoma, seguido de carcinomas de células escamosas e adenocarcinomas, condrossarcomas, linfossarcomas, sarcomas, carcinoma espinocelular, mastocitoma, hemangiossarcoma e osteocondrossarcoma multilobular.

Outro estudo retrospectivo realizado por Kondo et al. (2008), sobre neoplasias intranasais em 112 cães, o objetivo foi determinar o prognóstico e o estágio clínico, dos mesmos, baseado na extensão das lesões visibilizadas nas imagens tomográficas. Os cães foram submetidos ao exame radiográfico, TCC e as amostras foram coletadas por meio da rinotomia ou por meio de escova para o estudo citológico realizados imediatamente após a TCC. As neoplasias encontradas foram o adenocarcinoma (75,9\%), seguido de condrossarcoma $(10,7 \%)$, osteossarcoma $(4,5 \%)$, carcinoma de células escamosas $(2,7 \%)$ e tumor de células glandulares $(0,9 \%)$, todas confirmadas por meio do estudo histopatológico. As imagens visibilizadas foram divididas em três estágios (I,II e III) baseados em alterações como: (1) extensão da lesão tumoral com invasão uni ou bilateral nasal e ou paranasal; (2) destruição óssea e efeito de massa em plano nasal; (3) envolvimento da cavidade oral incluindo destruição do palato; (4) envolvimento da órbita e compressão ocular; (5) envolvimento de seio frontal e cerebral. O estágio I foi considerado nos casos onde não houvesse nenhum comprometimento das estruturas visibilizadas, de acordo, com as classificações propostas pela TCC. O estágio II quando houvesse uma imagem compatível com um dos parâmetros (1 ao 
5) e estágio III quando houvesse duas ou mais alterações, de acordo com os parâmetros de classificação, propostos pelos autores. Empregou-se o estágio IV nos casos em que houvesse envolvimento cerebral. Este estudo demonstrou que pacientes com condrossarcoma obtiveram melhor prognóstico e maior tempo de vida que os portadores de adenocarcinoma e carcinoma de células escamosas. Os 32 pacientes com imagens compatíveis com estágio III da TCC tiveram maior tempo de vida comparado com os 40 pacientes com imagens compatíveis ao estágio IV da TCC.

Proliferações teciduais, visibilizadas por meio da rinoscopia, na maioria dos casos, são recobertas por secreção mucosa a muco-purulenta, e também serosa a sanguinolenta, porém, de fácil remoção. A coloração de sua superfície pode ser esbranquiçada, rósea ou vinhosa, diferente das estruturas normais da cavidade nasal, pode ter superfície irregular ou lisa, vascularizada ou não e de aparência cística, sólida, ou polipóide. Algumas vezes, podem estar presentes, coágulos, fibrina ou necrose e inflamação ao redor da neoplasia, o que pode dificultar a coleta e não esclarecer o resultado do estudo histopatológico (McCARTHY, 2005). Portanto, a grande variabilidade no aspecto das neoplasias nasais, necessita a confirmação por meio histopatológico das amostras coletadas para classificar o tipo de neoplasia (McCARTHY, 2005). As neoplasias intranasais, também, acometem região de nasofaringe, e pode ser visibilizadas como proliferações teciduais em coanas, por meio da nasofaringoscopia ou rinoscopia posterior (BILLEN; DAY, 2006).

\subsubsection{Corpo estranho nasal}

Objetos podem adentrar a cavidade nasal rostralmente através das narinas e caudalmente pela nasofaringe. A rota caudal ocorre durante o engasgo, vômito ou regurgitação do material pelo palato duro na cavidade oral alojando na nasofaringe (WILLARD; RADLINSKY, 1999; McCARTHY, 2005). As manifestações clínicas apresentam-se de forma aguda, porém, a cronicidade pode estar presente quando não houve diagnóstico (VENKERVAN HAAGEN, 2005; McCARTHY, 2005). A presença de corpo estranho na cavidade nasal leva a produção de exsudato usualmente muco-purulento ou purulento de odor fétido, comumente unilateral. A 
secreção bilateral pode estar presente se houver dois corpos estranhos ou se estiver posicionado na nasofaringe (McCARTHY, 2005).

A imagem radiográfica nem sempre possibilita visibilizar o objeto, do qual depende de sua radiopacidade, e também, a sobreposição de imagens pode dificultar a detecção do corpo estranho, podendo passar despercebido (JOHNSON; WISNER, 2007). Na TCC, podem estar presentes, imagens diretas do corpo estranho e a sua localização no interior da cavidade nasal, porém, depende do grau de radiopacidade (JOHNSON; WISNER, 2007). O grau de destruição localizado ao redor do objeto, pode indicar a presença do mesmo, e o diagnóstico se torna suspeito juntamente com a queixa principal (TASKER, et al., 1999).

Durante a rinoscopia a presença de secreção em grande quantidade causada pela presença do corpo estranho, pode dificultar a visibilização. Pequenos corpos estranhos, na cavidade nasal, podem ser removidos rostralmente com pinça própria de remoção ou fórceps de biópsia. Nos casos de corpos estranhos de maios dimensão é indicado que desloque o mesmo para a nasofaringe para ser removido. A cirurgia pode ser requerida nos casos de insucesso (McCARTHY, 2005).

\subsubsection{Trauma}

Trauma de grande impacto em nariz pode causar hemorragia massiva com efeitos de choque hemorrágico (VENKERVAN HAAGEN, 2005). Fraturas dos ossos maxilar e nasal podem deslocar fragmentos ósseos para o interior da cavidade nasal e inviabilizar sua função. Estes fragmentos devem ser removidos, a fim de evitar infecção secundária levando a necrose das conchas (BEDFORD, 1997). Trauma em seios frontais, normalmente é secundário a perfuração ou batida muito forte. Podem estar associados sinais de choque, fraqueza muscular, demência e coma. A extensão da lesão deve ser diagnosticada pela radiografia ou TCC (VENKERVAN HAAGEN, 2005). 


\subsubsection{Rinite parasitária}

A rinite parasitária é rara no cão e é comumente associada ao ácaro nasal Pneumonyssoides caniun e o nematóide nasal Capillaria aerophila. A visão do ácaro através da rinoscopia e a identificação do nematódeo por biópsias e ou exame fecal concluem o diagnóstico (DAVIDSON et al., 2004; McCARTHY, 2005).

\subsubsection{Rinite secundária à afecção dental}

A doença nasal secundária à afecção dental pode levar a produção de secreção nasal uni ou bilateral com aspecto mucoso, muco-purulento ou purulento. A infecção e a inflamação originam-se do abscesso periapical ou de gengivite grave, associados à erosão óssea do maxilar ou dentes pré-maxilares. Os dentes comumente envolvidos são o canino superior, o quarto pré-molar superior e o primeiro molar superior devido ao tamanho e conformação de suas raízes. O envolvimento dental pode estar relacionado a toda a cavidade oral superior. A doença periodontal grave pode levar à reabsorção óssea, fístula pela maxila permitindo a passagem de material infectado para o interior da cavidade alveolar até a cavidade nasal (VENKERVAN HAAGEN, 2005). A incidência de rinite secundária, à doença dental, vem decrescendo com o aumento dos cuidados, higiene e tratamento bucal periódicos que vêm ocorrendo nos pequenos animais (McCARTHY, 2005).

A radiografia e a tomografia computadorizada usualmente apresentam imagens do canino superior ou mais dentes acometidos e osteólise periapical. Pela TCC ainda podem ser visibilizadas áreas de tumefação, lise óssea em palato e turbinados que podem confundir com imagens de neoplasia (KUEHN, 2006). Na rinoscopia são observadas secreções muco-purulentas ou sanguinolentas, presença de tecido com aspecto de fibrina, edema de conchas nasais, algumas vezes proliferações teciduais localizadas próximas a região da raiz do dente afetado, e 
também, pode estar presente diminuição das passagens aéreas (VENKERVAN HAAGEN, 2005).

\subsection{Abordagens diagnósticas para as principais doenças nasais e sinonasais}

Através da anamnese, deve-se abordar a quanto tempo está ocorrendo a doença e sua progressão, assim como os lados envolvidos, a presença e o tipo de descarga nasal, epistaxe, dor, incômodo nasal, tipo de respiração e halitose, (McCARTHY, 2005; VENKERVAN HAAGEN, 2005). Ao exame físico observa-se a presença de descarga nasal, crostas, lesões epiteliais, dor, ulcerações, despigmentação nas narinas, distorção das superfícies nasais e deformação facial. Caso o animal permita, a inspeção da cavidade oral poderá direcionar ou até concluir a ocorrência de doença nasal secundária à periodontite grave (NOONE, 2001; DAVIDSON et al., 2004; McCARTHY, 2005; VENKERVAN HAAGEN, 2005). Nos casos de rinite primária as manifestações clínicas são as mesmas ou muito semelhantes aos casos de rinite secundária, e alguns indícios clínicos são pouco específicos, e podem ser apresentados sistemicamente como mal-estar, letargia, perda de apetite e perda de peso (McCARTHY, 2005).

Hemograma completo, exame bioquímico, coagulograma ou teste de coagulação, aferição de pressão, dosagem de hormônios tireoidianos, testes alérgicos, pesquisa sorológica para fungos e pesquisa para hemoparasitas, são exames complementares que podem ser realizados sem a necessidade de anestesia (McCARTHY, 2005). A anestesia geral é necessária, na maioria dos exames radiográficos, na tomografia computadorizada e na rinoscopia devido a isso, indica-se a realização prévia de hemograma completo, perfil bioquímico e avaliação cardiológica. Perfis de coagulação, reação cruzada e possível transfusão sanguínea, também devem ser considerados, de acordo com a gravidade da doença e a ocorrência de epistaxe e o grau de invasão do método do exame, pois no caso da rinoscopia algum grau de hemorragia é inevitável (NOONE, 2001; DAVIDSON et al., 2004). 


\subsubsection{Exame radiográfico}

O exame radiográfico de crânio é indicado em todos os casos de afecções nasais e ou sinonasais, pois auxilia na identificação e extensão da doença colaborando com diagnósticos diferenciais. É necessário posicionar o paciente adequadamente para realizar diferentes projeções (MYER, 1994; NELSON; COUTO, 2001; McCARTHY, 2005; LAVIN, 2007). A projeção ventro-dorsal com a boca aberta, se realizada adequadamente, possibilita a visibilização da cavidade nasal e seios paranasais (MYER, 1994; McCARTHY, 2005), porém pode ocorrer distorção das estruturas. $\mathrm{Na}$ projeção intra-oral dorso-ventral diminui-se as chances de imagens distorcidas, mas existe falha em evidenciar a região caudal da cavidade nasal na maioria dos cães (DAVIDSON et al., 2004). A projeção lateral e a projeção oblíqua são úteis na avaliação da arcada dentária superior, ossos faciais e seios frontais, e a projeção frontal tangencial promove visibilização desobstruída dos seios frontais (DAVIDSON et al., 2004). A interpretação radiográfica da cavidade nasal e das estruturas circundantes é difícil no cão, e pode ser prejudicada pela sobreposição de imagens influenciada pelo posicionamento inadequado do paciente, a variabilidade racial e estrutural do crânio destes animais (MYER, 1994; DOUST; SULLIVAN, 2004; DAVIDSON et al., 2004; POWDER; ROSE; CRAWFORD, 2006). O estudo radiográfico tem como importância avaliar a integridade e simetria das conchas nasais e etmoturbinados, observando-se variações de opacidade, alterações em tecidos moles, e dos contornos da cavidade nasal (MYER, 1994; DOUST; SULLIVAN, 2004). A radiografia simples de crânio, nem sempre possibilita diferenciar com precisão rinite inflamatória, neoplásica ou fúngica (DAVIDSON et al., 2004; LEFEBVRE; KUEHN; WORTINGER, 2005), porém, na literatura existem relatos que descrevem alterações nas cavidades nasais e crânio, que podem sugerir o tipo de rinite, mas, estas descrições apresentam variações. Nos casos de rinite não destrutiva, são consideradas alterações como aumento disperso de opacidade uni ou bilateral, perda do padrão dos turbinados, raro acometimento dos seios frontais, ausência de destruição óssea de turbinados, do osso vômer ou ossos faciais circundantes e ausência de tumefação em tecidos moles externos ou imagens sugestivas de neoformações. Rinites destrutivas e nos casos de afecção 
fúngica, são comuns alterações como áreas de opacidade reduzida e destruição dos turbinados, lesões unilaterais ou bilaterais, lesões expansivas em cavidade nasal, envolvimento do seio frontal e lise óssea. Nos casos sugestivos de rinites neoplásicas, algumas imagens podem permitir visibilizar lise ou destruição dos turbinados, vômer, acometimento de palato duro e lise em ossos faciais com acometimento uni ou bilateral, comprometimento de seio frontal, placa cribriforme, palato, envolvimento do espaço retrobulbar e ou da órbita (GIBBS, et al., 1979; HARVEY, et al., 1979; SCHWARZ; SULLIVAN; HARTUNG, 2000; MYER, 1994; DAVIDSON, et al., 2004). A literatura também sugere que qualquer perda de padrão trabecular caracteriza doença nasal (GIBBS, et al., 1979), assim como desvio ou aumento da radioluscência (MYER, 1994; DOUST; SULLIVAN, 2004). Lises ósseas do palato duro ou dos ossos que revestem a face podem promover áreas de radioluscência que mimetizam a afecção. Neoplasias em fase inicial, particularmente se associadas com secreção nasal copiosa, podem ser de difícil detecção (DAVIDSON et al., 2004).

Russo, Lamb, Jakovlejevic, (2000) realizaram estudo comparativo sobre a incidência do tipo de lesão visibilizada por meio da imagem radiográfica em 72 cães, com rinites e neoplasias nasais primárias, que já haviam sido submetidos à radiografia convencional de crânio e com diagnóstico de rinite ou neoplasia confirmados por meio de cultura fúngica e ou bacteriana, estudo citológico ou histopatológico das amostras coletadas destes animais. Dois observadores que desconheciam o diagnóstico final e as manifestações clínicas dos pacientes incluídos no estudo, avaliaram as radiografias, e concordaram que os cães com alterações como opacificação em cavidades nasais generalizada (70\%); lise ou perda dos turbinados uni ou bilateral (80\%); acometimento de seio frontal (70\%), seriam indicativas de neoplasia. As rinites foram atribuídas aos animais que em suas imagens radiográficas havia opacificação localizada (43\%); lise ou perda de definição em região de turbinados focal ou multifocal (45\%); aumento da radioluscência (76\%). Quanto à extensão das lesões, a concordância entre os observadores, foi insatisfatória. Os autores avaliaram as radiografias nas posições dorso-ventral intraoral e rostrocaudal para seio frontal.

O exame radiográfico tem seus méritos e vantagens, e não deve ser dispensado. É também disponível universalmente e relativamente de baixo custo 
(RUSSO; LAMB; JAKOVLJEVIC, 2000; DAVIDSON et al., 2004; McCARTHY, 2005; JOHNSON; WISNER, 2007).

\subsubsection{Tomografia Computadorizada}

A tomografia computadorizada permite através de cortes transversais, avaliar detalhadamente a cavidade nasal e os seios paranasais melhorando a capacidade em diagnosticar doenças nasais de forma mais precisa (WITHROW, 1989; BURK, 1992 b; PARK; BECK; Le COUTEUR, 1992; SCHWARZ, 1995; DOUST; SULLIVAN, 2004; DAVIDSON et al., 2004; LEFEBVRE; KUEHN; WORTINGER, 2005; KUEHN, 2006). Com o ajuste da escala de contraste, é possível incrementar a discriminação das estruturas de tecidos moles daquelas que são apenas fracamente mineralizadas, melhorando e facilitando a visibilização das estruturas turbinadas na parte rostral da cavidade nasal (DAVIDSON et al., 2004). Por meio das imagens tomográficas avalia-se a extensão e o envolvimento das estruturas anatômicas como as conchas nasais, septo nasal, nasofaringe, placa cribriforme, seios frontais, seio esfenoidal e região periorbital (THRALL et al., 1989; WITHROW, 1989; SCHWARZ; SULLIVAN; HARTUNG, 2000; LEFEBVRE; KUEHN; WORTINGER, 2005 et al., , 2005; POWDER; ROSE; CRAWFORD, 2006; JOHNSON; WISNER, 2007). Existe, ainda, a possibilidade de se administrar contraste por via intravenosa, como recurso na delimitação das margens tumorais, colaborando com o diagnóstico, e auxiliando na diferenciação da existência de aumento de opacidade secundária à rinite ou atribuída à neoplasia, melhorando a acurácia do exame tomográfico (JOHNSON; WISNER, 2007). Imagens que apresentam regiões heterogêneas, destruição de conchas e ou etmóide, envolvimento do osso maxilar e ou nasal, envolvimento da órbita e ou do espaço retrobulbar sugerem neoplasia, entretanto, não se pode afirmar a existência de um único achado que caracterize definitivamente esta afecção (BURK, 1992 b).

Lefebvre, Kuehn e Wortinger (2005) realizaram um estudo retrospectivo utilizando 85 cães com manifestações clínicas associadas à doença nasal crônica. O objetivo foi demonstrar a eficiência TCC, correlacionado o aspecto da doença de 
acordo com as imagens visibilizadas, os resultados das biópsias nasais coletadas por meio da rinoscopia e as observações anatômicas, também vistas pela rinoscopia. Alterações como aumento da densidade tecidual associada à extensa destruição dos turbinados, visibilizadas por meio da TCC sugeriram neoplasia em 37 animais, das quais, foram confirmados pelo estudo histopatológico 25 carcinomas e 12 sarcomas, e a rinoscopia confirmou a presença de proliferação tecidual. Suspeitou-se de rinite inflamatória em 40 animais, onde visibilizou-se, por meio da TCC, aumento da densidade em tecidos moles, seguidos ou não de destruição leve a moderada nos turbinados, também confirmados com exame histopatológico, sendo a maioria rinite linfoplasmocitária, onde se observou alterações como hiperemia e edema na mucosa nasal e por meio da rinoscopia. Foi possível visibilizar extensa destruição dos turbinados e hiperluscência nas passagens nasais, por meio da TCC em sete animais, onde foi confirmado aspergilose nasal pela cultura e exame histopatológico do material coletado. A rinoscopia, também, permitiu a visibilização de placas fúngicas. Em três casos dos animais com suspeita de neoplasia, houve a necessidade de nova coleta, da qual foi realizada por meio da rinotomia, a fim de confirmar a suspeita da afecção sugerida pelo exame tomográfico, dos quais, não foram confirmados pelo diagnóstico histopatológico na primeira biópsia. Com a segunda coleta, em dois casos, confirmou pelo histopatológico sarcoma (fibrossarcoma bem diferenciado), sendo que foi sugerido respectivamente, pólipo inflamatório e rinite polipóide linfoplasmocitária-eosinofílica. O terceiro caso o diagnóstico inicial foi de proliferação fibro-óssea, sendo confirmado osteossarcoma, no segundo exame histopatológico. Em um caso, apesar de manifestações clínicas de afecção nasal, não foram demonstradas alterações no exame tomográfico e nem no exame histológico.

As imagens provenientes da TCC permitem guiar exames como a rinoscopia e um possível procedimento cirúrgico (JOHNSON; WISNER, 2007). Entretanto, há desvantagens como custo do exame, custo e manutenção do equipamento, o tempo do procedimento e a anestesia necessária na Medicina Veterinária (DAVIDSON et al., 2004). 


\subsubsection{Rinoscopia}

Antes da utilização da rinoscopia, cirurgias exploratórias de grande extensão nas cavidades nasais e seios paranasais eram realizadas com o intuito de se estabelecer o diagnóstico, porém este procedimento apresenta maior risco, com alta taxa de morbidade e mortalidade, principalmente quando comparado com a rinoscopia (McCARTHY; McDEIRMAN, 1990; NOONE, 2001). A endoscopia do trato respiratório alto é indicada em todos os casos com manifestações agudas ou crônicas, principalmente quando não se pode diagnosticar apenas pelos exames físico, de imagem e complementares, e ainda naqueles pacientes que não respondem ao tratamento empírico (FORD, 1990; ELIE; SABO, 2006). É indicada com intuito de confirmar a existência de lesão previamente visibilizada e sugerida pelos exames de imagem (McCARTHY, 2005; PIETRA et al., 2010). A rinoscopia anterior é realizada por meio do acesso rostral à cavidade nasal e permite a visibilização e inspeção do septo nasal, meato nasal comum dorsal, médio, ventral e as conchas nasal dorsal, ventral e os etmoturbinados. Dependendo do tipo constitucional do paciente é possível chegar à nasofaringe, porém na maioria dos casos a inspeção desta região ocorre por meio da rinoscopia posterior ou nasofaringoscopia, da qual permite a visibilização direta da nasofaringe pela técnica de retroflexão do endoscópio flexível (WILLARD; RADLINSKY, 1999; DAVIDSON et al., 2004; McCARTHY, 2005). Para a realização deste exame, podem ser utilizados equipamentos de endoscopia de fibra óptica rígida ou flexível (McCARTHY; McDEIRMAN, 1990; FORBES LENT; HAWKINS, 1992; DAVIDSON et al., 2004; ELIE; SABO, 2006; PIETRA, et al., 2010). Durante o procedimento são avaliados a presença e tipo de secreção, inflamação das conchas nasais, pólipos, proliferações teciduais, corpos estranhos, placas fúngicas e alterações anatômicas significativas. Considera-se qual a região acometida, e se há envolvimento uni ou bilateral (WILLARD, RADLINSKY, 1999; NELSON; COUTO, 2001; NOONE, 2001; McCARTHY, 2005; VENKERVAN HAAGEN, 2005).

A rinoscopia, também, é útil como forma terapêutica nos casos de remoção de corpos estranhos. Sua contribuição se estende ainda na coleta de material para realização de exame citológico e estudo histopatológico sob orientação visual 
(McCARTHY; McDEIRMAN,1990; DAVIDSON et al., 2004; VENKERVAN HAAGEN, 2005; PIETRA et al., 2010).

Em estudo realizado por Yoshitoshi (2003) sobre a contribuição e utilização da rinoscopia em 38 cães com manifestações clínicas sugestivas de afecções nasais, foram diagnosticados 25 casos de neoplasia intranasal, dos quais foram confirmados por meio do estudo histopatológico das amostras obtidas por meio da rinoscopia, sendo, dez casos de tumores venéreos transmissíveis, oito casos de neoplasias de origem mesenquimal (osteocondroma, fibrossarcoma e osteossarcoma) e sete casos de neoplasias de origem epitelial (adenocarcinoma, carcinoma indiferenciado, carcinoma espinocelular). Dois casos foram diagnosticados como rinite crônica não específica, cinco casos de pólipos intranasais, dois de aspergilose nasal e três de corpo estranho. Este estudo demonstrou eficiência na utilização deste procedimento como meio diagnóstico não invasivo das afecções nasais, e terapêutico quando houve remoção dos corpos estranhos encontrados.

Apesar de ser exame específico, efetivo e pouco invasivo, tem como desvantagem, não trazer informações precisas quanto à extensão da lesão independente do tamanho do paciente, ou do uso do equipamento e a dimensão da cavidade nasal pode impor algumas limitações ao exame sendo necessário utilizarse mais de um tipo de equipamento endoscópico (FORD, 1990). Nos casos dos cães de médio e grande porte a acessibilidade é maior (McCARTHY, 2005). A visibilização da cavidade nasal poder ser prejudicada, quando há presença de secreções muco-purulenta espessa ou sanguinolenta, no qual, ocorre na maioria das vezes. Por fim, outra desvantagem é o custo elevado na obtenção e manutenção dos equipamentos (DAVIDSON et al., 2004; McCARTHY, 2005).

\subsubsection{Sinoscopia}


O acesso ao seio frontal pela rinoscopia em cães, por norma, somente é possível quando há perda de etmoturbinados ou alterações anatômicas que facilitem o acesso a esta região. A maioria dos casos exige acesso invasivo para a realização deste procedimento, necessitando via percutânea e trepanação de 3 a $5 \mathrm{~mm}$ de diâmetro no seio frontal envolvido (McCARTHY; MCDEIRMAN,1990; DAVIDSON et al., 2004; VENKERVAN HAAGEN, 2005; MCCARTHY, 2005).

\subsubsection{Cultura bacteriana e fúngica}

A coleta de material para cultura tanto bacteriana como fúngica deve ser realizada anteriormente à rinoscopia, a fim de se evitar contaminação secundária, ou pelo fato da lavagem intranasal com solução salina durante o procedimento levar a diminuição da população dos agentes (McCARTHY, 2005). Na rinite fúngica a presença de placa esbranquiçada, na maioria dos casos, é visibilizada pela rinoscopia e parte dela pode ser coletada sendo enviada para cultura para identificar o agente fúngico (McCARTHY, 2005; VENKERVAN HAAGEN, 2005). Nos casos de criptococose em que se observa apenas proliferação tecidual no interior da cavidade nasal, a biópsia pode ser coletada através da rinoscopia, sendo o estudo histopatológico responsável pelo diagnóstico diferencial. Esta manifestação da criptococose é mais comum em felinos, no entanto, pode acometer os cães (VENKERVAN HAAGEN, 2005).

\subsubsection{Citologia}

A coleta de material para citologia também pode ser realizada, por meio de aspiração, por agulha, de massas tumorais palpáveis em planos nasais e que já invadiram as estruturas ósseas, ou por meio de escova ou "swab" durante a rinoscopia, ou ainda, ser realizada através da fricção do material tecidual coletado pela pinça fórceps durante o exame endoscópico nasal. A coleta "às cegas", também 
pode ser realizada, mas, não diferencia outras causas de doença nasal (DAVIDSON et al., 2004; McCARTHY, 2005).

\subsubsection{Biópsia}

A biópsia é realizada por meio da rinotomia ou métodos indiretos de obtenção de amostras teciduais, porém a técnica indireta pode trazer amostras pouco representativas e diagnóstico inconclusivo. Através da rinoscopia existe a vantagem de coletar material especificamente da área de interesse. No entanto, a biópsia coletada por meio deste método pode ocasionar sangramento considerável e com dificuldade em ser contido, da qual, prejudica a coleta de mais amostras durante o mesmo procedimento (FORD, 1990; DAVIDSON et al., 2004; McCARTHY, 2005; VENKERVAN HAAGEN, 2005). A coleta de material de lesões proliferativas presentes na cavidade nasal e ou nasofaringe por meio da rinoscopia, fornece material suficiente para estudo histológico (FORD, 1990), porém, como estão sempre associadas a áreas de extensas inflamações e necrose, a avaliação histopatológica pode não ser interpretada corretamente pelo patologista, necessitando-se novas coletas por rinoscopia ou através da rinotomia. A restrição de espaço da cavidade nasal, também, prejudica a coleta de material (DAVIDSON et al., 2004; McCARTHY, 2005; MILES et al., 2008). 


\section{OBJETIVO}

Este trabalho, através de estudo observacional, teve como objetivo avaliar a contribuição ao diagnóstico das afecções da cavidade nasal e seios paranasais de cães, da radiografia, tomografia computadorizada e rinoscopia, realizando-se a comparação dos métodos diagnósticos mediante ao escore comparativo idealizado para este fim. 


\section{MATERIAL E MÉTODO}

O presente estudo foi aprovado pela Comissão de Bioética da Faculdade de Medicina Veterinária e Zootecnia da Universidade de São Paulo - Protocolo $\mathrm{n}^{\circ}$ 1495/2008. Os proprietários foram cientificados pela assinatura do Termo de Ciência e Autorização do Hospital Veterinário (Anexos).

\subsection{Animais}

Foram atendidos 48 cães, com idade e sexo variados, na triagem da rotina do Hospital Veterinário da FMVZ da Universidade de São Paulo e encaminhados para o Serviço de Cirurgia de Pequenos Animais do Departamento e Cirurgia no período compreendido entre Agosto de 2008 a Agosto de 2010, com manifestações clínicas como secreção nasal uni ou bilateral, esternutações, epistaxe, tosse crônica, respiração estertorosa, dificuldade respiratória e deformidade facial, com suspeita de afecções nasais e sinonasais e enviados para a rinoscopia como exame final. Entretanto, foram selecionados 20 cães que seguiram os critérios de inclusão propostos por este estudo, totalizando em onze machos e nove fêmeas, com idade entre três anos de idade a 19 anos de idade, e de raças variadas.

\subsection{Critérios de inclusão}

Foram inclusos no protocolo cães com sexo, raça e idade variadas, submetidos à radiografia de crânio digital, tomografia computadorizada e rinoscopia, com hemograma completo e exames bioquímicos de função hepática e função renal, sem alterações dignas de nota, além de avaliação cardiológica, quando necessária. Assim, foram excluídos pacientes com distúrbio de coagulação ou trombocitopenia, hipóxia severa, cardiopatas severos, urêmicos ou portadores de insuficiência renal, ou ainda, que apresentassem qualquer contra-indicação para anestesia e não tivessem sido submetidos aos exames de imagem radiográfico digital e tomografia computadorizada, e rinoscopia. 


\subsection{Exame radiográfico}

O exame radiográfico do crânio, para avaliação das cavidades nasais e seios paranasais, foi realizado no Serviço de Diagnóstico por Imagem do Departamento de Cirurgia, junto ao Hospital Veterinário da Faculdade de Medicina Veterinária da Universidade de São Paulo.

Os exames radiográficos foram obtidos com ajuda do aparelho de radiografia digital modelo RAY-TEC 500 mA (miliámperes) e TECHNO DESIGN 500 mA. A técnica radiográfica utilizada foi de alto contraste, ou seja, alto $\mathrm{mA}$ e baixo $\mathrm{kV}$ (quilovoltagem), ajustados de acordo com o tamanho do animal e níveis adequados para cavidade nasal. Foram realizados diferentes decúbitos e projeções, sendo decúbito lateral para a realização da projeção latero-lateral (Figura 01), decúbito dorsal para a projeção dorso-ventral (Figura 02) e ou decúbito ventral para a projeção ventro-dorsal com boca aberta (Figura 03 e 04).
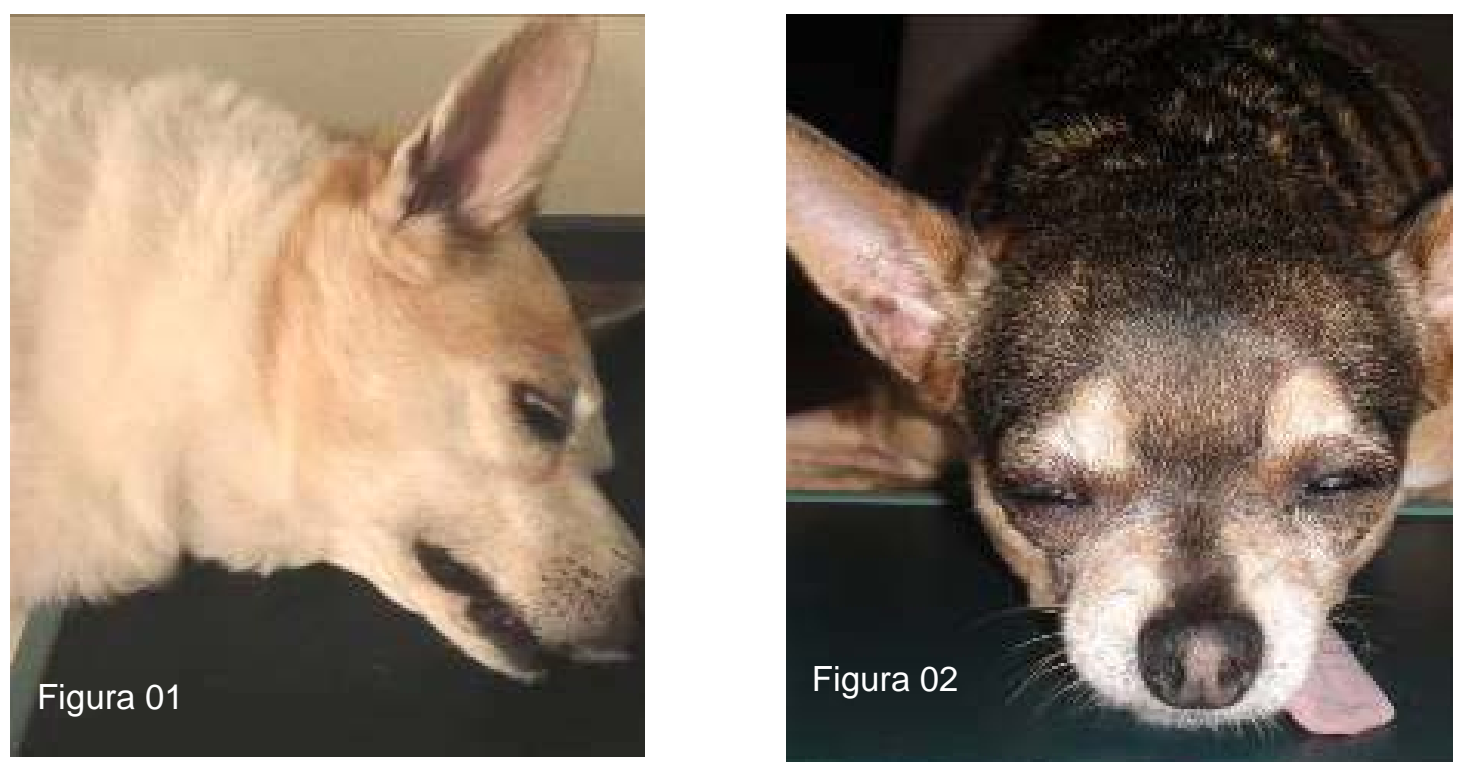

Fonte: Fernanda Auler; Serviço de Diagnóstico por Imagem do Hospital Veterinário da Faculdade de Medicina Veterinária da Universidade de São Paulo, SP. 2010.

Figura 01 - Posicionamento em decúbito lateral do paciente durante a realização da radiografia na projeção latero-lateral

Figura 02 - Posicionamento em decúbito dorsal do paciente durante a realização da radiografia na projeção dorso-ventral 

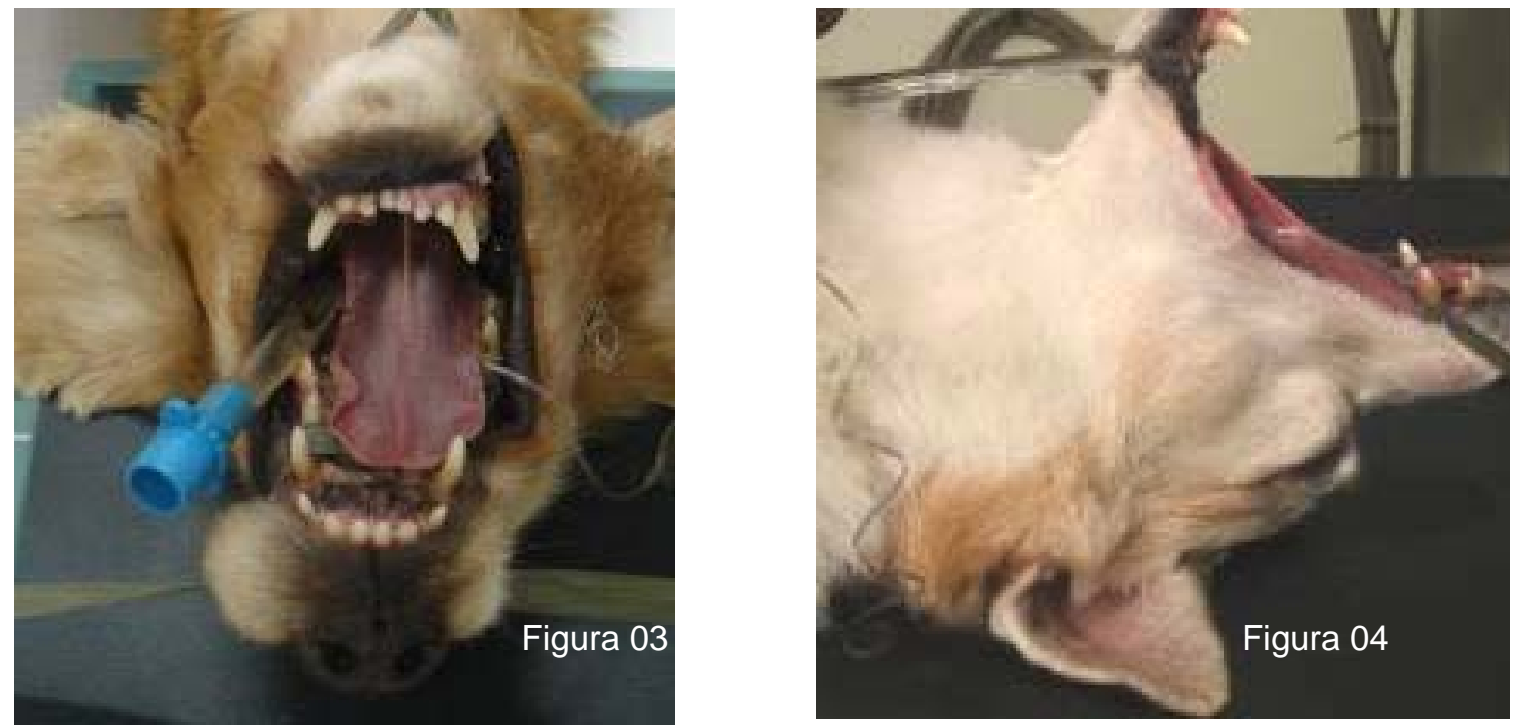

Fonte: Fernanda Auler; Serviço de Diagnóstico de Imagem do Hospital Veterinário da Faculdade de Medicina Veterinária da Universidade de São Paulo, SP. 2010.

Figura 03 e 04 - Posicionamento em decúbito ventral do paciente durante a realização da radiografia na projeção ventro-dorsal com a boca aberta

Realizou-se avaliação quanto às alterações nas regiões do crânio dos 20 animais inclusos no estudo como: opacificação em cavidades nasais; lise de turbinados; lise em vômer; lise do osso nasal e maxilar; envolvimento seio frontal; acometimento de placa cribriforme; comprometimento de palato; alvéolo dentário; comprometimento arco zigomático; envolvimento da órbita e parede naso-orbital; bulas timpânicas; opacificação com efeito de massa tecidual.

\subsection{Anestesia}

Os pacientes foram submetidos à anestesia geral, conforme protocolos preconizados pelo Serviço de Anestesia do Departamento de Cirurgia junto ao Hospital Veterinário da Faculdade de Medicina Veterinária e Zootecnia da Universidade de São Paulo (ASA I a IV). A oxigenação e monitoração cardiovascular e respiratória foram realizadas, a fim de evitar riscos durante o procedimento de tomografia do crânio e rinoscopia. Os animais permaneceram entubados em ambos procedimentos. 


\subsection{Tomografia Computadorizada}

O exame tomográfico das cavidades nasais e seios paranasais foi realizado no Serviço de Diagnóstico por Imagem do Departamento de Cirurgia junto ao Hospital Veterinário da Faculdade de Medicina Veterinária da Universidade de São Paulo. Foram obtidos com ajuda do tomógrafo helicoidal "single slice" TOSHIBA Xpress/GX. A técnica tomográfica empregada foi de 120 kV, 150 mA e 1 segundo de tempo de aquisição de dados. Foram realizadas reconstruções transversais de $3,0 \mathrm{~mm}$ a $5,0 \mathrm{~mm}$ de espessura e $3,0 \mathrm{~mm}$ a $5,0 \mathrm{~mm}$ de incremento, utilizando janela e níveis adequados para cavidade nasal. Foi também aplicado via intravenosa amidotrizoato sódico $80 \mathrm{mg} / \mathrm{ml}$ e amidotrizoato de meglumina $520 \mathrm{mg} / \mathrm{ml}$, na dose de 1,4 a 1,5 ml por quilograma $(\mathrm{kg})$, como contraste em cães que não apresentaram contra-indicação para sua aplicação. Para a realização da tomografia computadorizada, o paciente foi posicionado em decúbito esternal sem angulação (Figuras 05 e 06).

Também, realizou-se avaliação, quanto às alterações nas regiões do crânio dos 20 animais inclusos no estudo, por meio do exame tomográfico, como: opacificação em conchas nasais dorsais e ventrais; ausência ou destruição de conchas nasais; opacificação nas conchas etmoidais, células etmoidais e labirinto etmoidal; lise labirinto etmoidal; lise de vômer horizontal e sagital; lise de septo nasal; comprometimento palato; lise osso nasal e maxilar; envolvimento de recesso maxilar, seio esfenoidal e seio frontal; envolvimento nasofaringe e meato nasofaríngeo; acometimento placa cribriforme; comprometimento alvéolo dentário; opacificação com efeito massa tecidual; comprometimento órbita e parede nasoorbital; lise óssea peri-orbital; realce pós-contraste. 

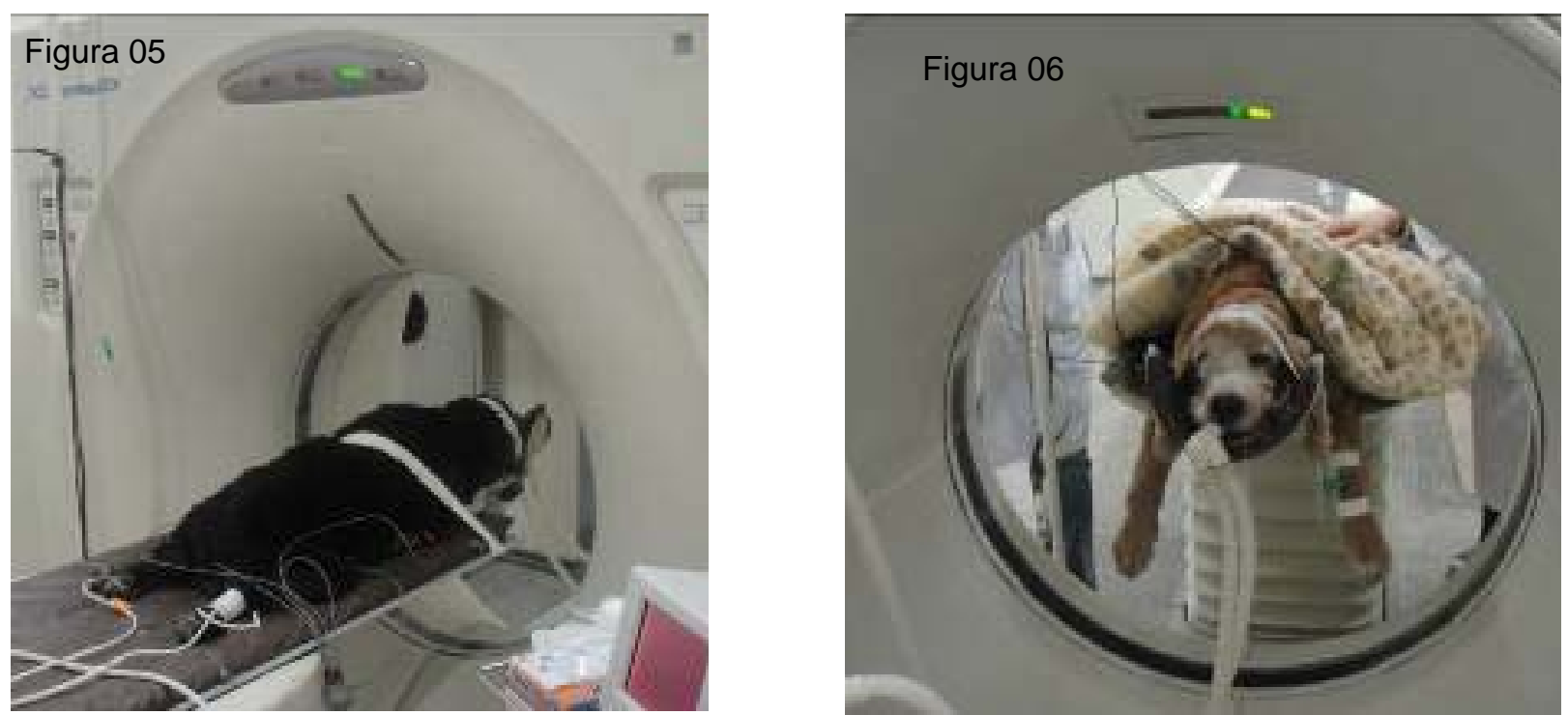

Fonte: Serviço de Diagnóstico por Imagem do Hospital Veterinário da Faculdade de Medicina Veterinária da Universidade de São Paulo. SP. 2010

Figura 05 e 06- Posicionamento, em decúbito esternal, do paciente durante a realização da tomografia computadorizada

\subsection{Rinoscopia}

A rinoscopia foi realizada com aparelho fibroendoscópio flexível da marca OILYMPUS ${ }^{\circledR}$ modelo LF-DP de $3,1 \mathrm{~mm}$ de diâmetro externo e 8,5 cm de comprimento total e campo de visão de $90^{\circ}$ e acoplado a sistema de captura e digitalização de imagens. Nos casos de cães de médio e grande portes foi utilizado fibroendoscópio da marca OLYMPUS ${ }^{\circledR}$ modelo XQ10 de 9,8 mm de diâmetro externo, com aproximadamente $13 \mathrm{~cm}$ de comprimento e campo de visão de $120^{\circ}$ para avaliação de nasofaringe.

O procedimento endoscópico teve início logo após a tomografia. Principiou-se o exame com a inspeção da cavidade bucal e orofaringe, com o intuito de avaliar qualquer anormalidade que poderia estar relacionada com afecção nasal, sendo ainda observados o palato duro e palato mole.

Os pacientes foram posicionados em decúbito lateral e a boca foi aberta e fixada por artefato específico durante a avaliação da nasofaringe. Para esta avaliação o endoscópio flexível foi inserido, com sua ponta pré-angulada dorsalmente cerca de $180^{\circ}$, caudal ao palato mole, e posicionado para a 
visibilização das coanas, septo nasal, etmoturbinados, palato duro, parede da nasofaringe conforme modelo das figuras 07 e 08.

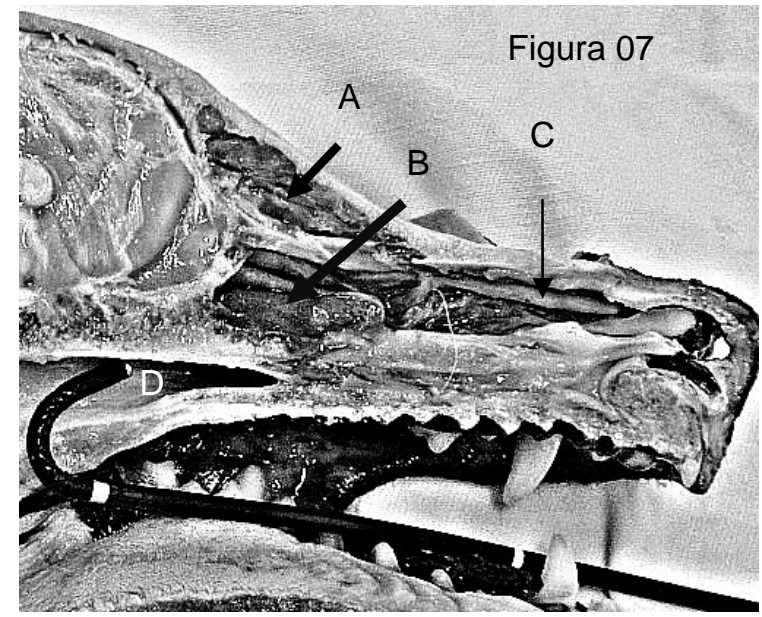

Fonte: São Paulo - SP. Fernanda Auler -2010

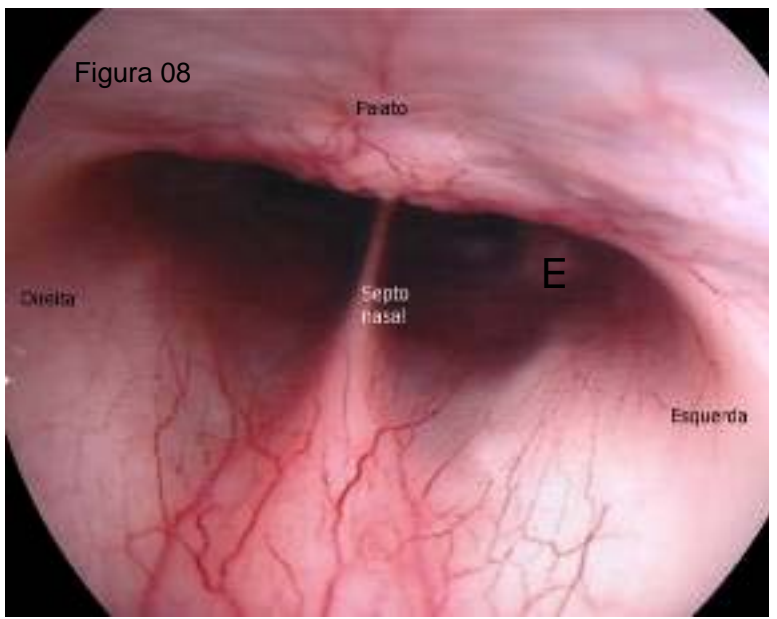

Fonte: São Paulo - SP. Franz Naoki Yoshitoshi - 2008

Figura 07- Inspeção das coanas, pela técnica de retroflexão, por meio da rinoscopia posterior com endoscópio flexível, em cadáver de cão: (A) Seio frontal; (B) Etmoturbinados; (C) Concha nasal dorsal; (D) Nasofaringe

Figura 08- Imagem da nasofaringe de cão e das coanas normais visibilizadas pela técnica de retroflexão, por meio da rinoscopia posterior com endoscópio flexível: (E) Etmoturbinados

Após a rinoscopia posterior, o animal retornou para decúbito esternal e realizou-se avaliação anterior das cavidades nasais. Antes da inserção do aparelho, inspecionou-se o plano nasal quanto a presença de lesões proliferativas, ressecamento, despigmentação ou crostas nas narinas. A presença de secreções, também foi avaliada. O lado a ser primeiramente examinado foi sempre o direito, com intuito de padronizar a seqüência do exame e foi mensurada a distância entre as narinas e o canto medial do olho para evitar a penetração da placa cribriforme. 0 aparelho foi inserido a partir do meato nasal comum, avançando para o meato nasal comum dorsal e meato nasal comum ventral, divididos entre região anterior, média, posterior e suas limitações pelo septo nasal, concha dorsal, maxiloturbinados e etmoturbinados (Figuras 09 e 10).

Durante a rinoscopia avaliou-se presença e tipo de secreção, presença de coágulos, presença de hiperemia, presença de edema, acesso ao seio frontal, obstrução em nasofaringe, proliferação tecidual, corpo estranho e placa fúngica . 


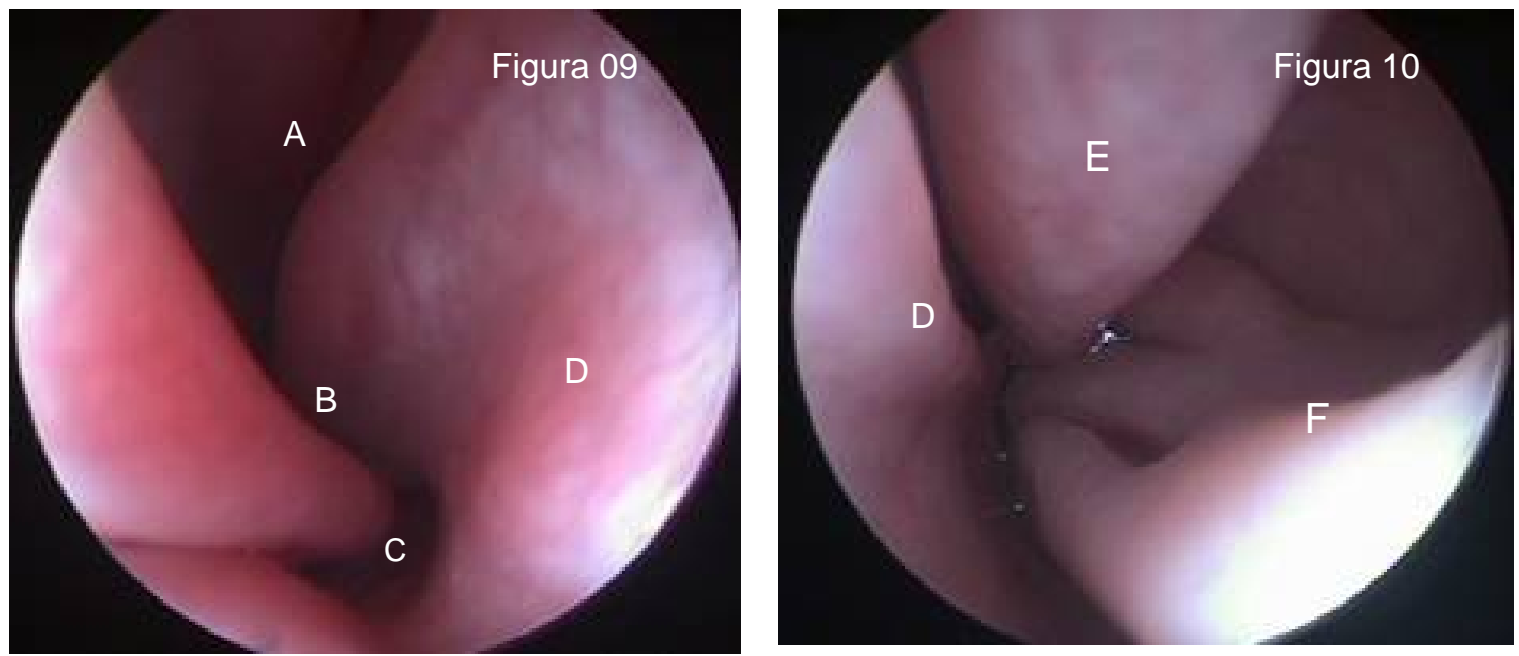

Fonte: São Paulo - SP. Franz Naoki Yoshitoshi ; Fernanda Auler, 2008

Figura 09 e 10- Cavidade nasal anterior de cão normal, visibilizada por meio da rinoscopia com endoscópio rígido: (A) Meato nasal comum dorsal; (B) Meato nasal comum médio; (C) Meato nasal comum ventral; (D) Septo nasal; (E) Concha nasal dorsal; (F) Etmoturbinados

As biópsias foram coletadas de regiões que apresentaram maior comprometimento e de proliferações teciduais. Os fragmentos foram fixados em formol a $10 \%$ e enviados para análise histopatológica, realizada pelo Serviço de Patologia do Departamento de Patologia junto ao Hospital Veterinário da FMVZ-USP após serem corados pela técnica de hematoxilina e eosina.

Para a realização de todo o exame empregou-se ainda pinça fórceps flexível, pinça rígida para biópsia, fontes de luz halógena marca ENDOSCOPY SOLUTIONS ${ }^{\circledR}$ e $S O N Y{ }^{\circledR}$, microcâmera marca $S O N Y \AA$, cabo de luz de fibra ótica, impressora de fotos da marca SONY®, gravador de DVD da marca $L G ~ \circledR{ }^{\circledR}$ ou vídeo cassete da marca SONY® e aspirador cirúrgico da marca TAKAOKA®.

$\mathrm{Na}$ presença de secreção copiosa, realizou-se lavagem com solução fisiológica e aspiração através de sonda uretral estéril para melhorar a visualização. Nos casos em que houve necessidade, além da rinorragia e hemorragia após a coleta de biópsia e sem contra-indicação, utilizou-se adrenalina injetável como vasoconstritor por via tópica na mucosa nasal como tentativa de diminuir o edema e propiciar melhor visibilidade 


\subsection{Avaliação dos resultados}

A avaliação da contribuição dos métodos diagnósticos foi realizada por meio de um escore idealizado para este fim, onde as alterações visibilizadas por meio dos exames de imagem e da rinoscopia, foram comparadas com os resultados do estudo histopatológico das amostras coletadas por meio da rinoscopia, de acordo com o tipo de lesão maligna ou benigna, independente da presença ou não de proliferação tecidual.

Também, foram selecionadas, algumas regiões onde as imagens entre radiografia e tomografia pudessem ser comparadas entre si, com os resultados do estudo histopatológico.

Classificou-se os tipos de rinites de acordo com as alterações visibilizadas por meio do exame radiográfico e tomográfico baseadas nos critérios propostos por Harvey e colaboradores (1979) e Gibbs e colaboradores (1979) de rinite não destrutiva, rinite destrutiva e neoplasia, como opacidade; lise dos turbinados; acometimento dos seios frontais; destruição óssea envolvendo osso vômer ou ossos faciais circundantes; efeito massa tecidual; destruição da placa cribiforme; acometimento da cavidade oral; envolvimento do espaço retrobulbar e lise periorbital. Os tipos de rinites classificados pelos exames de imagem foram comparados com o diagnóstico final da lesão.

\subsubsection{Avaliação radiográfica}

Para determinação da contribuição do exame radiográfico comparou-se com os outros métodos diagnósticos utilizados no presente estudo seguindo o escore (Tabela 26): (a) visibilização de presença de lesão: 0 =Não sugere; $1=$ Sugere; 2=Provável lesão; 3= Confirma existência da lesão; (b) Extensão da lesão (b): 0= Não delimita; 1= Limite impreciso; 2= Limite preciso; 3 = Delimita a lesão; (c) avaliação quanto a suspeita diagnóstica e sua classificação: $0=$ Não Suspeita; $1=$ Suspeita; 2= Forte suspeita; 3= Confirma. O resultado do escore foi comparado com o resultado do histológico quanto à presença de lesão maligna ou benigna.

As alterações visibilizadas, para serem classificadas junto ao escore, foram baseadas de acordo com o acometimento e extensão das lesões presentes nas 
cavidades nasais e seios paranasais, e a presença de opacificação de cavidades nasais e seio frontal; presença ou não de lise em turbinados; em osso nasal e maxilar; comprometimento de palato; invasão da placa cribriforme; comprometimento órbita e parede naso-orbital.

\subsubsection{Avaliação tomográfica computadorizada}

A contribuição do exame tomográfico computadorizado foi também, comparada com os outros métodos diagnósticos do presente estudo. As mesmas classificações avaliadas no exame radiográfico foram utilizadas na TCC (Tabela 27): a) presença de lesão: 0 =Não sugere; 1= Sugere; 2=Provável lesão; 3= Confirma existência da lesão; b) extensão da lesão: 0= Não delimita; 1= Limite impreciso; 2= Limite preciso; 3 = Delimita a lesão; c) Suspeita diagnóstica: 0= Não Suspeita; 1= Suspeita; 2= Forte suspeita; 3= Confirma. As alterações em cavidades nasais e seios paranasais, avaliadas junto ao escore, também, foram de acordo com o acometimento e extensão das lesões presentes nas cavidades nasais e seios paranasais como opacificação em conchas nasais dorsais e ventrais; em conchas etmoidais e células etmoidais; opacificação e lise em labirintos etmoidais; ausência ou destruição de conchas nasais; lise em vômer na parte horizontal e ou sagital; lise em septo nasal; comprometimento de palato; lise do osso nasal e maxilar; comprometimento em recesso maxilar; seio esfenoidal e seio frontal; envolvimento de nasofaringe e meato nasofaringeo; acometimento de placa cribriforme; comprometimento de alvéolo dentário; efeito massa tecidual; envolvimento da órbita e ou parede naso-orbital; lise óssea periorbital; realce pós-contraste.

\subsubsection{Avaliação da rinoscopia}

A contribuição da rinoscopia também foi comparada com os demais exames do presente estudo e o escore, foi o mesmo empregado no exame radiográfico e na TCC: a) presença de lesão por meio de classificação (Tabela 28): 0 =Não sugere; 1= 
Sugere; 2=Provável lesão; 3= Confirma existência da lesão; b) extensão da lesão: $0=$ Não delimita; $1=$ Limite impreciso; $2=$ Limite preciso; 3 = Delimita a lesão; c) suspeita diagnóstica: $0=$ Não Suspeita; $1=$ Suspeita; $2=$ Forte suspeita; $3=$ Confirma. As alterações visibilizadas na rinoscopia estiveram de acordo com o acometimento e extensão das lesões presentes nas cavidades nasais como a presença e tipo de secreção, inflamação das conchas nasais, pólipos, proliferações teciduais, corpos estranhos, placas fúngicas e alterações anatômicas significativas.

\subsection{Análise estatística}

As variáveis classificatórias foram descritivamente apresentadas em tabelas de contingência contendo freqüências absolutas (n) e relativas (\%). A associação entre elas e o tipo da lesão foram avaliadas com o teste da razão de verossimilhança ou teste exato de Fisher. A evidência de lesão foi atribuída de acordo com o escore, para cada um dos métodos de avaliação.

Foram calculados escores somando-se os graus de cada evidência para cada método diagnóstico (radiografia, tomografia, rinoscopia). O valor mínimo do escore para cada método é zero e o máximo pode chegar a 9.

Calculou-se também o escore total incluindo todos os métodos. O valor mínimo possível de zero e o máximo de 27.

Os escores foram apresentados descritivamente em tabelas contendo média, desvio padrão. As médias destas variáveis foram comparadas com o teste t-Student.

As variáveis que apresentarem significância estatística na análise univariada, foram utilizadas no ajuste do modelo de regressão logística.

Os valores de $p<0,05$ foram considerados estatisticamente significantes. 


\section{RESULTADOS}

Foram incluídos neste estudo 20 cães submetidos à radiografia digital de crânio, tomografia computadorizada e rinoscopia atendidos no Hospital Veterinário da Faculdade de Medicina Veterinária e Zootecnia da Universidade de São Paulo com manifestações clínicas referentes a afeecções nasais e ou sinonasais (Tabela 01) sendo onze machos e nove fêmeas. Destes animais, 05 eram cães Sem Raça Definida (SRD), e os demais das raças Cocker Spaniel $(n=04)$, Poodle $(n=03)$, Labrador $(n=03)$, Pinscher $(n=02)$, Daschund ou Teckel $(n=01)$, Rottweiler $(n=01)$ e Golden Retriver ( $n=01)$. A idade dos animais variou entre três anos de idade e 19 anos de idade, sendo a média 10 anos. As manifestações clínicas (Tabela 01) referentes a doenças nasais foram em sua maioria secreção nasal (Figura 11) (75\%) onde, 53,3\% dos casos de aspecto mucopurulento à purulento, 20\% sanguinolento, aspecto purulento com sangue $6,6 \%$ e de aspecto seroso a mucoso $20 \%$. Esternutações foram apresentadas em $45 \%$ dos casos, $10 \%$ com sangue e $10 \%$ esternutações reversas, seguidos das demais manifestações como distrição respiratória (30\%); epistaxe (30\%); tosse (20\%); deformidade facial (Figura 12) (15\%); crostas ou ressecamento das narinas (15\%); incômodo nasal (10\%); engasgos (10\%); e halitose (10\%); ferida proliferativa em plano nasal e narinas (5\%).

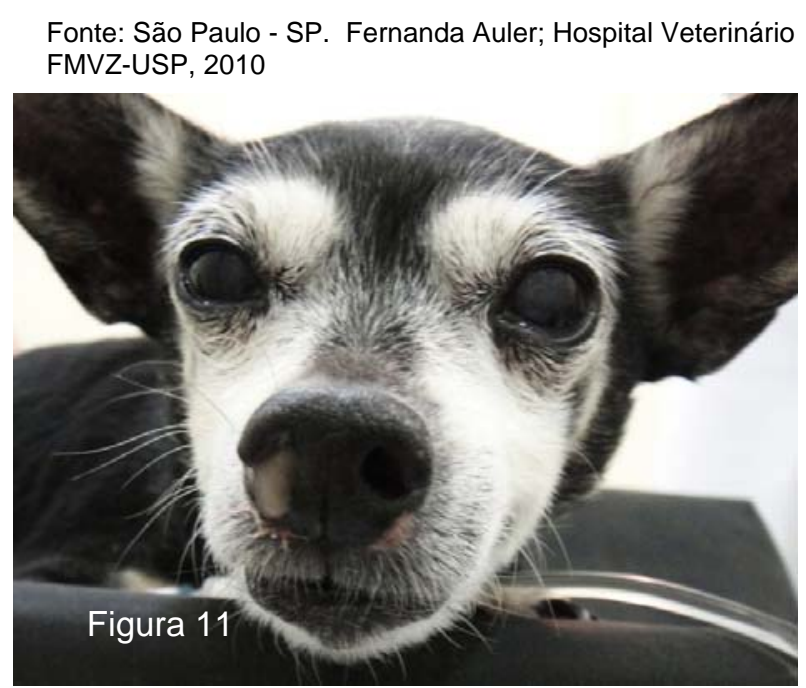

Figura 11- Imagem de cão com secreção nasal muco-purulenta
Fonte: São Paulo - SP. Fernanda Auler; Hospital Veterinário -FMVZ-USP, 2010

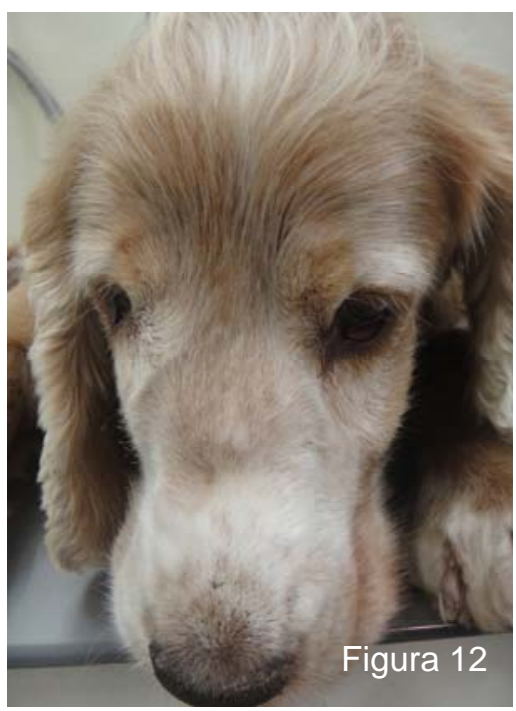

Figura 12- Imagem de cão com deformaçãp facial 
Tabela 01 - Descrição das raças, sexo e idade dos animais incluídos no presente estudo e submetidos ao estudo radiográfico digital, tomografia e rinoscopia, e suas manifestações clinicas presentes

\begin{tabular}{|c|c|c|c|c|}
\hline Casos & Raça & Sexo & Idade & Histórico clínico/ Queixa principal \\
\hline 01 & SRD & M & 03 anos & $\begin{array}{l}\text { Distrição respiratória; epistaxe; secreção nasal } \\
\text { muco-purulenta bilateral. }\end{array}$ \\
\hline 02 & Golden Retriver & M & 10 anos & $\begin{array}{l}\text { Conjuntivite bilateral; crostas e ressecamento nas narinas; } \\
\text { secreção sanguinolenta lado direito; deformação facial. }\end{array}$ \\
\hline 03 & Rottweiler & $\mathrm{F}$ & 06 anos & $\begin{array}{l}\text { Secreção nasal muco-purulenta bilateral; crostas nas narinas; } \\
\text { deformação facial; dor. }\end{array}$ \\
\hline 04 & SRD & $\mathrm{M}$ & 12 anos & $\begin{array}{l}\text { Secreção nasal mucosa bilateral; distrição respiratória. Histórico } \\
\text { de hemangioma há } 03 \text { anos }\end{array}$ \\
\hline 05 & Labrador & $\mathrm{M}$ & 09 anos & $\begin{array}{l}\text { Histórico de corpo estranho nasal retirado após rinotomia; } \\
\text { distrição respiratória; secreção nasal sanguinolenta bilateral. }\end{array}$ \\
\hline 06 & Cocker Spaniel & $\mathrm{M}$ & 15 anos & Melanoma intraocular direito. Epistaxe lado direito. \\
\hline 07 & Poodle & $\mathrm{F}$ & 11 anos & Epistaxe bilateral. \\
\hline 08 & Poodle & $\mathrm{F}$ & 10 anos & Secreção nasal serosa bilateral; esternutações; incômodo nasal. \\
\hline 09 & Cocker Spaniel & $\mathrm{M}$ & 12 anos & Epistaxe lado direito; distrição respiratória. \\
\hline 10 & Labrador & M & 10 anos & $\begin{array}{l}\text { Ferida proliferativa em plano nasal e narinas; tosse; distrição } \\
\text { respiratória. }\end{array}$ \\
\hline 11 & Labrador & $\mathrm{F}$ & 08 anos & Esternutações com sangue; secreção nasal bilateral purulenta. \\
\hline 12 & Daschhund & $\mathrm{M}$ & 10 anos & $\begin{array}{l}\text { Tosse; engasgos; esternutações com sangue; distrição } \\
\text { respiratória; secreção nasal muco-purulenta bilateral }\end{array}$ \\
\hline 13 & Poodle & $\mathrm{F}$ & 05 anos & $\begin{array}{l}\text { Esternutações; secreção nasal muco-purulenta unilateral } \\
\text { esquerda. }\end{array}$ \\
\hline 14 & Cocker Spaniel & $\mathrm{F}$ & 10 anos & $\begin{array}{l}\text { Piodermite na região ocular e nasal; secreção nasal purulenta } \\
\text { bilateral; otite; conjuntivite; tosse; engasgos; esternutações. }\end{array}$ \\
\hline 15 & SRD & $F$ & 14 anos & $\begin{array}{l}\text { Secreção nasal purulenta bilateral com sangue; tosse; secreção } \\
\text { ocular. }\end{array}$ \\
\hline 16 & SRD & $\mathrm{F}$ & 08 anos & $\begin{array}{l}\text { Esternutações; esternutações reversas; secreção nasal bilateral } \\
\text { purulenta. }\end{array}$ \\
\hline 17 & Cocker Spaniel & $M$ & 10 anos & Esternutações; epistaxe; deformidade facial. \\
\hline 18 & Pinscher & $M$ & 09 anos & $\begin{array}{l}\text { Esternutações; secreção nasal purulenta unilateral direita, mau } \\
\text { hálito }\end{array}$ \\
\hline 19 & Pinscher & $F$ & 19 anos & $\begin{array}{l}\text { Secreção sanguinolenta unilateral direita; esternutações; } \\
\text { distrição respiratória. }\end{array}$ \\
\hline 20 & SRD & M & 05 anos & $\begin{array}{l}\text { Secreção nasal mucosa bilateral; esternutações, ressecamento } \\
\text { narinas; epistaxe bilateral. }\end{array}$ \\
\hline
\end{tabular}

$\mathrm{M}=\mathrm{MACHO} ; \mathrm{F}=\mathrm{FÊMEA} ; \mathrm{SRD}=$ Sem raça definida

\subsection{Descrição do exame radiográfico}

Dos 20 cães submetidos à radiografia digital de crânio (Tabela 02), visibilizouse opacificação em cavidades nasais $(n=19)$, lise de turbinados $(n=15)$, em vômer/septo $(n=10)$, em osso nasal $(n=04)$ e osso maxilar $(n=03)$, envolvimento seio frontal $(n=16)$, comprometimento de palato $(n=01)$, envolvimento da placa cribriforme $(n=10)$, alvéolo dentário $(n=09)$, efeito massa tecidual $(n=05)$, comprometimento arco zigomático $(n=01)$, órbita (parede naso - orbital) $(n=03)$ e opacificação em bulas timpânicas $(n=12)$. 
Tabela- 02 - Descrição das alterações visibilizadas por meio do exame radiográfico digital do crânio

\begin{tabular}{|c|c|c|c|c|c|c|c|c|c|c|c|c|c|c|c|c|c|c|c|c|}
\hline Casos & 01 & 02 & 03 & 04 & 05 & 06 & 07 & 08 & 09 & 10 & 11 & 12 & 13 & 14 & 15 & 16 & 17 & 18 & 19 & 20 \\
\hline $\begin{array}{l}\text { Opacificação das } \\
\text { cavidades nasais }\end{array}$ & PB & PB & PB & PB & PB & PD & PE & PB & PB & $A$ & PE & PB & PB & PB & PB & PB & PB & PB & PB & PB \\
\hline Lise de turbinados & A & PB & PB & PB & PB & PD & PB & A & PD & A & PE & A & A & PB & PB & PB & PB & PB & PD & PD \\
\hline $\begin{array}{l}\text { Lise de vômer/septo } \\
\text { ósseo }\end{array}$ & A & $P$ & P & P & $P$ & A & $\mathrm{P}$ & A & $P$ & A & A & A & $A$ & A & $P$ & A & $P$ & A & $P$ & $\mathrm{P}$ \\
\hline Lise do osso nasal & A & A & A & PB & PB & A & A & A & A & A & PB & A & A & A & A & A & PB & A & A & A \\
\hline Lise osso maxilar & A & A & A & PB & A & A & A & A & A & A & A & A & A & A & PE & A & PB & $A$ & A & A \\
\hline $\begin{array}{l}\text { Envolvimento de } \\
\text { seio frontal }\end{array}$ & PB & PD & PB & PB & PB & PD & PB & A & PB & $A$ & PE & PB & A & $A$ & PB & PB & PB & PB & PD & PD \\
\hline $\begin{array}{l}\text { Comprometimento } \\
\text { de palato }\end{array}$ & A & A & A & A & A & A & A & A & A & A & A & A & A & A & A & A & PB & $A$ & $A$ & A \\
\hline $\begin{array}{l}\text { Alteração da placa } \\
\text { cribriforme }\end{array}$ & A & PB & PB & PB & PB & PB & A & A & PB & $A$ & PE & A & $A$ & PB & A & A & PB & $A$ & A & PD \\
\hline $\begin{array}{l}\text { Comprometimento } \\
\text { alvéolo dentário }\end{array}$ & NA & A & A & PB & A & PD & A & A & PD & A & A & PB & A & PB & PB & PB & PD & $A$ & PD & A \\
\hline $\begin{array}{l}\text { Efeito massa } \\
\text { tecidual }\end{array}$ & A & A & A & $P$ & A & A & A & A & $P$ & $P$ & PE & A & A & A & A & A & PD & $A$ & A & A \\
\hline $\begin{array}{l}\text { Comprometimento } \\
\text { de arco zigomático }\end{array}$ & A & A & A & A & A & A & A & A & A & A & A & A & A & A & A & A & PD & $A$ & A & A \\
\hline $\begin{array}{l}\text { Compromete órbita } \\
\text { (parede naso-orbital) }\end{array}$ & A & PD & PB & A & A & A & A & A & A & A & A & A & A & A & A & A & PD & $A$ & A & A \\
\hline $\begin{array}{l}\text { Alteração bulas } \\
\text { timpânicas }\end{array}$ & A & PB & A & PB & PB & A & A & A & PB & PB & PB & PB & PB & $A$ & PB & PB & PB & PB & A & A \\
\hline
\end{tabular}

$A=$ Ausente; $P=$ Presente; $D$ =Direito; $E$ = Esquerdo; $P B=$ Presente bilateral; NA = Não foi possível avaliar

\subsection{Descrição do exame tomográfico computadorizado}

Dos 20 cães submetidos ao exame tomográfico computadorizado (Tabela 03), visibilizou-se opacificação $(n=18)$ em conchas nasais dorsais e ou ventrais, e etmoidais $(n=15)$. Além das conchas etmoidais, na região dos etmoturbinados, foram também, avaliadas quanto à opacificação, as células etmoidais, localizadas a partir do $4^{\circ}$ pré-molar $(n=19)$ e os labirintos etmoidais $(n=14)$ localizados caudalmente. Ausência ou destruição de conchas nasais foi visibilizada em 12 animais. Quanto à lise óssea nas cavidades nasais, visibilizou-se em labirinto etmoidal $(n=13)$, vômer na parte horizontal $(n=18)$ e na parte sagital $(n=07)$, e também em septo nasal $(\mathrm{n}=14)$. Em 08 animais detectou-se comprometimento de palato do lado direito $(n=03)$, lado esquerdo $(n=02)$ e bilateral $(n=05)$. Lise em osso nasal $(n=08)$ unilateral direito $(n=03)$, esquerdo $(n=02)$ e bilateral $(n=03)$, sendo, um caso com imagem 
sugestiva de espessamento do lado direito. Em osso maxilar, observou-se lise do lado direito $(n=07)$, lado esquerdo $(n=03)$ e bilateral $(n=01)$.

Em seios paranasais visibilizou-se acometimento em recesso maxilar $(n=14)$, seio esfenoidal $(n=14)$ e seio frontal $(n=12)$. Comprometimento em região de nasofaringe $(n=14)$ e em meato nasofaringeo $(n=20)$ sendo algumas imagens sugestivas de espessamento.

Tabela 03 - Descrição das alterações visibilizadas por meio do exame tomográfico do crânio dos cães inclusos no presente estudo

\begin{tabular}{|c|c|c|c|c|c|c|c|c|c|c|c|c|c|c|c|c|c|c|c|c|}
\hline Casos & 01 & 02 & 03 & 04 & 05 & 06 & 07 & 08 & 09 & 10 & 11 & 12 & 13 & 14 & 15 & 16 & 17 & 18 & 19 & 20 \\
\hline $\begin{array}{l}\text { Opacificação } \\
\text { conchas nasais } \\
\text { dorsais }\end{array}$ & A & PB & PE & PB & PB & $A$ & PD & $A$ & PD & PD & PB & PB & $A$ & PE & PE & PB & PB & PD & PD & PB \\
\hline $\begin{array}{l}\text { Opacificação } \\
\text { conchas nasais } \\
\text { ventrais }\end{array}$ & PB & PD & PE & PB & PB & A & PD & $A$ & PD & A & PB & PE & PE & PB & PE & PB & PB & PD & PD & PB \\
\hline $\begin{array}{l}\text { Ausência/ } \\
\text { destruição } \\
\text { conchas nasais }\end{array}$ & A & PB & PD & A & $A$ & PB & $\mathrm{PE}$ & $A$ & PE & $A$ & $A$ & PB & PE & PB & PD & PB & $A$ & PB & $A$ & PB \\
\hline $\begin{array}{l}\text { Opacificação em } \\
\text { concha etmoidal }\end{array}$ & PB & PD & PE & PB & PB & PD & PE & $A$ & PB & $A$ & PE & A & $A$ & PE & PE & PB & PB & $A$ & PD & PB \\
\hline $\begin{array}{l}\text { Lise labirinto } \\
\text { etmoidal }\end{array}$ & PD & PB & PE & PB & PB & PB & $\mathrm{PE}$ & $A$ & PD & $A$ & $A$ & $A$ & $A$ & PB & PE & $A$ & PD & $A$ & PD & PB \\
\hline Lise vômer & PHS & PHS & $\mathrm{PH}$ & PHS & PHS & $\mathrm{PH}$ & $\mathrm{PH}$ & A & $\mathrm{PH}$ & A & $\mathrm{PH}$ & $\mathrm{PH}$ & $\mathrm{PH}$ & $\mathrm{PH}$ & $\mathrm{PH}$ & $\mathrm{PH}$ & PHS & PHS & PHS & $\mathrm{PH}$ \\
\hline Lise septo nasal & $\mathrm{P}$ & $\mathrm{P}$ & $P$ & $\mathrm{P}$ & $P$ & $P$ & $P$ & $A$ & $\mathrm{P}$ & $A$ & $\mathrm{P}$ & $A$ & $\mathrm{P}$ & $A$ & $A$ & $A$ & $\mathrm{P}$ & $\mathrm{P}$ & $\mathrm{P}$ & $\mathrm{P}$ \\
\hline $\begin{array}{l}\text { Comprometimento } \\
\text { de palato }\end{array}$ & PB & PB & A & A & PB & A & $A$ & $A$ & $A$ & $A$ & $A$ & $A$ & PE & $A$ & $\mathrm{PE}$ & $A$ & PB & PB & PD & $A$ \\
\hline Lise osso nasal & $A$ & $A$ & $\mathrm{PE}$ & PB & PD & PD & $\mathrm{PE}$ & A & $A$ & $A$ & $A$ & $A$ & $A$ & $\mathrm{~PB}$ & $A$ & $A$ & PB & $A$ & $A$ & $\mathrm{PD}^{*}$ \\
\hline Lise osso maxilar & $A$ & $\mathrm{PD}$ & PE & PB & PD & A & $\mathrm{PE}$ & $A$ & $A$ & $A$ & $A$ & $A$ & PD & PD & PE & $A$ & PD & $A$ & PD & PD \\
\hline Recesso maxilar & PD & $\mathrm{PD}$ & PE & PB & $\mathrm{PB}$ & $A$ & PE & A & PB & $A$ & PE & PE & $A$ & $A$ & PE & PE & PD & A & PD & PD \\
\hline $\begin{array}{l}\text { Envolvimento seio } \\
\text { esfenoidal }\end{array}$ & PD & $\mathrm{PB}$ & PE & PB & PB & PD & A & $A$ & PB & $A$ & PE & $A$ & $A$ & PB & PE & PB & PB & $A$ & PD & PD \\
\hline $\begin{array}{l}\text { Envolvimento seio } \\
\text { frontal }\end{array}$ & $A$ & PD & PB & PB & PB & $A$ & PE & $A$ & PB & $A$ & PE & A & A & $A$ & PE & PB & PB & A & PD & PD \\
\hline $\begin{array}{l}\text { Envolvimento } \\
\text { nasofaringe }\end{array}$ & PB & PB & PE & PB & PB & PD & $A$ & PB & $\mathrm{PB}^{*}$ & $\mathrm{~PB}^{\star}$ & PE & PB & $\mathrm{PB}^{\star}$ & $A$ & A & $A$ & PB & $A$ & PB & A \\
\hline $\begin{array}{l}\text { Meato } \\
\text { nasofaringeo }\end{array}$ & PB & PB & PE & PB & PB & PD & $\mathrm{PE}$ & $\mathrm{PB}^{*}$ & PB & $\mathrm{PB}$ & PE & PD & PB & PB & PB & $\mathrm{P}^{*}$ & PB & $\mathrm{PB}$ & PB & PE \\
\hline $\begin{array}{l}\text { Acometimento } \\
\text { placa cribriforme }\end{array}$ & A & PB & PE & A & PB & $A$ & PB & A & PB & A & A & $A$ & $A$ & $A$ & A & $A$ & PB & A & PD & A \\
\hline $\begin{array}{l}\text { Comprometimento } \\
\text { alvéolo dentário }\end{array}$ & A & $P$ & $A$ & $A$ & A & $P$ & A & A & $A$ & A & $A$ & $P$ & PD & PD & PE & PB & PD & PB & PD & $A$ \\
\hline $\begin{array}{l}\text { Efeito massa } \\
\text { tecidual }\end{array}$ & A & $\mathrm{P}$ & $P$ & $A$ & $P$ & $\mathrm{P}$ & $A$ & A & $P$ & $A$ & $P$ & $A$ & A & A & A & $A$ & $P$ & A & $\mathrm{P}$ & A \\
\hline $\begin{array}{l}\text { Comprometimento } \\
\text { órbita (parede } \\
\text { naso- orbital) }\end{array}$ & $A$ & $\mathrm{P}$ & PE & A & A & A & $A$ & $A$ & $A$ & A & A & $A$ & $A$ & $A$ & A & $A$ & PD & NA & PD & A \\
\hline $\begin{array}{l}\text { Lise óssea } \\
\text { periorbital }\end{array}$ & A & PD & $\mathrm{PE}$ & PD & PD & $A$ & $P$ & A & $A$ & $A$ & A & $A$ & A & $A$ & PE & A & PD & NA & $P D$ & PD \\
\hline $\begin{array}{l}\text { Realce pós- } \\
\text { contraste }\end{array}$ & $P$ & $P$ & $P$ & NR & $P$ & $P$ & $\mathrm{P}$ & $\mathrm{P}$ & $P$ & $\mathrm{P}$ & $P$ & $\mathrm{P}$ & $\mathrm{P}$ & $P$ & $\mathrm{P}$ & $P$ & $P$ & $P$ & NR & $P$ \\
\hline
\end{tabular}

$\mathrm{A}=$ Ausente; $\mathrm{P}=$ Presente; $\mathrm{P}^{*}=$ Espessamento; $\mathrm{D}=$ Direito; $\mathrm{E}=$ Esquerdo; $\mathrm{H}=$ Horizontal; $\mathrm{S}=\mathrm{Sagital}$; NA = Não foi possível avaliar; NR = Não realizado 
Visibilizou-se em alguns animais envolvimento da placa cribriforme $(n=07)$, comprometimento de alvéolo dentário $(n=10)$ e efeito massa tecidual $(n=08)$.

Envolvimento da órbita e ou parede naso-orbital $(n=04)$, lise óssea periorbital $(n=09)$, também, foram detectadas, e apenas um cão apresentou comprometimento do arco zigomático. Realce pós-contraste foi avaliado e visibilizado em 18 animais, porém, não foi realizado em dois cães, do qual impossibilitou esta avaliação nestes pacientes.

\subsection{Descrição dos exames radiográficos e tomográficos}

Algumas regiões do crânio foram selecionadas e comparadas entre os exames de imagem (Tabela 04).

Tabela 04 - Descrição das regiões selecionadas e as alterações visibilizadas através do exame radiográfico e tomográfico do crânio dos cães inclusos no presente estudo

\begin{tabular}{|c|c|c|c|c|c|c|c|c|c|c|c|c|c|c|c|c|c|c|c|c|}
\hline Casos & 01 & 02 & 03 & 04 & 05 & 06 & 07 & 08 & 09 & 10 & 11 & 12 & 13 & 14 & 15 & 16 & 17 & 18 & 19 & 20 \\
\hline $\begin{array}{l}\text { Opacificação } \\
\text { cavidades nasais }\end{array}$ & PP & PP & PP & PP & PP & PP & $\mathrm{PP}$ & PA & PP & AP & PP & PP & PP & PP & PP & PP & PP & PP & PP & $\mathrm{PP}$ \\
\hline Lise turbinados & AP & PP & PP & PP & PP & PP & PP & AA & PP & AA & PA & AA & AA & PP & PP & PA & PP & PA & PP & PP \\
\hline Lise vômer & AP & PP & PP & PP & PP & $\mathrm{AP}$ & PP & AA & PP & AA & $\mathrm{AP}$ & $\mathrm{AP}$ & $\mathrm{AP}$ & $\mathrm{AP}$ & PP & $A P$ & PP & AP & PP & $\mathrm{PP}$ \\
\hline $\begin{array}{l}\text { Comprometimento } \\
\text { palato }\end{array}$ & AP & $\mathrm{AP}$ & AA & AA & AP & AA & AA & AA & AA & AA & AA & AA & $\mathrm{AP}$ & AA & AP & AA & PP & AP & AP & AA \\
\hline Lise osso nasal & AA & AA & AP & PP & PP & AP & AP & AA & AA & AA & PA & AA & AA & AP & $\mathrm{AA}$ & AA & PP & AA & AA & AP \\
\hline Lise osso maxilar & AA & $A P$ & AP & PP & AP & AA & AP & AA & AA & AA & AA & AA & AP & AP & PP & AA & PP & AA & AP & $\mathrm{AP}$ \\
\hline $\begin{array}{l}\text { Acomete placa } \\
\text { cribriforme }\end{array}$ & AA & PP & PP & PA & PP & PA & $\mathrm{AP}$ & AA & $\mathrm{PP}$ & AA & PA & AA & AA & PA & $\mathrm{AA}$ & AA & PP & AA & $\mathrm{AP}$ & PA \\
\hline $\begin{array}{l}\text { Envolvimento seio } \\
\text { frontal }\end{array}$ & PA & PP & PP & PP & PP & PA & PP & AA & PP & AA & PP & PA & AA & AA & PP & PP & PP & PA & PP & $\mathrm{PP}$ \\
\hline $\begin{array}{l}\text { Comprometimento } \\
\text { alvéolo dentário }\end{array}$ & ${ }^{*} \mathrm{~A}$ & AP & AA & PA & AA & PP & AA & AA & PA & AA & AA & PP & $\mathrm{AP}$ & PP & PP & PP & PP & AP & PP & $A A$ \\
\hline $\begin{array}{l}\text { Efeito massa } \\
\text { tecidual }\end{array}$ & $\mathrm{AA}$ & $\mathrm{AP}$ & $\mathrm{AP}$ & $\mathrm{PA}$ & $\mathrm{AP}$ & AP & $A A$ & $\mathrm{AA}$ & PP & PA & PP & $A A$ & $A A$ & $A A$ & $\mathrm{AA}$ & $A A$ & PP & $\mathrm{AA}$ & AP & $\mathrm{AA}$ \\
\hline $\begin{array}{l}\text { Comprometimento } \\
\text { órbita (parede } \\
\text { naso- orbital) }\end{array}$ & AA & PP & PP & $A A$ & AA & $\mathrm{AA}$ & $A A$ & AA & $A A$ & AA & AA & $A A$ & $A A$ & $A A$ & $\mathrm{AA}$ & AA & PP & $A^{*}$ & AP & $A A$ \\
\hline
\end{tabular}

$\mathrm{PP}=$ Presente na imagem radiográfica e tomográfica; $\mathrm{PA}=$ Presente na imagem radiográfica e ausente na imagem tomográfica; $A P=A u s e n t e$ na imagem radiográfica e presente na imagem tomográfica; $A A=$ Ausente na imagem radiográfica e tomográfica; $\left({ }^{\star} A\right)=$ Não foi possível avaliar na imagem radiográfica; $\left(A^{\star}\right)$ = Não foi possível avaliar na imagem tomográfica 
Visibilizou-se opacificação por meio da radiografia e da TCC $(n=19)$. Na região dos turbinados houve resultados semelhantes em 16 casos. As outras alterações avaliadas, como lise vômer $(n=10)$, acometimento de palato $(n=13)$, lise osso nasal $(n=14)$ e osso maxilar $(n=12)$, placa cribriforme $(n=13)$, envolvimento de seio frontal $(n=12)$, alvéolo dentário $(n=15)$, efeito massa tecidual $(n=13)$ e $(n=18)$ comprometimento órbita e parede naso-orbital, também, foram visibilizadas.

Das alterações avaliadas quanto aos tipos de rinites, 14 animais apresentaram lesões, em ambos os exames, classificadas como rinite não destrutiva $(n=2)$, rinite destrutiva $(n=8)$ e rinite sugestiva de neoplasia $(n=04)$. Os outros seis animais apresentaram classificações diferentes entre os exames de imagem (Tabela 05).

Tabela 05 - Classificação das rinites, sugeridas pelas alterações visibilizadas por meio do exame radiográfico e tomográfico do crânio dos cães inclusos no presente estudo

\begin{tabular}{lllllllllllllllllllll}
\hline Casos & 01 & 02 & 03 & 04 & 05 & 06 & 07 & 08 & 09 & 10 & 11 & 12 & 13 & 14 & 15 & 16 & 17 & 18 & 19 & 20 \\
\hline Radiografia & 1 & 3 & 3 & 2 & 3 & 2 & 2 & 1 & 2 & 1 & 2 & 1 & 1 & 2 & 2 & 2 & 3 & 1 & 2 & 2 \\
\hline $\begin{array}{l}\text { Tomografia } \\
\text { Computadorizada }\end{array}$ & 2 & 3 & 3 & 3 & 3 & 2 & 3 & 1 & 2 & 1 & 2 & 2 & 2 & 2 & 2 & 2 & 3 & 2 & 2 & 2 \\
\hline
\end{tabular}

1)Rinite não destrutiva; 2) Rinite Destrutiva; 3) Sugere neoplasia.

\subsection{Descrição da rinoscopia}

Dos 20 cães submetidos à rinoscopia (Tabela 06), visibilizou-se secreção muco-purulenta em conchas nasais de maxiloturbinados e nasoturbinados $(n=11)$, em na região de etmoturbinados $(n=10)$, em coanas e ou nasofaringe $(n=08)$; secreção sanguinolenta em conchas nasais de maxiloturbinados e nasoturbinados $(n=01)$, em etmoturbinados $(n=01)$ e em coanas e ou nasofaringe $(n=02)$; presença de coágulos em conchas nasais de maxiloturbinados e nasoturbinados $(n=01)$, etmoturbinados $(n=01)$ e coanas e ou nasofaringe $(n=01)$; hiperemia em conchas nasais de maxiloturbinados e nasoturbinados $(n=18)$ e em etmoturbinados $(n=15)$; edema em conchas nasais de maxiloturbinados e nasoturbinados $(n=18)$ e etmoturbinados ( $n=15)$; destruição de conchas nasais $(n=02)$; erosão ou fístula em mucosa de cavidades nasais e nasofaringe $(n=03)$; proliferação tecidual em conchas 
nasais de maxiloturbinados e nasoturbinados $(n=04)$, etmoturbinados $(n=12)$, e em coanas e ou nasofaringe $(n=10)$; presença de placa fúngica $(n=01)$; alterações anatômicas $(n=01)$; destruição de conchas nasais $(n=02)$; presença de corpo estranho $(n=01)$.

Tabela 06 - Descrição das alterações em cavidade nasal e nasofaringe, visibilizadas por meio da rinoscopia

\begin{tabular}{lllllllllllllllllllllll}
\hline Casos & 01 & 02 & 03 & 04 & 05 & 06 & 07 & 08 & 09 & 10 & 11 & 12 & 13 & 14 & 15 & 16 & 17 & 18 & 19 & 20 \\
\hline $\begin{array}{l}\text { Lesão em plano } \\
\text { nasal }\end{array}$ & A & A & A & A & A & A & A & A & A & PB & A & A & A & A & A & A & A & A & A & A \\
\hline $\begin{array}{l}\text { Secreção muco- } \\
\text { purulenta em } \\
\text { cavidades nasais }\end{array}$ & PB & A & A & A & PB & A & A & PB & PD & NA & PB & PB & PE & PB & PB & PB & A & PB & PB & A \\
\hline $\begin{array}{l}\text { Secreção muco- } \\
\text { purulenta em } \\
\text { coanas/ } \\
\text { nasofaringe }\end{array}$ & PB & A & A & A & PB & A & A & A & PD & A & A & PB & PE & PE & PE & A & A & A & PD & A \\
\hline $\begin{array}{l}\text { Secreção } \\
\text { sanguinolenta em } \\
\text { cavidades nasais }\end{array}$ & A & A & A & A & A & A & A & A & A & NA & A & A & A & A & A & A & A & A & A & PB \\
\hline $\begin{array}{l}\text { Secreção } \\
\text { sanguinolenta } \\
\text { coanas/nasofaringe }\end{array}$ & A & A & A & PB & A & A & A & A & A & A & A & A & A & PE & A & A & A & A & A & A \\
\hline $\begin{array}{l}\text { Coágulos em } \\
\text { cavidades nasais }\end{array}$ & A & A & A & A & A & A & A & A & A & NA & A & A & A & A & A & A & A & A & A & PB \\
\hline $\begin{array}{l}\text { Coágulos em } \\
\text { nasofaringe }\end{array}$ & A & A & A & A & A & A & A & A & A & A & A & A & A & PE & A & A & A & A & A & A \\
\hline
\end{tabular}

Hiperemia em conchas nasais

PB PB PB A PE PB PB PB PE NA PB PB PB PB PB PB PE PB PB PE

Hiperemia em etmoturbinados

A A PD A A PE PD PB PE NA PD PB PD PB PB PB PE PB PB PE

Edema em conchas nasais

PB PE PB A PE PE PB PB PE NA PB PB PB PB PB PB PE PB PB PE \begin{tabular}{llllllllllllllllllllll}
\hline $\begin{array}{l}\text { Edema em } \\
\text { etmoturbinados }\end{array}$ & $A$ & $A$ & $P D$ & $A$ & $A$ & $P E$ & $P D$ & $P B$ & $P E$ & $N A$ & $P D$ & $P B$ & $P D$ & $P B$ & $P B$ & $P B$ & $P E$ & $P B$ & $P E$ & $P E$ \\
\hline
\end{tabular}

Destruição de conchas nasais

Erosão ou fístula em mucosa

Proliferação

tecidual

maxiloturbinados/

nasoturbinados

Proliferação

tecidual em etmoturbinados

Proliferação

tecidual em

coanas/

nasofaringe

\begin{tabular}{llllllllllllllllllllll}
\hline Placa fúngica & A & A & A & A & A & A & A & A & A & NA & A & A & A & A & A & A & A & A & A & PD \\
\hline $\begin{array}{l}\text { Alterações } \\
\text { anatômicas }\end{array}$ & A & A & A & A & A & A & A & A & A & NA & A & A & PE & A & A & A & A & A & A & A \\
\hline Corpo estranho & A & A & A & A & A & A & A & A & A & NA & A & A & A & A & A & A & A & PD & A & A \\
\hline
\end{tabular}

$\mathrm{A}=$ AUSENTE; $\mathrm{P}=$ PRESENTE; NA = NÃO FOI POSSIVEL AVALIAR; $\mathrm{D}=$ DIREITO; $E=$ ESQUERDO; $\mathrm{B}=\mathrm{BILATERAL}$ $P(*)=$ PRESENTE EM MUCOSA DE NASOFARINGE. 


\subsection{Descrição do estudo histopatológico}

Realizou-se biópsia por meio da rinoscopia em 18 cães (Tabela 07), sendo 13 animais com proliferação tecidual nas cavidades nasais e em um caso em plano nasal. Nos outros cães $(n=04)$ realizou-se biópsia nas regiões em que havia alterações na mucosa nasal como úlcera, fístula, erosão ou destruição de conchas nasais. Dos cães em que foram coletadas biópsias das proliferações teciduais foram diagnosticados carcinoma $(n=03)$, carcinoma de células escamosas $(n=01)$ carcinoma espinocelular $(n=01)$, adenocarcinoma mucinoso $(n=01)$, adenocarcinoma papilar ( $n=01)$, sarcoma $(n=01)$ e tumor venéreo transmissível $(n=01)$, e nos outros casos, o estudo histopatológico diagnosticou pólipos eosinofílicos $(n=01)$, processo inflamatório ulcerativo $(n=01)$ e rinite linfoplasmocitária com exsudação neutrofílica $(\mathrm{n}=01)$. Nos demais casos, o resultado do estudo histopatológico das amostras coletadas foi de rinite linfoplasmocitária $(n=05)$ e aspergilose nasal $(n=01)$. Não realizou-se biópsia $(n=03)$ nos casos de doença periodontal grave $(n=01)$, onde, não visibilizou-se proliferação tecidual, úlcera ou erosão em cavidade nasal, no caso de corpo estranho ( $n=01)$ e no cão com rinite não específica e piodermite grave $(n=01)$.

Tabela 07 - Resultados do estudo histopatológico do material coletado por meio da rinoscopia

\begin{tabular}{|c|c|c|c|}
\hline Casos & Proliferação tecidual & Histopatológico & Resultado \\
\hline 01 & $\operatorname{Sim}$ & Sim & TVT \\
\hline 02 & Sim & Sim & Carcinoma \\
\hline 03 & Sim & Sim & Carcinoma de células escamosas \\
\hline 04 & Sim & Sim & Pólipos eosinofílicos \\
\hline 05 & Sim & Sim & Processo inflamatório ulcerativo \\
\hline 06 & Sim & Sim & Adenocarcinoma mucinoso \\
\hline 07 & Sim & Sim & Carcinoma \\
\hline 08 & Não & Sim & Rinitelinfoplasmocitária \\
\hline 09 & Sim & Sim & Sarcoma \\
\hline 10 & Sim & Sim & Carcinoma espinocelular \\
\hline 11 & Sim & Sim & Adenocarcinoma papilar \\
\hline 12 & Não & Não* & Doença periodontal grave \\
\hline 13 & Não & Sim & Rinite linfoplasmocitária \\
\hline 14 & Não & Não* & Rinite não específica \\
\hline 15 & Sim & Sim & Rinite linfoplasmocitária e exsudação neutrofílica \\
\hline 16 & Não & Sim & Rinite linfoplasmocitária \\
\hline 17 & Sim & Sim & Carcinoma \\
\hline 18 & Não & Não* & Corpo estranho \\
\hline 19 & Sim & Sim & Rinite linfoplasmocitária \\
\hline 20 & Não & Sim & Aspergilose nasal \\
\hline
\end{tabular}




\subsection{Avaliação estatística dos resultados}

Para melhor compreensão da avaliação estatística dos resultados, dividiu-se os escores de cada exame, distribuição dos cães quanto aos tipos de lesão, classificação das rinites, avaliação da média e desvio padrão e avaliação multivariada dos escores.

\subsubsection{Avaliação do escore da radiografia}

A distribuição dos cães seguindo o escore idealizado para este estudo, quanto a presença de lesão foi sugerida em $65 \%$ dos casos por meio da radiografia. Em $15 \%$ dos casos a presença de lesão foi provável e em $20 \%$ foi confirmada (Tabela 08). Já, quanto a extensão da lesão (Tabela 09) não se pode delimitar em $40 \%$ dos cães, em 55\% dos casos o limite foi impreciso e em $5 \%$ limite preciso. Houve suspeita diagnóstica (Tabela 10) em $40 \%$ dos casos, $35 \%$ como forte suspeita e não houve suspeita em $25 \%$ dos casos.

Tabela 08 - Distribuição dos cães segundo a presença de lesão pela radiografia

\begin{tabular}{cccc}
\hline Radiografia - Presença de lesão & $\mathrm{N}$ & $\%$ \\
\hline 1 & 13 & 65 \\
2 & 03 & 15 \\
3 & 04 & 20 \\
\hline
\end{tabular}

Escore presença da lesão: 0- Não sugere; 1-Sugere; 2- Provável lesão; 3-Confirma existência da lesão

Tabela 09 - Distribuição dos cães segundo a extensão de lesão pela radiografia

\begin{tabular}{ccc}
\hline Radiografia - Extensão da lesão & $\mathrm{N}$ & $\%$ \\
\hline 0 & 08 & 40 \\
1 & 11 & 55 \\
2 & 01 & 5 \\
\hline
\end{tabular}

Escore: Extensão da lesão: 0- Não limita 1-Limite impreciso; 2- Limite preciso; 3-Delimita a lesão 
Tabela 10 - Distribuição dos cães segundo a suspeita diagnóstica pela radiografia

\begin{tabular}{ccc}
\hline Radiografia - Suspeita diagnóstica & $\mathrm{N}$ & $\%$ \\
\hline 0 & 05 & 25 \\
1 & 08 & 40 \\
2 & 07 & 35 \\
\hline
\end{tabular}

Escore suspeita diagnóstica: 0- Não Suspeita 1-Suspeita; 2- Forte suspeita; 3-Confirma

\subsubsection{Avaliação escore da tomografia computadorizada}

Pela tomografia computadorizada, seguindo o escore, a presença de lesão (Tabela 11) foi sugerida em 5\%, como provável presença de lesão em $65 \%$ dos casos e lesão confirmada em 30\%. Quanto à extensão da lesão (Tabela 12), o limite impreciso foi de $5 \%$, e limite preciso em $95 \%$ dos casos. Não houve nenhum caso sem alterações dignas de nota visibilizadas por meio da tomografia computadorizada. A suspeita diagnóstica (Tabela 13) esteve presente em $25 \%$ dos casos, forte suspeita em 50\% e não houve suspeita em 10\% dos casos.

Tabela 11 - Distribuição dos cães segundo a presença da lesão pela tomografia computadorizada

\begin{tabular}{cccc}
\hline Tomografia - Presença de lesão & N & $\%$ \\
\hline 1 & 01 & 5 \\
2 & 13 & 65 \\
3 & 6 & 30 \\
\hline
\end{tabular}

Escore presença da lesão: 0- Não sugere; 1-Sugere; 2- Provável lesão; 3-Confirma existência da lesão.

Tabela 12 - Distribuição dos cães segundo a extensão da lesão pela tomografia computadorizada

\begin{tabular}{cll}
\hline Tomografia - Extensão da lesão & $\mathrm{N}$ & $\%$ \\
\hline 0 & 1 & 5 \\
2 & 19 & 95 \\
\hline
\end{tabular}

Escore extensão da lesão: 0- Não limita 1-Limite impreciso; 2- Limite preciso; 3-Delimita a lesão 
Tabela13 - Distribuição dos cães segundo a suspeita diagnóstica pela tomografia

\begin{tabular}{cccc}
\hline Tomografia - Suspeita diagnóstica & N & $\%$ \\
\hline 0 & 2 & 10 \\
1 & 5 & 25 \\
2 & 10 & 50 \\
3 & 3 & 15 \\
\hline
\end{tabular}

Escore suspeita diagnóstica: 0- Não Suspeita 1-Suspeita; 2- Forte suspeita; 3-Confirma

\subsubsection{Avaliação escore da rinoscopia}

De acordo com o escore, a presença da lesão, foi confirmada em todos os casos por meio da rinoscopia (Tabela14), já quanto à extensão da lesão (Tabela 15), o limite impreciso pode ser considerado em $50 \%$ dos casos e o limite preciso em $30 \%$. A extensão da lesão foi delimitada em $10 \%$ dos casos, mas também, não foi delimitada nos outros $10 \%$ dos casos. A suspeita diagnóstica (Tabela 16) esteve presente em $25 \%$ dos casos e em $50 \%$ dos casos houve forte suspeita, sendo confirmada em $25 \%$ dos casos.

Tabela 14 - Distribuição dos cães segundo a presença da lesão pela rinoscopia

\begin{tabular}{ccc} 
Rinoscopia - Presença de lesão & $\mathrm{N}$ & $\%$ \\
\hline 3 & 20 & 100 \\
\hline
\end{tabular}

Escore suspeita diagnóstica: 0- Não Suspeita

1-Suspeita; 2- Forte suspeita; 3-Confirma.

Tabela 15 -Distribuição dos cães segundo a extensão da lesão pela rinoscopia

\begin{tabular}{cccc}
\hline Rinoscopia - Extensão da lesão & N & $\%$ \\
\hline 0 & 2 & 10 \\
1 & 10 & 50 \\
3 & 6 & 30 \\
\hline
\end{tabular}

Escore extensão da lesão: 0- Não limita 1-Limite impreciso; 2- Limite preciso; 3-Delimita a lesão 
Tabela 16 - Distribuição dos cães segundo a suspeita diagnóstica pela rinoscopia

\begin{tabular}{cccc}
\hline Rinoscopia - Suspeita diagnóstica & N & $\%$ \\
\hline 1 & 5 & 25 \\
2 & 10 & 50 \\
3 & 5 & 25 \\
\hline
\end{tabular}

Escore suspeita diagnóstica: 0- Não Suspeita 1-Suspeita; 2- Forte suspeita; 3-Confirma

5.6.4 Avaliação distribuição resultado histopatológico

A distribuição, quanto a porcentagem, dos resultados do estudo histopatológico foi considerada apenas nos 18 cães em que realizou-se biópsia, sendo excluído o caso de doença periodontal grave sem proliferação tecidual e o de rinite inespecífica associada a piodermite grave (Tabela 17). Os resultados quanto a sua distribuição foram de 38,9\% carcinomas e adenocarcinomas, 22,2\% de rinites linfoplasmocitária, 5,6\% de aspergilose nasal, 5,6\% de corpo estranho, 5,6\% de pólipo eosinofílico, 5,6\% de processo necrótico ulcerativo, 5,6\% de sarcoma e 5,6\% de tumor venéreo transmissível (TVT). Lesões benignas foram diagnosticadas em $50 \%$ e lesões malignas em 50\% dos casos (Tabela 18). Apesar de não ter sido realizado biópsia no caso do corpo estranho, este foi considerado como lesão benigna, pois obteve o diagnóstico conclusivo e seus resultados foram comparados com os demais métodos diagnósticos. 
Tabela 17 - Distribuição dos cães segundo os resultados do estudo histopatológico

\begin{tabular}{lll}
\hline Resultado Histopatológico & $\mathrm{N}$ & $\%$ \\
\hline Carcinoma & 7 & 38,9 \\
Rinite linfoplasmocitaria & 5 & 27,7 \\
Aspergillus & 1 & 5,6 \\
Corpo estranho & 1 & 5,6 \\
Pólipo eosinofilico & 1 & 5,6 \\
Processo necrótico ulcerativo & 1 & 5,6 \\
Sarcoma & 1 & 5,6 \\
TVT & 1 & 5,6 \\
\hline Total & 18 & 100,0 \\
\hline Não realizado & 2 & 10
\end{tabular}

Tabela 18 - Distribuição dos cães segundo o tipo de lesão

\begin{tabular}{ccc}
\hline Lesão & $\mathrm{N}$ & $\%$ \\
\hline Benigna & 09 & 50 \\
Maligna & 09 & 50 \\
\hline
\end{tabular}

5.6.5 Classificação das rinites por meio do exame radiográfico

Quanto à distribuição dos cães segundo a classificação das rinites visibilizadas pela radiografia $30 \%$ foram classificados com acometimento não destrutivo, 50\% acometimento destrutivo e $25 \%$ sugestivos de neoplasia (Tabela 19). 
Tabela 19 - Distribuição dos cães segundo a rinite pelo exame radiográfico

\begin{tabular}{lcc}
\hline Radiografia - rinites & $\mathrm{N}$ & $\%$ \\
\hline 1 & 06 & 30 \\
2 & 10 & 50 \\
3 & 04 & 20 \\
\hline
\end{tabular}

1)Rinite não destrutiva; 2) Rinite Destrutiva; 3) Sugere neoplasia

5.6.6 Classificação das rinites por meio do exame tomográfico

Por meio do exame tomográfico a distribuição dos cães segundo a classificação das rinites classificadas foram $10 \%$ dos casos com acometimento não destrutivo, $60 \%$ com acometimento destrutivo e $30 \%$ sugestivo de neoplasia (Tabela 20).

Tabela 20 - Distribuição dos cães segundo a rinite pelo exame tomográfico

\begin{tabular}{lll}
\hline Tomografia - rinite & $\mathrm{N}$ & $\%$ \\
\hline 1 & 2 & 10 \\
2 & 12 & 60 \\
3 & 6 & 30 \\
\hline
\end{tabular}

1)Rinite não destrutiva; 2) Rinite Destrutiva; 3) Sugere neoplasia

5.6.7 Avaliação comparativa dos escores e o tipo de lesão

De acordo com a distribuição segundo os escores dos métodos (radiografia, tomografia computadorizada e rinoscopia) e o resultado histopatológico das lesões (Tabela 21), utilizando o Teste de razão de verossimilhança e o Teste exato de 
Fischer, houve resultado significante quanto à suspeita diagnóstica de lesão maligna por meio da tomografia, e também, na rinoscopia.

Quanto a extensão e presença de lesão, os resultados não foram significantes, ou seja, > 0,05 entre os métodos diagnósticos comparados ao diagnóstico de lesão maligna.

Tabela 21 - Distribuição dos cães segundo os escores e o tipo de lesão

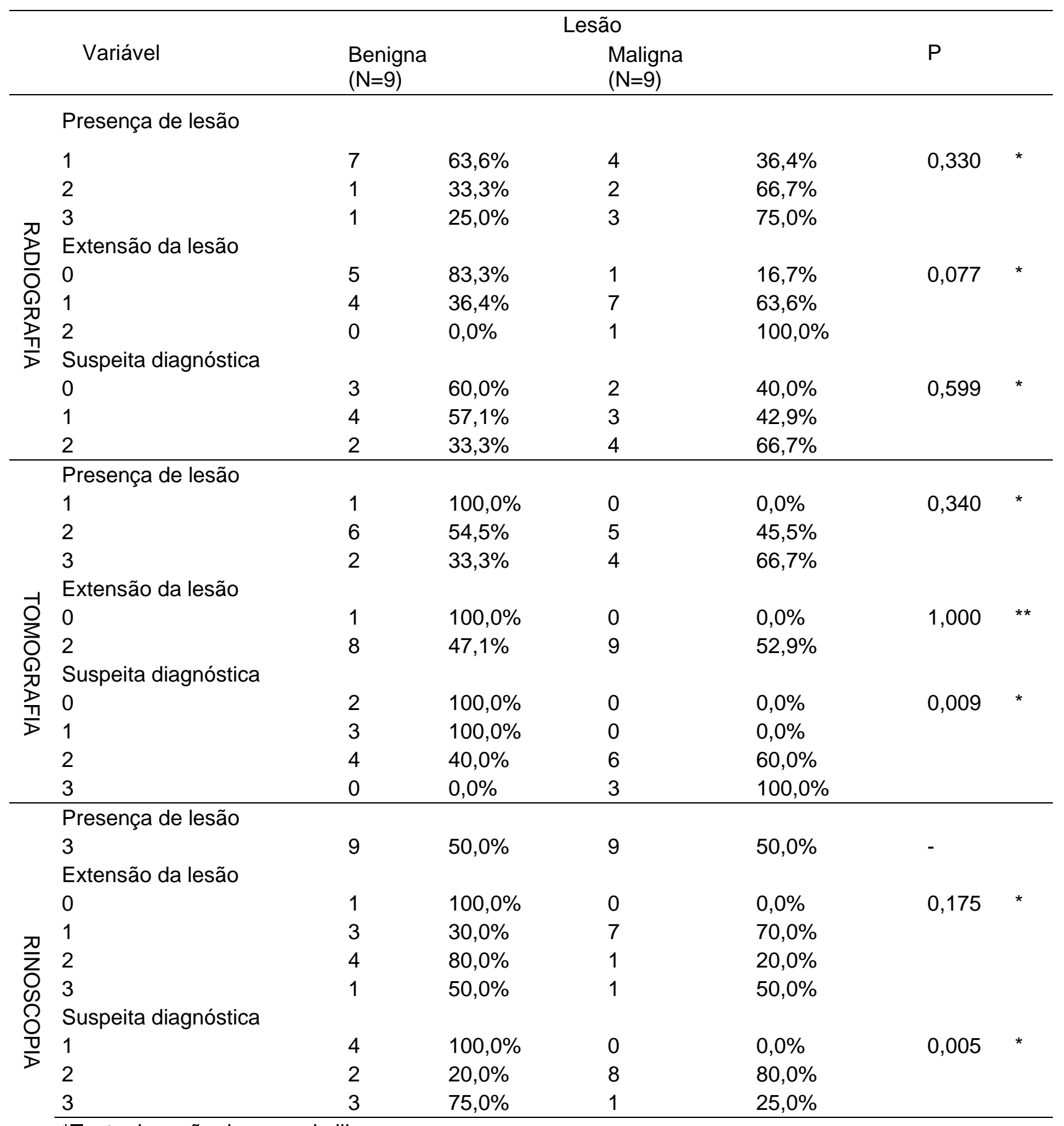

*Teste da razão de verossimilhança

${ }^{* *}$ Teste exato de Fisher 
5.6.8 Avaliação segundo a classificação de rinite e o tipo de lesão

Segundo a classificação dos tipos de rinite de acordo com as alterações visibilizadas, por meio da radiografia e tomografia, comparadas com os tipos de lesão, os resultados foram estatisticamente não significantes segundo o teste de razão de verossimilhança (Tabela 22).

Tabela 22 - Distribuição dos cães segundo os escores de rinite e o tipo de lesão

\begin{tabular}{|c|c|c|c|c|c|c|}
\hline \multirow[b]{2}{*}{ Variável } & \multicolumn{3}{|c|}{ Lesão } & \multirow[b]{2}{*}{$(\mathrm{N}=8)$} & \multirow[b]{2}{*}{$P$} & \multirow[b]{2}{*}{ Teste } \\
\hline & & $(\mathrm{N}=10)$ & Maligna & & & \\
\hline \multicolumn{7}{|c|}{ Radiografia } \\
\hline 1 & 3 & $60,0 \%$ & 2 & $40,0 \%$ & 0,507 & * \\
\hline 2 & 5 & $55,6 \%$ & 4 & $44,4 \%$ & & \\
\hline 3 & 1 & $25,0 \%$ & 3 & $75,0 \%$ & & \\
\hline \multicolumn{7}{|c|}{ Tomografia } \\
\hline 1 & 1 & $50,0 \%$ & 1 & $50,0 \%$ & 0,582 & * \\
\hline 2 & 6 & $60,0 \%$ & 4 & $40,0 \%$ & & \\
\hline 3 & 2 & $33,3 \%$ & 4 & $66,7 \%$ & & \\
\hline
\end{tabular}


5.6.8 Avaliação da média e desvio padrão

De acordo com a avaliação entre as médias e desvio padrão das somas dos escores dos métodos diagnósticos comparados com o resultado histopatológico de lesão maligna, houve resultados significantes na utilização da rinoscopia $(P=0,028)$, radiografia em conjunto com tomografia computadorizada $(P=0,042)$ e a rinoscopia em conjunto com a tomografia computadorizada de acordo com o teste de t-Student. Os métodos diagnósticos de radiografia e tomografia demonstraram resultados não significativos quando utilizados isoladamente (Tabela 23).

Tabela 23 - Média e desvio padrão das somas de escores por tipo de lesão

\begin{tabular}{|c|c|c|c|}
\hline \multirow[b]{2}{*}{ Variável } & \multicolumn{2}{|c|}{ Lesão } & \multirow[b]{2}{*}{$\mathrm{P}^{*}$} \\
\hline & $\begin{array}{l}\text { Benigna } \\
(\mathrm{N}=10)\end{array}$ & $\begin{array}{l}\text { Maligna } \\
(\mathrm{N}=8)\end{array}$ & \\
\hline Radiografia & $2,7 \pm 1,8$ & $4,1 \pm 1,7$ & 0,099 \\
\hline Tomografia & $6,4 \pm 1,6$ & $6,4 \pm 1$ & 1,000 \\
\hline Rinoscopia & $5,1 \pm 1,8$ & $6,8 \pm 1$ & 0,028 \\
\hline \multirow{2}{*}{ Radiografia+Tomografia } & $7,8 \quad \pm$ & $10,9 \pm$ & \multirow{2}{*}{0,042} \\
\hline & 3,3 & 2,6 & \\
\hline \multirow{2}{*}{ Radiografia+Rinoscopia } & \multirow{2}{*}{$9,1 \pm 1,5$} & $10,6 \pm$ & \multirow{2}{*}{0,074} \\
\hline & & 1,7 & \\
\hline \multirow{2}{*}{ Rinoscopia+Tomografia } & 11,6 & $13,2 \pm$ & \multirow{2}{*}{0,020} \\
\hline & 1,6 & 1,1 & \\
\hline \multirow{2}{*}{ Escore total } & 14,2 & $17,3 \quad \pm$ & \multirow{2}{*}{0,019} \\
\hline & 2,6 & 2,4 & \\
\hline
\end{tabular}

*Teste t-Studet

5.6.9 Avaliação comparativa das alterações e o tipo de lesão

A avaliação isolada das alterações presentes nas cavidades nasais e crânio, visibilizadas por meio da radiografia e da tomografia computadorizada, não 
apresentaram valores estatisticamente significativos, ou seja, todos os resultados foram > que 0,05 , de acordo com os testes utilizados para este cálculo (Tabela 24).

Tabela 24 - Média e desvio padrão das somas de escores por tipo de lesão e alterações visibilizadas nos exames de imagem

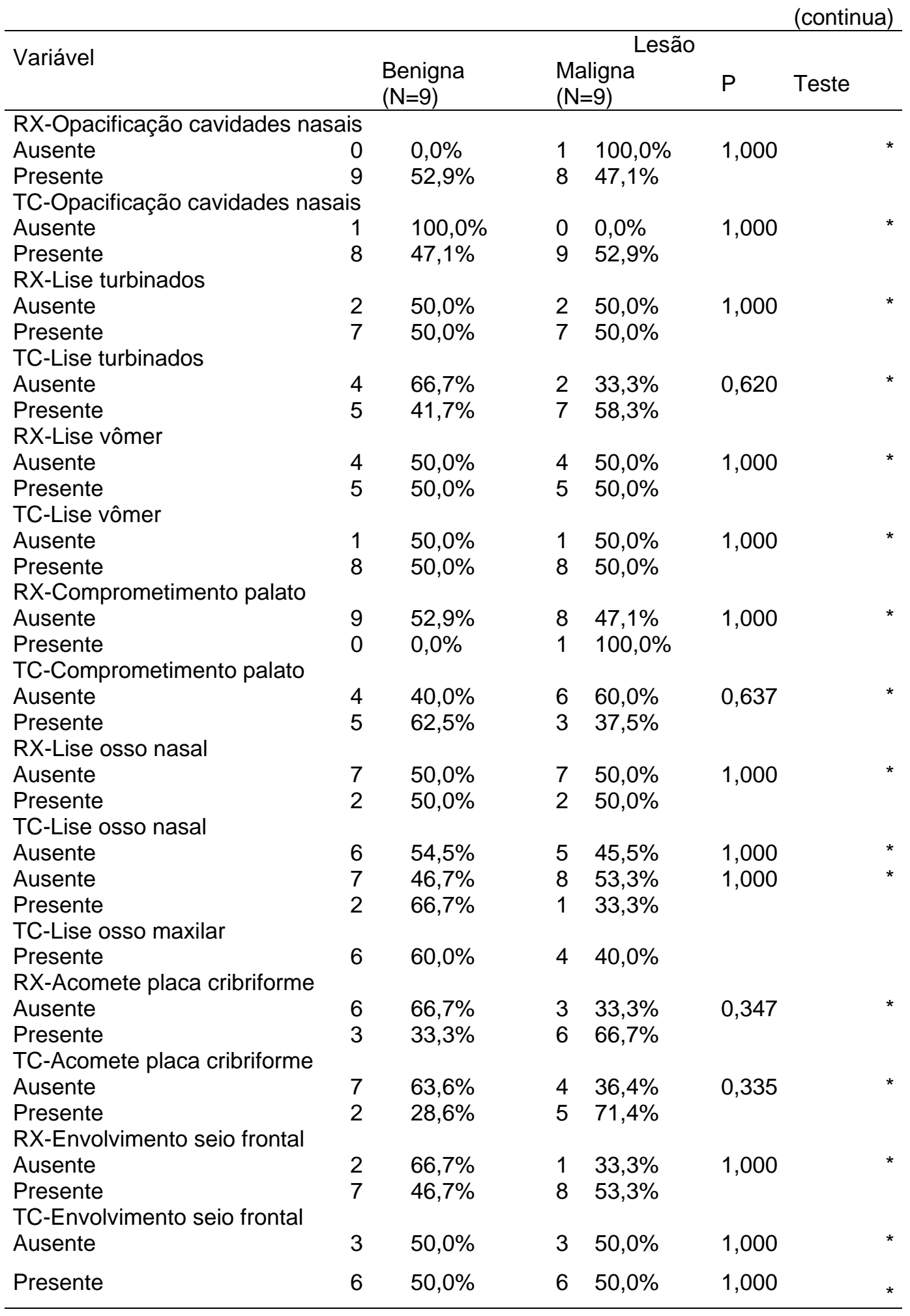


(continuação)

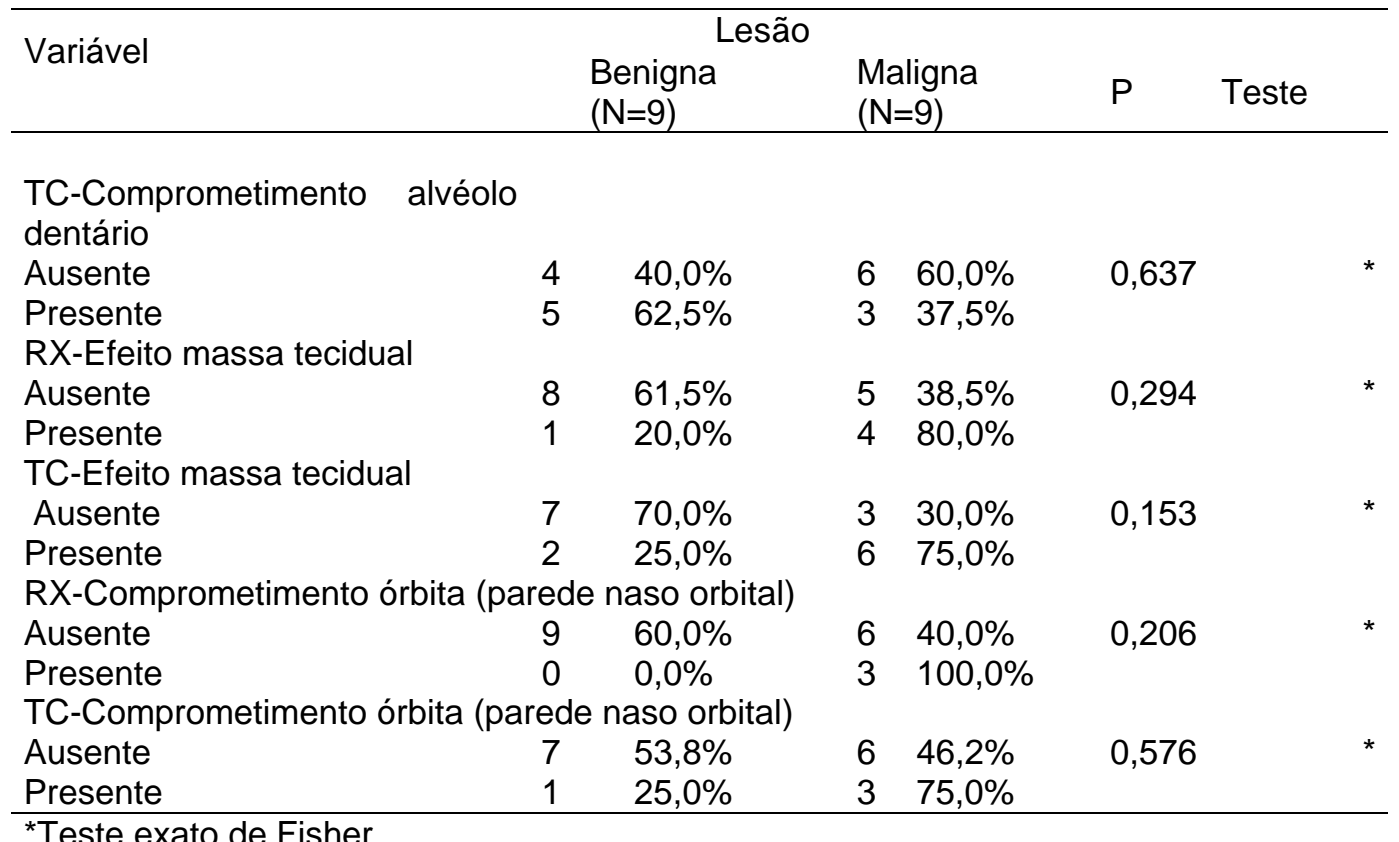

\subsubsection{Avaliação multivariada}

Os resultados utilizando o modelo de regressão logística multivariado demonstraram que a radiografia em conjunto com a tomografia computadorizada, a rinoscopia associada com a tomografia computadorizada e a rinoscopia utilizada isoladamente, foram mais específicos na diferenciação de lesão maligna (Tabela 25).

O valor da probabilidade estimada de lesão maligna é de aproximadamente 16, seguindo o escore estabelecido (Gráfico 01).

Tabela 25 - Resultados modelo de regressão logística multivariada

\begin{tabular}{llllll}
\hline Variável & $\begin{array}{l}\text { Parâmetro } \\
\text { estimado }\end{array}$ & $\begin{array}{l}\text { Erro } \\
\text { padrão }\end{array}$ & $\begin{array}{l}\text { "Odds } \\
\text { Ratio" }\end{array}$ & IC 95\% & P \\
\hline Escore total & 0,552 & 0,275 & 1,737 & 1,012 & 2,979 \\
Constante & $-8,736$ & 4,392 & 0,000 & & 0,045 \\
\hline P=0.50 & & & & & 0,047 \\
Sensibilidade & 77,8 & & & & \\
Especificidade & 77,8 & & & &
\end{tabular}




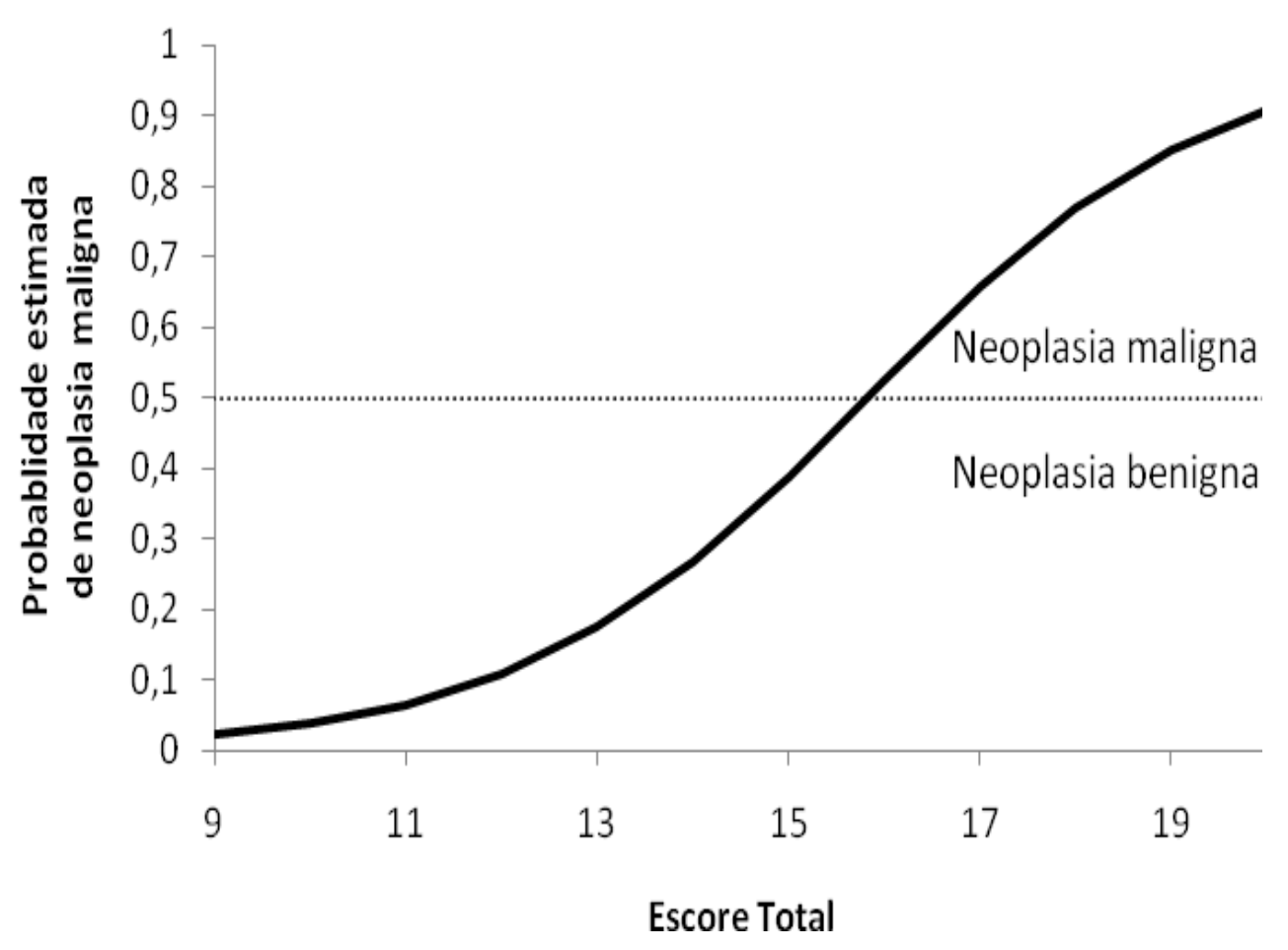

Gráfico 1 - Probabilidade estimada de neoplasia maligna segundo o escore. 


\section{DISCUSSÃO}

Os resultados do presente estudo demonstram que a utilização da radiografia digital, tomografia computadorizada, rinoscopia e o estudo histopatológico das amostras coletadas se complementam como métodos diagnósticos nas afecções nasais e sinonasais dos cães avaliados. Entretanto, pelo teste de regressão multivariada e a soma dos escores os métodos a tomografia computadorizada em conjunto com a radiografia, a tomografia computadorizada em conjunto com a rinoscopia e o emprego da rinoscopia isoloda, apresentam significância estatística para o diagnóstico de lesão maligna.

Não avaliou-se idade, raça ou sexo dos animais quanto sua predisposição para afecções nasais, porém, assim como, outros estudos realizados, os cães dolicocefálicos e mesaticefálicos, foram mais acometidos (TASKER, 1999; BURK, 1992 b; YOSHITOSHI, 2003; LEFEBVRE; KUEHN; WORTINGER, 2005, et al., 2005; KONDO, 2008 ).

As manifestações clínicas referentes a doenças nasais dos cães, neste estudo, foram apresentadas conforme descritas na literatura (McCARTHY; MCDEIRMAN, 1990; TASKER, et al., 1999; DAVIDSON et al., 2004; DOUST; SULLIVAN, 2004, LEFEBVRE; KUEHN; WORTINGER, 2005). No entanto, não avaliou-se o tipo de manifestação clínica com a afecção nasal.

Comparando a distribuição dos casos de afecções nasais deste estudo, obteve-se resultados semelhantes aos de Yoshitoshi (2003), sendo a principal causa de afecção nasal as neoplasias malignas, porém, foram diferentes os tipos histológicos, onde, no estudo de Yoshitoshi (2003) a principal neoplasia encontrada foi o TVT (40\%), e no presente o estudo foi carcinoma. Saunders et al., (2003) obteve em seu estudo a aspergilose nasal como a principal causa. No estudo de Lefebvre et al., (2005) e Pietra et al., (2010) as rinites inflamatórias foram descritas como causa principal.

Nos casos confirmados como neoplasia maligna, neste estudo, as alterações visibilizadas, por meio do exame radiográfico, conforme descrito na figura 13 (A e B), foram opacificação (88\%), lise de turbinados (77\%), vômer (55\%), em osso nasal (22\%), em osso maxilar (11\%), acometimento seio frontal (88\%), comprometimento 
de palato (11\%), placa cribriforme (66\%), efeito massa tecidual (44\%) e comprometimento órbita e lise periorbital (33\%). Estes resultados são semelhantes ao estudo realizado por Russo Lamb, Jakovljevic (2000), quando compara-se a presença de lise ou pouca definição na região dos turbinados (96\%), acometimento de seio frontal (73\%) nos casos de neoplasia maligna, sendo 30 animais. Estes autores utilizaram outras projeções radiográficas para avaliação da cavidade nasal como dorso-ventral intraoral e a projeção rostrocaudal para avaliação de seio frontal, ainda, consideraram lise em septo nasal (vômer) em conjunto com ossos que envolvem a cavidade nasal, obtendo resultado de 73\%. Considerando os cães que apresentaram lise em vômer em conjunto com osso maxilar e nasal, obteve-se resultado semelhante (88\%) no presente estudo. A opacificação de cavidades nasais, lise de turbinados e acometimento de seio frontal, só não foram visibilizadas apenas no caso de carcinoma espinocelular em plano nasal e narinas, porém, visibilizou-se efeito de massa tecidual na região acometida pela lesão proliferativa.
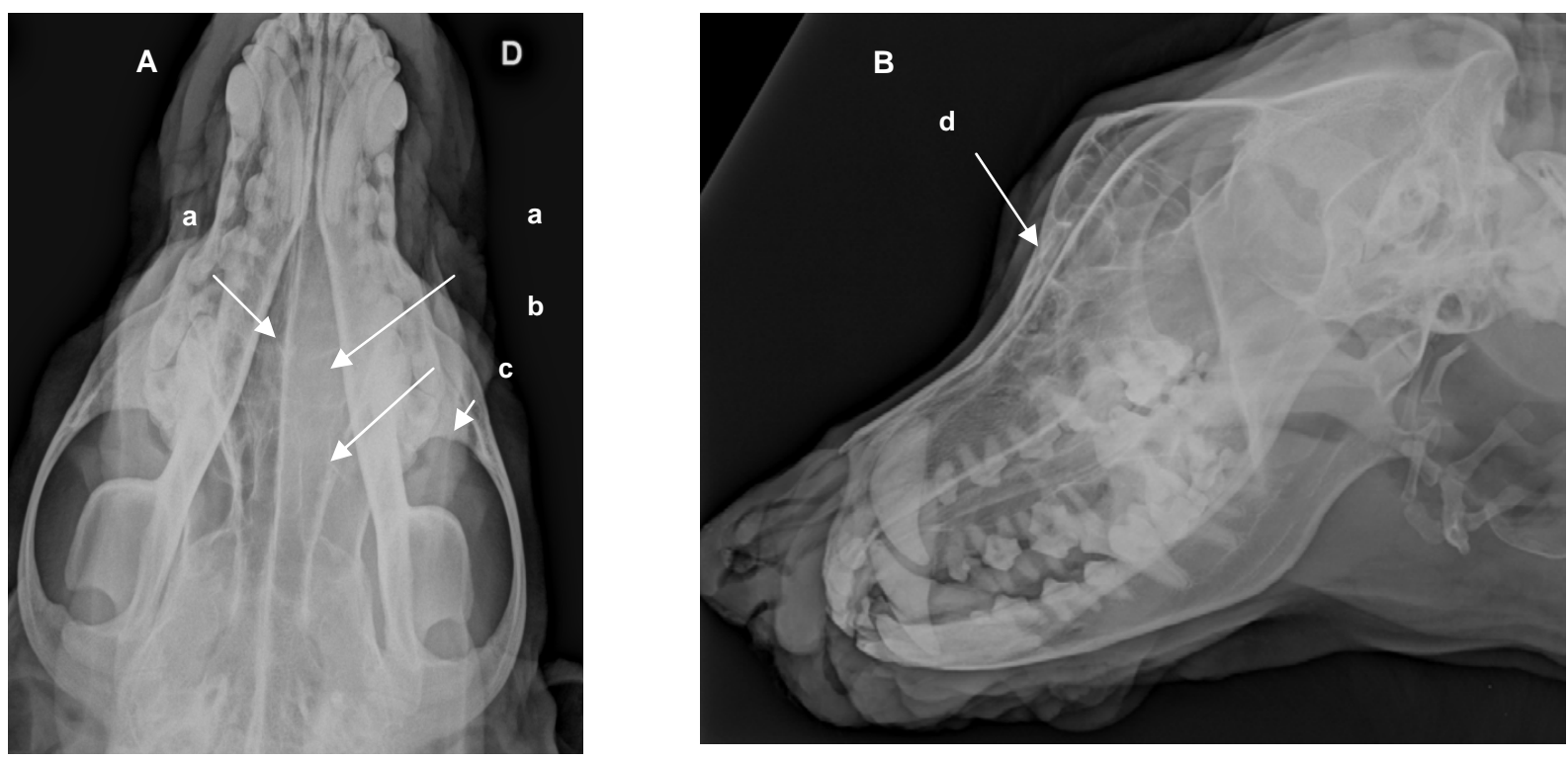

Fonte: Serviço de Diagnóstico por Imagem do Hospital Veterinário da Faculdade de Medicina Veterinária da Universidade de São Paulo, SP. 2010

Figura 13 - (A) Imagem radiográfica digital de crânio de cão, Golden Retriver, macho, dez anos de idade, em projeção dorso-ventral e diagnóstico conclusivo de carcinoma: (a) opacificação bilateral em cavidades nasais, sendo mais visível do lado direito; (b) lise em turbinados; (c) lise em parede peri-orbital. (B) Imagem radiográfica digital de crânio, do mesmo animal, em projeção latero-lateral: (c) opacificação em seio frontal

As alterações nos casos de lesão benigna, visibilizadas por meio do exame radiográfico, neste estudo, incluindo doença periodontal grave sem proliferação tecidual, rinite não específica com piodermite grave, corpo estranho e aspergilose 
nasal, foram opacificação (100\%), lise de turbinados (72\%), em vômer (45\%), em osso nasal (18\%) e em osso maxilar (18\%), acometimento seio frontal (72\%), placa cribriforme (36\%) e efeito massa tecidual (9\%). Não foi visibilizado nenhum caso de comprometimento órbita e lise periorbital nestes casos.

Os resultados do estudo de Russo, Lamb, Jakovljevic (2000) com 42 cães, foram inclusos 30 casos de aspergilose nasal como rinites, não especificando a causa, sendo $74 \%$ os casos de lise em turbinados e acometimento de seio frontal em $26 \%$ e $7 \%$ de lise em septo nasal e ossos envolvidos na cavidade nasal. Comparando estes resultados com as alterações visibilizadas no caso de aspergilose nasal, do presente estudo, conforme figura 14, as descrições são semelhantes, assim como as descritas por Saunders e Van Bree (2003), em seu estudo com cães acometidos por esta afecção.

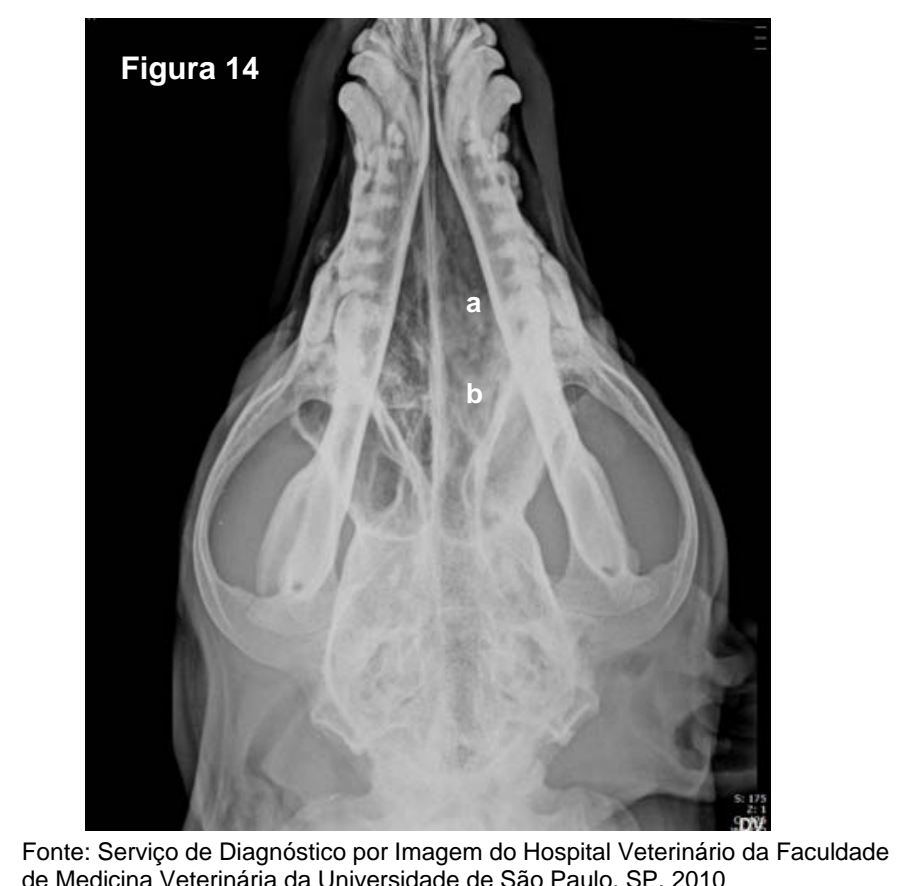

Figura 14- Imagem radiográfica digital de crânio de cão, SRD, macho, cinco anos de idade, em projeção dorso-ventral e diagnóstico conclusivo de aspergilose nasal: (a) opacificação bilateral em cavidades nasais, sendo mais visível do lado direito; (b) lise em turbinados

Por meio do exame radiográfico, neste estudo, as alterações visibilizadas nos casos de rinites linfoplasmocitárias foram semelhantes as descritas por Tasker et al., (1999) quanto à opacificação, conforme figura 15. Lise em turbinados esteve presente nos casos de rinite hiperplásica com infiltrado de células inflamatórias (TASKER, et al., 1999). 

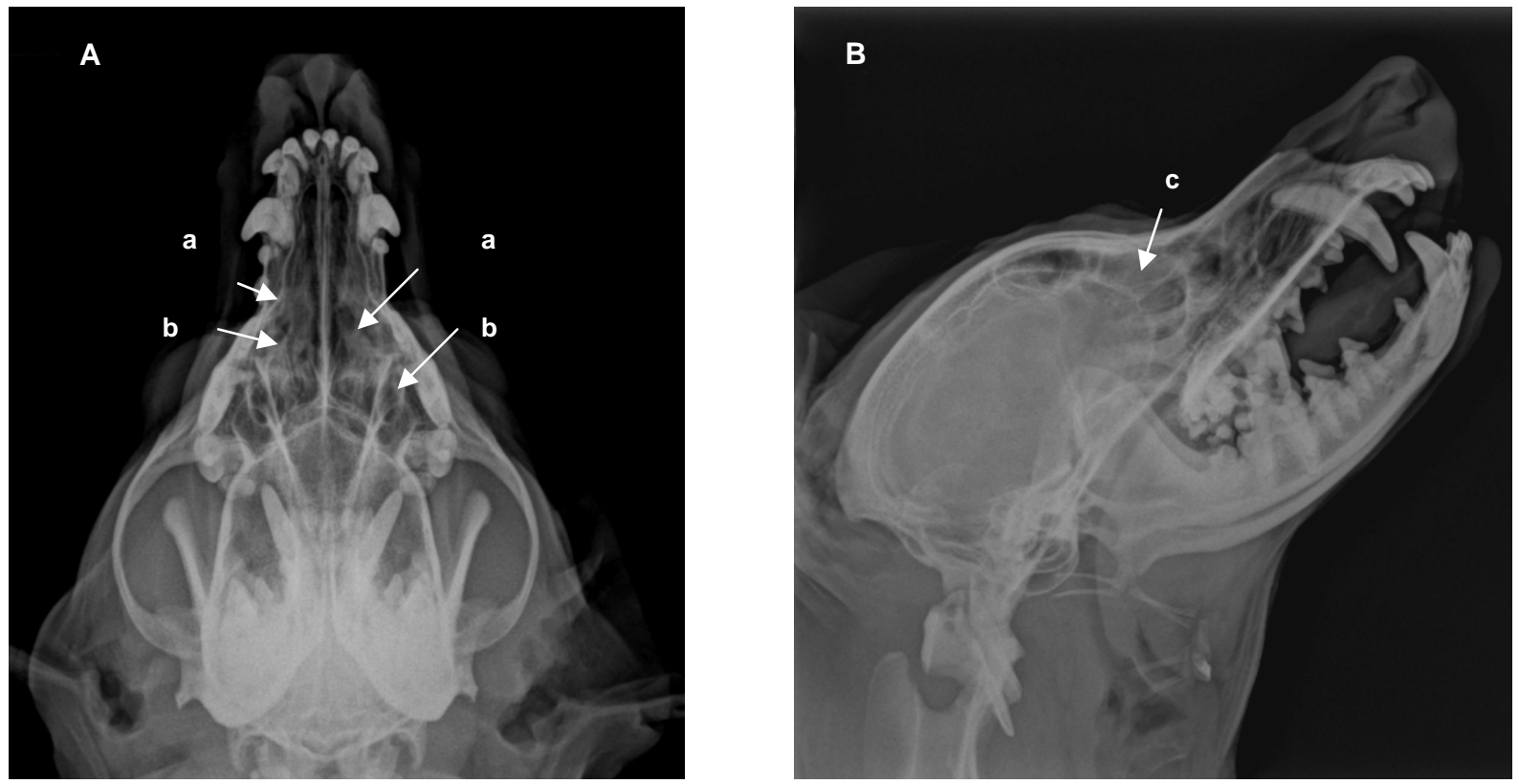

Fonte: Serviço de Diagnóstico por Imagem do Hospital Veterinário da Faculdade de Medicina Veterinária da Universidade de São Paulo, SP. 2010.

Figura 15 - (A) Imagem radiográfica digital de crânio de cão, SRD, fêmea, oito anos de idade, em projeção ventro-dorsal com a boca aberta e diagnóstico conclusivo de rinite linfoplasmocitária: (a) opacificação em cavidades nasais direita e esquerda; (b) lise em turbinados. (B) Imagem radiográfica digital de crânio, do mesmo animal, em projeção laterolateral: (c) opacificação em seio frontal

De acordo com as alterações visibilizadas por meio da TCC, neste trabalho, opacificação foi visibilizada em todos os casos, lise de turbinados em $77 \%$, vômer em $88 \%$ e em septo nasal $88 \%$, comprometimento de palato $33 \%$, lise em osso nasal $44 \%$ e maxilar $44 \%$, acometimento de recesso maxilar $77 \%$, seio esfenoidal em $77 \%$ e seio frontal em $66 \%$. Comprometimento em nasofaringe foi visibilizada em $77 \%$, porém $22 \%$ considerados como espessamento, e em todos os casos houve comprometimento em meato nasofaringeo, onde, também considerou-se espessamento, e não apenas obliteração . Efeito massa tecidual foi visibilizado em $66 \%$, acometimento de placa cribriforme em 55\%, comprometimento órbita e parede naso-orbital em 33\%, lise óssea periorbital em 44\%, e apenas um caso de comprometimento em arco zigomático. Realce pós-contraste foi visibilizado em todos os animais.

Assim, como as alterações radiográficas (Figura 13), comprometimento de órbita e parede naso-orbital foi evidenciado nos casos de carcinoma nasal, com deformidade facial (Figura.12). No entanto, também, foi visibilizada em um caso de rinite linfoplasmocitária, por meio da TCC. 
Estas alterações presentes neste estudo são semelhantes as descritas por Saunders et al., (2003), porém, lise moderada a severa foi visibilizada por meio da TCC em todos os 19 cães com neoplasia maligna, conforme figura 16. Não verificouse o mesmo resultado, neste estudo, mas, delimitou-se com precisão a região dos turbinados. Em um dos casos de neoplasia maligna confirmada, não visibilizou-se, lise na região de labirinto etmoidal, mas, havia lise em septo nasal e vômer horizontal. No caso de carcinoma espinocelular, lise não foi visibilizada em nenhuma região, pois o acometimento era apenas em plano nasal e narinas.
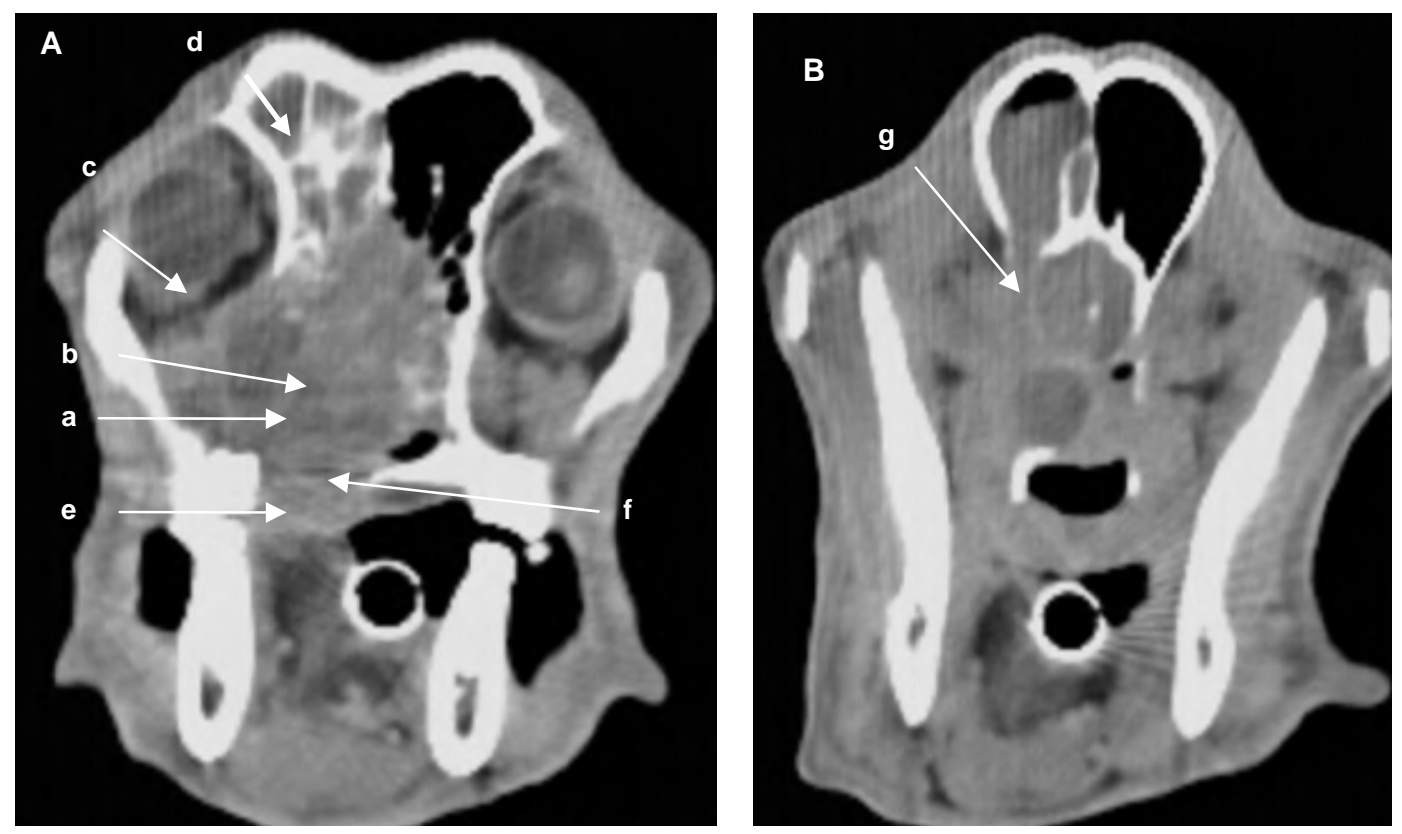

Fonte: Fernanda Auler; Serviço de imagem do Hospital Veterinário da Faculdade de Medicina Veterinária da Universidade de São Paulo, SP. 2010.

Figura 16 - (A) Imagem tomográfica digitalizada de crânio de cão, Golden Retriver, macho, dez anos de idade a nível de cavidades nasais e seio frontal com diagnóstico conclusivo de carcinoma: (a) opacificação em conchas nasais, (b) lise em vômer, septo nasal e labirinto etmoidal; (c) lise periorbital e acometimento órbita do lado direito; (d) envolvimento seio frontal direito; (d) acometimento de nasofaringe e meato nasofaringeo bilateral; (f) envolvimento de palato duro e placa cribriforme. Para este tomograma foram utilizadas janela e reconstrução para tecido mole. (B) Imagem tomográfica digitalizada de crânio do mesmo animal a nível de cavidades nasais e seio frontal: (g) envolvimento cerebelar e de bulbo olfatório. Para este tomograma foram utilizadas janela e reconstrução para tecido ósseo

Quanto aos casos de doenças nasais sem lesão maligna, neste estudo, as alterações visibilizadas, por meio da TCC, foram opacificação em 90\%, ausência ou destruição de conchas nasais em 63\%, lise em labirinto etmoidal 54\%, em vômer em $90 \%$ e septo nasal $63 \%$, comprometimento do palato em $45 \%$, lise de osso nasal em $36 \%$ e em osso maxilar 63\%. Acometimento de recesso maxilar em $63 \%$ dos casos, assim como em seio esfenoidal e em seio frontal $54 \%$. Visibilizou-se acometimento 
em meato nasofaringeo, em todos os casos, porém, não necessariamente caracterizando obstrução, e em nasofaringe 27\%. Efeito massa tecidual, esteve presente em 18\%, comprometimento órbita e parede naso-orbital em 9\%, e lise óssea periorbital em 45\% (Figura 16). Realce pós-contraste esteve presente em $72 \%$ dos casos, porém, não foi administrado contraste em dois casos.

As alterações visibilizadas no caso de aspergilose nasal, conforme figura 17, do presente estudo são semelhantes as descritas por Saunders et al., (2004), que, verificaram nos 46 casos de aspergilose nasal acometimento de seio frontal, opacificação, destruição de turbinados e lise em ossos envolvendo a cavidade nasal. Destruição ou adelgaçamento da placa cribriforme, também foi descrita, mas, esta alteração não esteve presente neste caso. Entretanto, o número de casos descrito pelos autores é maior sendo detectada em 15\% dos casos.
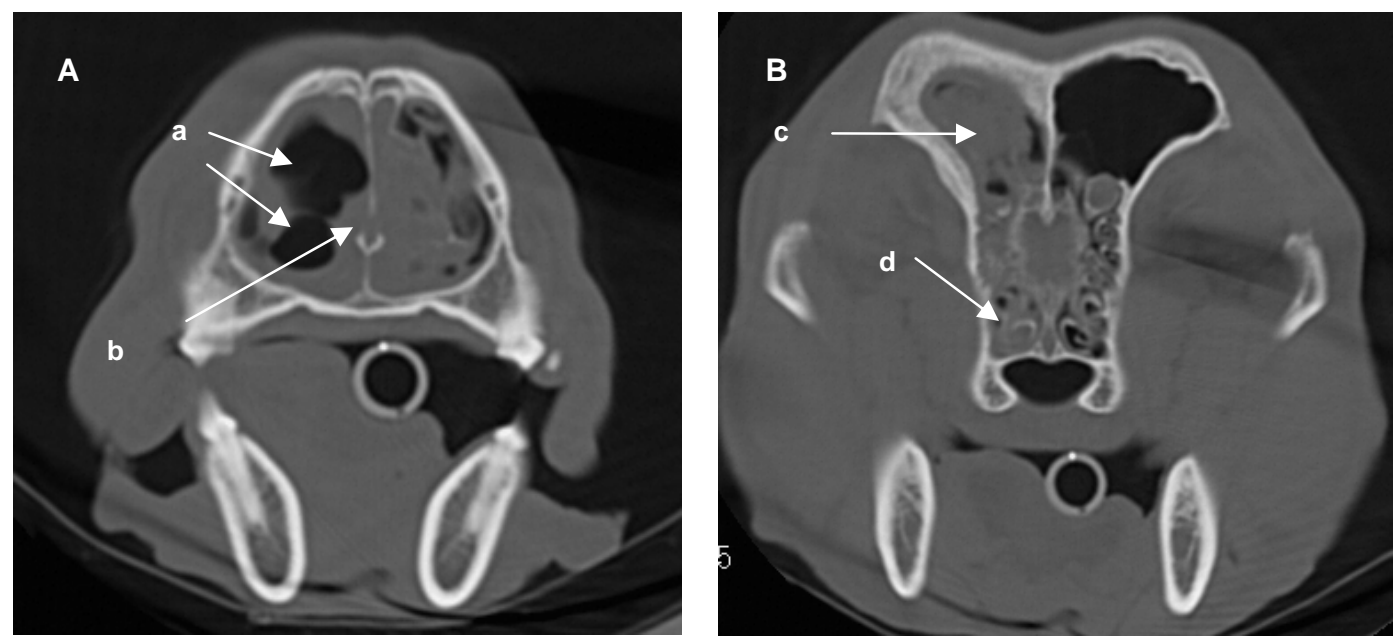

Fonte: Serviço de Diagnóstico por Imagem do Hospital Veterinário da Faculdade de Medicina Veterinária da Universidade de São Paulo, SP. 2010.

Figura 17 - (A) Imagem tomográfica digitalizada de crânio de cão, SRD, macho, cinco anos de idade a nível de cavidades nasais com diagnóstico conclusivo de aspergilose nasal: (a) destruição de conchas nasais do lado direito, (b) lise em vômer e septo nasal.( B) Imagem tomográfica digitalizada de Crânio do mesmo animal a nível de seio frontal: (c) opacificação em seio esfenoidal direito; (d) envolvimento seio frontal direito. Para estes tomogramas foram utilizadas janela e reconstrução para tecido ósseo

No caso de corpo estranho, identificou-se pela TCC opacificação em cavidade nasal direita, lise em septo e vômer. Saunders et al., (2003) e Tasker et al, (1999) também, descreveram estas alterações em seus casos de corpo estranho nasal.

O aspecto nos casos de rinite linfoplasmocitária conforme figura 18 (A eB), quanto as alterações, foram semelhantes as descritas por Windsor et al. (2004), tais como lise na região dos turbinados e acometimento de seio frontal. Estes resultados 
também foram descritos por outros autores (PARK, et al., 1992; SAUNDERS, et al., 2003; LEFEBVRE; KUEHN; WORTINGER, 2005, et al., 2005).
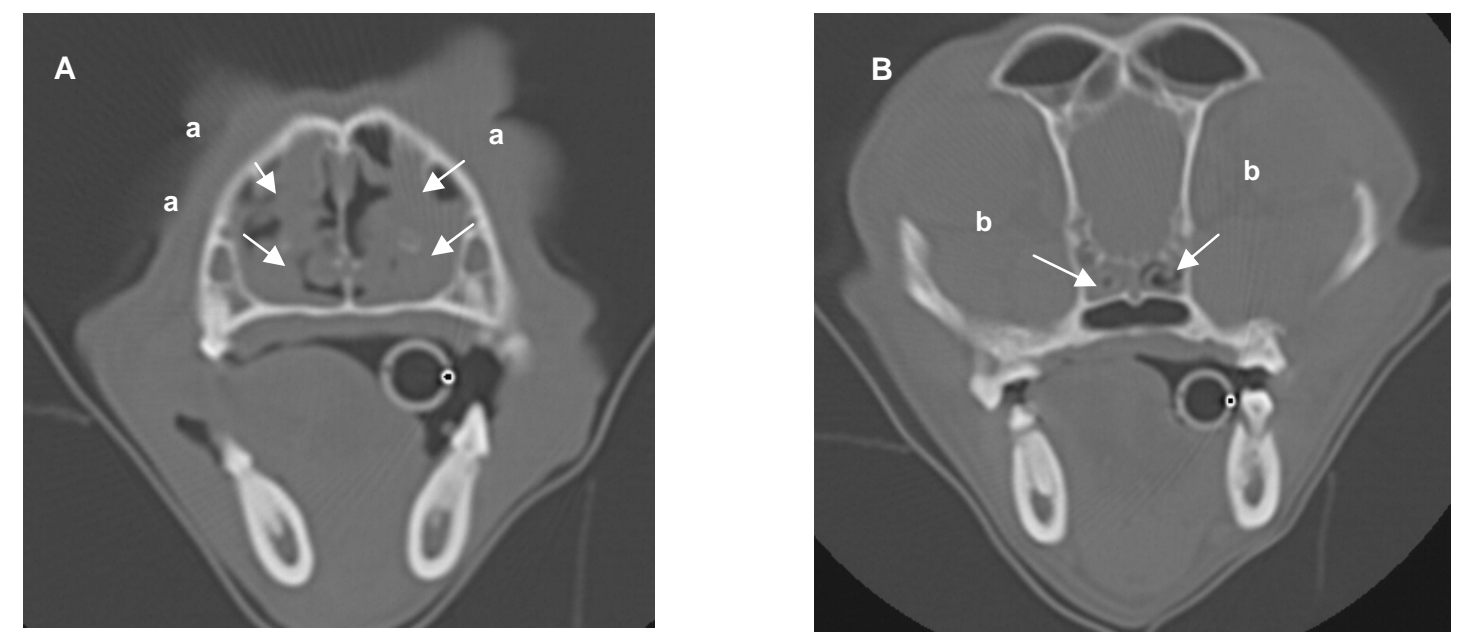

Fonte: Serviço de Diagnóstico por Imagem do Hospital Veterinário da Faculdade de Medicina Veterinária da Universidade de São Paulo, SP. 2010.

Figura 18 - (A) Imagem tomográfica digitalizada de crânio de cão, SRD, fêmea, oito anos de idade a nível de cavidades nasais com diagnóstico conclusivo de rinite linfoplasmocitária: (a) opacificação em conchas nasais direita e esquerda. (B) Imagem tomográfica digitalizada de crânio do mesmo animal a nível de seio frontal:(b) opacificação em seio esfenoidal bilateral. Para estes tomogramas foram utilizadas janela e reconstrução para tecido ósseo

Assim como, descrito por Tasker et al. (1999), Yoshitoshi (2003), Lana e Withrow (2001), McCarthy (2005), Billen, Day, Clercx (2006), a proliferação tecidual, foi a principal alteração, vista, por meio da rinoscopia, nos casos de lesão maligna, conforme figuras 19 e 20. No entanto, em dois casos com proliferação tecidual acometendo região dos turbinados nasais e obstruindo coanas direita e esquerda, havia histórico, em um deles, de diagnóstico histopatológico de hemangioma nasal há 04 anos. Na segunda rinoscopia realizada, coletou-se sete fragmentos da proliferação tecidual em ambas as cavidades nasais medindo cerca de 5,0 a 7,0 cm de comprimento com $0,5 \mathrm{~cm}$ de largura, e também, coletados cinco fragmentos medindo cerca de 0,5 a $1,0 \mathrm{~cm}$ da proliferação tecidual em coanas, e o resultado histopatológico não demonstrou hemangioma. No segundo caso, havia histórico de pólipo granulomatoso associado a corpo estranho, removido através de rinotomia, este animal necessitou ser submetido à nova rinoscopia e foi visibilizada proliferação tecidual em cavidade nasal direita e acometimento bilateral em coanas, sendo, realizado coleta de material, com resultado histopatológico de rinite ulcerativa crônica. 


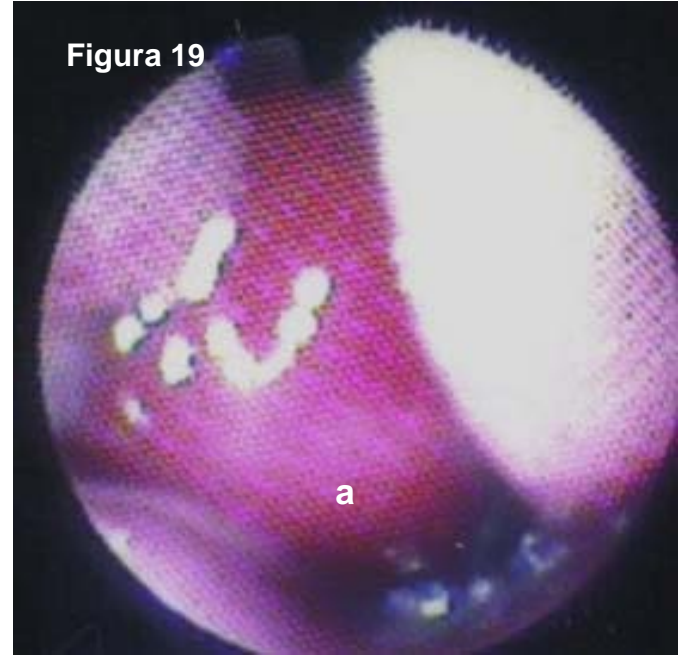

Fonte: São Paulo - SP. Fernanda Auler; Hospital Veterinário -FMVZ-USP, 2010.

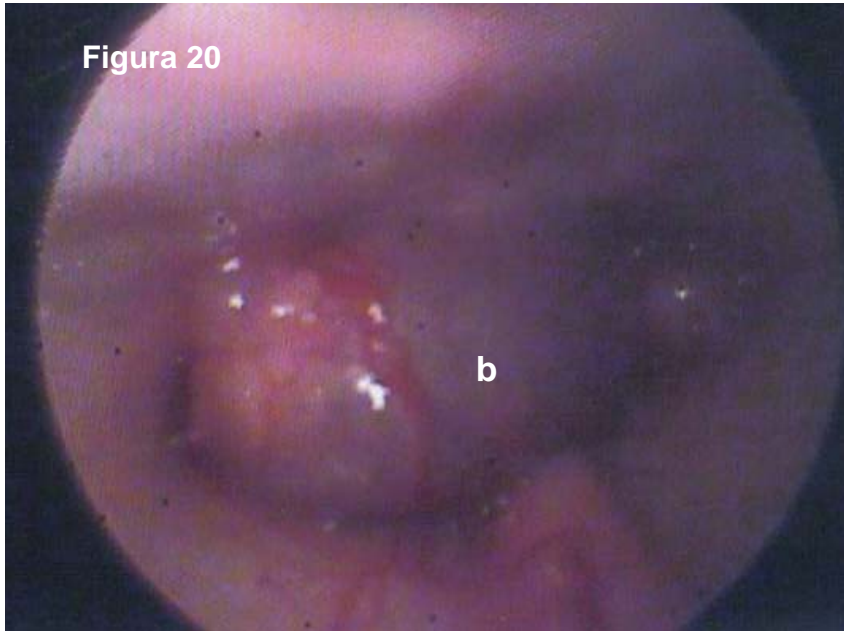

Fonte: São Paulo - SP. Fernanda Auler; Hospital Veterinário -FMVZ-USP, 2010.

Figura 19 - Imagem digitalizada de cavidade nasal direita durante a rinoscopia anterior de cão, Golden Retriver, macho, dez anos de idade com diagnóstico conclusivo de carcinoma: (a) proliferação tecidual acometendo meato nasal comum médio, dorsal e ventral

Figura 20- Imagem digitalizada de nasofaringe durante a rinoscopia posterior de cão Golden Retriver, macho, dez anos de idade com diagnóstico conclusivo de carcinoma por meio da rinoscopia posterior:(B) proliferação tecidual em nasofaringe obstruindo coanas direita e esquerda

Nos casos de rinites inflamatórias, do presente estudo, estavam presentes secreção muco-purulenta, edema e hiperemia, conforme figura 21 e 22, sendo alterações comuns com as descritas por Windsor et al. 2004. Também, visibilizou-se em um caso diminuição de espaço na cavidade nasal esquerda da qual na permitiu a avaliação rinoscópica. Em outro caso, o aspecto visibilizado por meio da rinoscopia, foi destruição de conchas nasais e presença de pequena proliferação tecidual em região de etmoturbinados, sendo coletado biópsia e diagnóstico histopatológico de rinite inflamatória, porém, a amostra foi superficial, não descartando a possibilidade de malignidade em tecidos subjacentes. Windsor e colaboradores (2004), também, reportaram em seu estudo alterações como atrofia moderada e destruição de conchas nasais. 

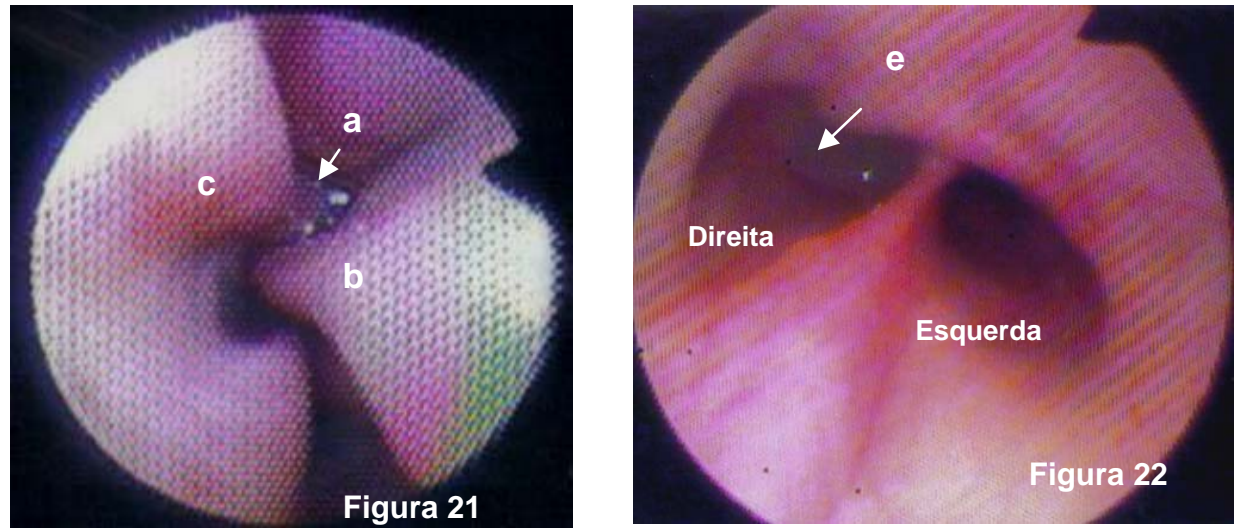

Fonte: São Paulo - SP. Fernanda Auler; Hospital Veterinário -FMVZ-USP, 2010.

Figura 21 - Imagem digitalizada de cavidade nasal esquerda durante a rinoscopia anterior de cão SRD, fêmea, oito anos de idade com diagnóstico conclusivo de rinite linfoplasmocitária: (a) secreção muco-purulenta; (b) edema; (c) hiperemia; (c) septo nasal

Figura 22- Imagem digitalizada de nasofaringe durante a rinoscopia posterior cão SRD, fêmea, oito anos de idade com diagnóstico conclusivo de rinite linfoplasmocitária: (e) Secreção mucosa em coana do lado direito

Conforme estudos realizados por Saunders e Van Bree (2003), Saunders et al. (2004), Johnson et al. (2006), sobre aspergilose nasal, haviam casos em que estavam presentes secreção sanguinolenta, ausência de conchas, necrose e fragmentos ósseos, recobertos por placa fúngica esbranquiçada, sendo semelhantes aos achados no caso avaliado do presente estudo, conforme figura 23 e 24 . Não observou-se, neste caso, descoloração de narinas.
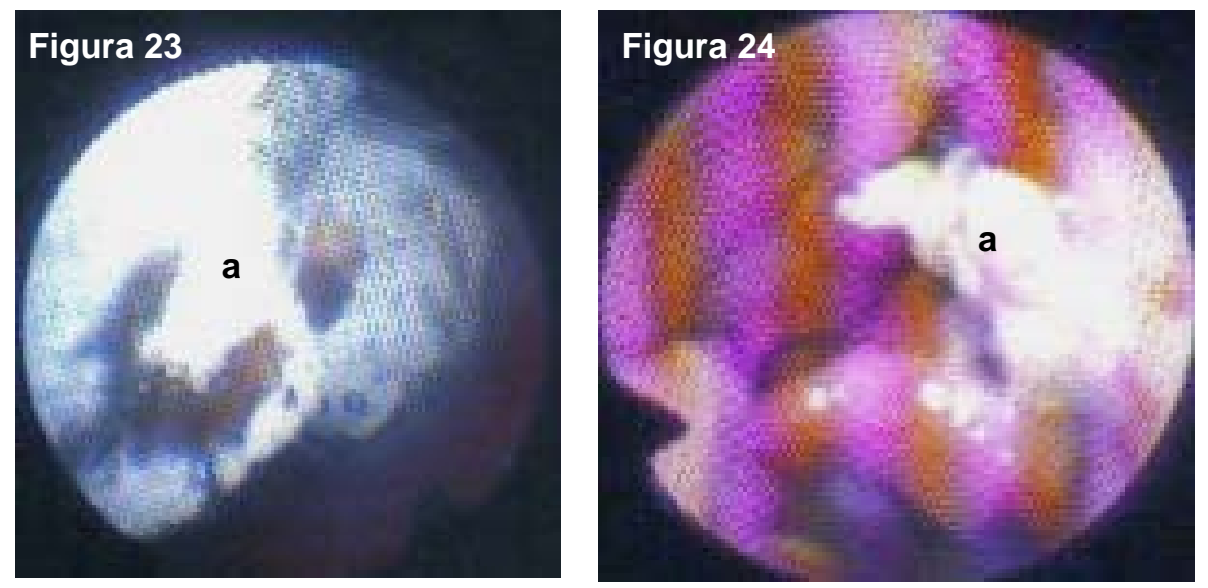

Fonte: São Paulo - SP. Fernanda Auler; Hospital Veterinário -FMVZ-USP, 2010.

Figura 23 e 24- Imagem digitalizada de cavidade nasal direita durante a rinoscopia anterior de cão, SRD,macho, cinco anos de idade com diagnóstico conclusivo de aspergilose nasal: (a) placa fúngica em cavidade nasal . 
Com base na avaliação estatística deste trabalho segundo os escores e tipo de neoplasia, o exame radiográfico, apresentou resultados não significativos quanto à presença de lesão, extensão e suspeita diagnóstica. No entanto, presença de lesão visibilizada por meio da radiografia foi confirmada em 33\% dos casos dos quais, foram diagnosticados como carcinoma por meio do estudo histopatológico. $O$ exame tomográfico demonstrou resultados significativos quanto a suspeita diagnóstica, assim como a rinoscopia, da qual, também, confirmou a presença ou não de lesão em $100 \%$ dos casos.

De acordo com a média e desvio padrão da soma dos escores por tipo de lesão, os resultados estatísticos deste trabalho, demonstram como significantes na contribuição diagnóstica, a utilização da radiografia em conjunto com a tomografia computadorizada, da qual, também, foi significativa em conjunto com a rinoscopia.

A rinoscopia apresentou resultado significativo, mesmo quando empregada isoladamente. Apesar de ter sido utilizado um escore idealizado para avaliar a contribuição dos métodos diagnósticos, estes resultados corroboram com os de outros autores (PARK; BECK; Le COUTEURS, 1992; SAUNDERS, et al., 2003; LEFEBVRE; KUEHN; WORTINGER, 2005; PIETRA et al., 2010)

As regiões do crânio e cavidades nasais visibilizadas por meio da TCC são pouco especificadas e delimitadas pelos autores, sendo avaliadas em conjunto. Saunders et al (2003) consideraram em seus casos, como critérios diagnósticos de lise em turbinados em conjunto com vômer e septo nasal, sem delimitar estas regiões. Drees, Forrester e Chappell (2009), também, utilizaram esta mesma forma de avaliação. No estudo de Kondo et al.(2008) o envolvimento da cavidade oral incluindo destruição do palato foi um dos parâmetros utilizados na classificação do estágio clínico e prognóstico dos cães com neoplasia nasal, mas não foi descrito quantitativamente. Já no estudo de Miles et al. (2008) estas regiões foram delimitadas, mas, avaliadas por meio da ressonância magnética, não podendo comparar os resultados com este estudo.

Opacificação em cavidades nasais, lise de turbinados, no vômer e septo nasal, comprometimento em palato, lise em osso nasal e maxilar, acometimento dos seios paranasais, envolvimento nasofaringe e meato nasofaríngeo, destruição da placa cribriforme, acometimento da órbita e ou parede naso-orbital, lise óssea periorbital, são considerados achados importantes nos exames radiográficos e tomográficos para diagnóstico, e na avaliação da gravidade da doença (GIBBS, et 
al., 1979; HARVEY, et al., 1979; THRALL et al., 1989; WITHROW, 1989; BURK, 1992 b; PARK; BECK; Le COUTEURS,1992; MYER, 1994; TASKER, 1999; DAVIDSON et al., 2004; LEFEBVRE; KUEHN; WORTINGER, 2005; POWDER; ROSE; CRAWFORD, 2006, et al., 2006; JOHNSON; WISNER, 2007; DREES; FORRESTER; CHAPPEL, 2009).

Embora, os resultados do presente estudo, assim como os de outros estudos realizados (RUSSO; LAMB; JAKOVLJEVIC, 2000; SAUNDERS, et al., 2003; LEFEBVRE; KUEHN; WORTINGER, 2005; POWDER; ROSE; CRAWFORD, 2006, et al., 2006; DREES; FORRESTER; CHAPPELL, 2009), não caracterizaram alterações específicas na diferenciação da afecção quanto ao tipo de lesão, se benigna ou maligna já que as mesmas foram reportadas em casos de rinites linfoplasmocitárias, rinites por corpo estranho, fúngica e neoplásica.

Os resultados não foram significativos, na análise multivariada, quanto à avaliação das alterações visibilizadas isoladamente por meio dos exames de imagem quando comparadas com o tipo de lesão maligna. No entanto, o acometimento das estruturas avaliadas, associadas à doença nasal maligna, visibilizadas pela TCC, no presente estudo, foram semelhantes as descritas anteriormente por outros autores (PARK; BECK; Le COUTEURS, 1992; SAUNDERS et al., 2002; LEFEBVRE; KUEHN; WORTINGER, 2005 et al., 2005; DREES et al., 2009).

Classificou-se os tipos de rinites como não destrutivas, destrutivas ou neoplásica, comparando apenas os exames de imagem, não obteve-se, resultados significativos, porém, o exame tomográfico, permitiu sugerir mais casos de neoplasia, dos quais foram confirmados como lesão maligna (44\%). Ambos os exames classificaram o caso de aspergilose nasal como rinite destrutiva. Nos casos de rinite linfoplasmocitária, os exames de imagem consideraram 60\% dos casos como destrutivas, sendo apenas um caso, classificado como rinite destrutiva na TCC e não destrutiva no exame radiográfico. Estas alterações corroboram com os critérios propostos e descritos por Gibbs et al. (1979) e Harvey et al. (1979), os demais casos, não demonstraram alterações semelhantes visíveis pelos exames.

A rinoscopia pode ser considerada o padrão ouro, pois, confirmou a presença ou não de lesão em 100\% dos casos, além de diagnosticar o corpo estranho, sendo, também resolutiva na remoção do mesmo. 
Assim como em outros estudos, a rinoscopia foi significativa quanto a especificidade e contribuição diagnóstica (YOSHITOSHI, 2003; PIETRA et al., 2010). Sua limitação, neste estudo, esteve associada na delimitação precisa, quanto à extensão da lesão. Mesmo confirmando a existência da lesão é necessário a coleta de material para avaliação histopatológica.

Apesar de utilizar o resultado histopatológico das amostras coletadas por meio da rinoscopia no diagnóstico diferencial de lesão benigna e maligna neste estudo, corrobora-se com McCarthy (2005), sobre a presença de fibrina, necrose e inflamação estarem associadas à proliferação tecidual dificultando a coleta devida, e com isto prejudicar a interpretação diagnóstica do estudo histológico devido à qualidade da amostras. Dentre outras complicações relacionadas, esteve a conformação anatômica da cavidade nasal, dificultando a inspeção adequada e a coleta de biópsia. Em alguns casos, a hemorragia nasal secundária, impossibilitou a realização de novas coletas durante o mesmo procedimento.

Durante a realização dos procedimentos, não houve complicações como parada cardíaca ou outras intercorrências durante a anestesia em todos os animais incluídos neste estudo.

\subsection{Limitações do estudo}

Os resultados do presente estudo foram semelhantes a outros no tocante o emprego da radiografia, tomografia computadorizada e rinoscopia. No entanto, considera-se como limitação a validação do escore quanto a contribuição diagnóstica e os tipos de rinites, por um único observador.

Considera-se outra limitação, os resultados histopatológicos, dos quais poderiam ser reavaliados nos casos de forte suspeita de lesão maligna, quando visibilizadas pela radiografia, tomografia computadorizada e rinoscopia ou novamente coletados por meio da rinoscopia ou rinotomia, para nova avaliação histopatológica. Outra sugestão seria avaliação destas amostras por meio do estudo imunohistoquímico. 


\section{CONCLUSÕES}

A análise dos resultados obtidos permitiu tecer as seguintes conclusões:

$\checkmark$ O exame de rinoscopia permite por meio da visibilização direta da cavidade nasal, confirmar a presença de lesão, auxiliando sobre a suspeita diagnóstica, além de possibilitar, de forma minimamente invasiva a coleta de material, para a conclusão diagnóstica. Sua contribuição diagnóstica, mesmo isoladamente, foi significativa nos casos de lesão maligna.

$\checkmark$ Oxame tomográfico, quando utilizado isoladamente, não obteve resultados significativos nos casos de lesão maligna, neste estudo. No entanto, permitiu avaliar maior número de regiões acometidas, e aumentar a suspeita diagnóstica dos casos avaliados. Em conjunto com o exame radiográfico sua contribuição diagnóstica foi significativa nos casos de lesão maligna, assim como, seu emprego em conjunto com a rinoscopia.

$\checkmark$ exame radiográfico, isoladamente, não obteve resultados significativos quanto sua contribuição diagnóstica nos casos de lesão maligna, porém, permitiu auxiliar na triagem dos casos suspeitos de rinites, inclusive com forte suspeita de neoplasia. Quando utilizado em conjunto com a tomografia computadorizada, demonstrou resultados significativos.

$\checkmark$ Os exames de imagem radiográfico, tomográfico e a rinoscopia, se complementam no diagnóstico das afecções nasais e sinonasais de cães, porém, não descartam a necessidade de avaliação histológica de amostras dos casos suspeitos de lesão maligna, para assim, concluir o diagnóstico. 


\section{REFERÊNCIAS}

BAGATIN, E.; ANDRADE DA COSTA, E. Doenças das vias aéreas superiores. Jornal Brasileiro Pneumologia, v. 32, n.2, p.17-26, 2006.

BEDFORD, P. G. C. Afecções do focinho. In: ETTINGER, S.J. ; FELDMAN, E. C. Tratado de medicina interna veterinária: moléstias do cão e do gato. São Paulo: Manole, 1997. p. 786-805.

BILLEN, F.; DAY, M.; CLERCX, C. Pharyngeal disorders in dogs. Journal of Small Animal Practice, v. 47, p. 122-29, 2006.

BENITAH, N. Canine nasal Aspergillosis. Clinical Techiniques in Small Animal Practice, v. 21, n. 2, p. 82-88, may. 2006.

BURGENER, D. C.; SLOCOMBE, R. F.; ZERBE, C. A. Lymphoplasmacytic rhinitis in 5 dogs. Journal of the American Animal Hospital Association, v. 23, p. 565, 1987.

BURK, R. L. Computed tomographic anatomy of the canine nasal passages.

Veterinary Radiology Ultrassonography, v. 33, p. 170- 76, 1992. a.

BURK, R. L. Computed tomographic imaging of nasal disease in 100 dogs. Veterinary Radiology Ultrassonography, v. 33, p. 177- 92, 1992. b.

DAVIDSON, A. P.; MATHEWS, K. G.; KOBLIK, P. D.; THÉON, A. Doenças do nariz e dos seios nasais. In: ETTINGER, S. J.; FELDMAN, E. C. Tratado de medicina interna veterinária: doenças do cão e do gato. 5 ed. Rio de Janeiro: Guanabara Koogan, 2004. p.1059- 82.

DOUST, R.; SULLIVAN, M. Nasal discharge, sneezing, and reverse sneezing. In: KING, L. G., Textbook of respiratory disease in dogs and cats. St. Louis: Elsevier, 2004. p. 17- 28.

DREES, R.; FORREST, L. J.; CHAPPELL, R. Comparison of computed tomography and magnetic resonance imaging for the evaluation of canine intranasal neoplasia. Journal of Small Animal Practioner. v. 50, n. 7, p.334 - 40. Disponível em: <http://www.ncbi.nlm.nih.gov/pmc/articles/PMC2706309/>. Acesso em: 15 mar 2010.

ELIE, M.; SABO, M. Basics in canine and feline rhinoscopy. Clinical Techiniques in Small Animal Practice, v. 21, n. 2, p. 60-63, may. 2006.

ELLIOT, M. K.; MAYER, M. N. Radiation therapy for tumors of the nasal cavity and paranasal sinuses in dogs. The Canine Veterinary Journal. v. 50, p. 309-12, march, 2009. Disponível em:

<http://www.ncbi.nlm.nih.gov/pmc/articles/PMC2643460/> Acesso em: 25 out 2009. 
EVANS, H. E. The respiratory system. In:

Philadelphia: W.B. Saunders, 1993. p. 463-493.

Miller's anatomy of the dog.

FORBES LENT, S. E.; HAWKINS, E. C. Evaluation of rhinoscopy and rhinoscopyassisted mucosal biopsy in diagnosis of nasal disease in dogs: 119 cases (19851989). Journal of American Veterinary Medical Association, v. 201, p.1425-29. 1992.

FORD, R. B. Endoscopy of the upper respiratory tract of the dog and cat. In: TAMS, T. R. Small Animal Endoscopy. St.Louis: Mosby Company, 1990. p. 297-307.

FORRESTER, S.D.; JONES, J. C. Indentyfing the cause of nasal diseases in dogs. Veterinary Medicine, n. 97, p. 530-42, 2002.

FORRESTER, S. D.; NOFTSINGER, M. H. Initial approach in dogs with nasal discharge. Veterinary Medicine, n. 97, p. 521-29, 2002.

GIBBS, C; LANE, J. G.; DENNY, H. R. Radiological features of intra-nasal lesions in the dog: a review of 100 cases. Journal of Small Animal Practioner, v. 20, n.9, p. 515, 1979.

HARE, W. C. D. Sistema respiratório do carnívoro. In: GETTY, R. Anatomia dos animais domésticos. 5 ed. Rio de Janeiro: Guanabara Koogan, 1986. v. 2, p. 146580.

HARVEY, C. E.;. BIERY, D. N.; MORELLO, J.; O'BRIEN, J. A. Chronic nasal disease in the dog: its radiographic diagnosis. Veterinary Radiology, v. 20. p. 91. 1979.

JOHNSON, E. G.; WISNER, E. R. Advances in respiratory imaging. Veterinary Clinics of North America:Small Animal Practice, v.37, p. 879-900, 2007.

JOHNSON, L. R.; DRAZENOVICH, T. L.; HERRERA, M. A.; WISNER, E. R. Results of rhinoscopy alone or in conjuction with sinuscopy with aspergilosis: 46 cases (2001-2004). Journal of American Veterinary Association, v. 228, n. 5, p. 738742, 2006.

KING, L. G. Bacterial pathogens of the respiratory tract. In: Bacterial infections of the respiratory tract in dogs and cats. Bayer AG- veterinary learning systems. 1997. p. 11-18

KONDO, Y.; MATSUNAGA, S.; MOCHIZUKI, M.; KADOSAWA, T.; NAKAGAWA, T.; NISHIMURA, R.; SASAKI, N. Prognosis of canine patients with nasal tumors according to modified clinical stages based on computed tomography: A

Retrospective Study. Journal of Veterinary Medicine Science. v. 70, n. 3, p. 207 212, 2008. Disponível em:<http://www.jstage.jst.go.jp/article/jvms/70/3/70_207/_article> Acesso em: 21 out. 2010.

KUEHN, N. F. Nasal computed tomography. Clinical Techiniques in Small Animal Practice, v. 21, n. 2, p. 55-59, may 2006. 
LANA. S. E.; WITHROW, S. J. Tumors of the respiratory system - nasal tumors. In: WITHROW, S. J; Mac EWEN, E.G. (Ed). Small animall oncology. 3 ed.

Philadelphia: Saunders, 2001. p. 370-377.

LAVIN, L. M. Small animal skull. In: Radiography in veterinary technology. Saunders Elsevier:Philadelphia. 2007. p. 193-198.

LEFEBVRE, J.; KUEHN, N. F.; WORTINGER, A. Computed tomography as an aid in the diagnosis of chronic nasal disease in dog. Journal of Small Animal Practice. $v$, 46, p. 280-85, 2005.

McCARTHY, T. C.; McDEIRMAN, S. L. Rhinoscopy. Veterinary Clinics of North America: Small Animal Practice, v.20, n. 5, p. 1265-90, 1990.

McCARTHY, T. C. Rhinoscopy: the diagnostic approach to chronic nasal disease. In:__ Veterinary Endoscopy. St.Louis: Elsevier Saunders, 2005. p. 137-200.

MILES, M. S.; DHALIWAL, R. S.; MOORE, M. P.; REED, A. L. Association of magnetic resonance imaging findings and histologic diagnosis in dogs with nasal disease: 78 cases (2001 - 2004). Journal of American Veterinary Association, v. 232, n. 12, p. 1844-49, 2008.

MYER, W. The nasal cavity and paranasal sinuses. In: THRALL, D.E. Textbook of veterinary diagnostic radiology. 2 ed. Philadelphia: W.B Saunders, 1994. p.40-45.

NELSON, R.; COUTO, C. G. Medicina interna de pequenos animais. 2 ed. Rio de Janeiro: Guanabara Koogan, 2001. p. 177-186.

NOONE, K. E. Rhinoscopy, pharingoscopy and laryngoscopy. Veterinary Clinics of North America: Small Animal Practice. v.31, n.4, p. 671-689, 2001.

PARK, R. D.; BECK, E. R.; LeCOUTEUR, R. A. Comparsion of computed tomography and radiography for detecting changes induced by malignant nasal neoplasia in dogs. Journal of American Veterinary Medical Association, v. 201, n. 11, p. 1720-24, 1992.

PIETRA, M.; SPINELLA, G.; PASQUALI, F.; ROMAGNOLI, N.; BETTINI, G. SPADARI, A. Clinical findings, rhinoscopy and histological evaluation of 54 dogs with chronic nasal disease. Journal of Veterinary Medicine Science. v.11, n 3, p. 249 55, 2010. Disponível em: <http://www.ncbi.nlm.nih.gov/pmc/articles/PMC2924487/> Acesso em: 18 set. 2010.

POWDER, S.; ROSE., M.; CRAWFORD, J. Radiographic techiniques of the nasal cavity and sinuses. Clinical Techiniques in Small Animal Practice, v. 21, n. 2, p. 46-54, may 2006.

RUSSO, M., LAMB, C. R., JAKOVLJEVIC, S. Distinguishing rhinitis and nasal neoplasia by radiography. Veterinary Radiology Ultrassond. v. 41, n. 2, p. 118124, 2000. 
SAUNDERS, J.; CLERCX, C.; SNAPS, F.; SULLIVAN, M.; DUCHATEAU, L.; VAN BREE, H.J.; DONDELINGER, R.F. Radiographic, magnetic resonance imaging, computed tomographic, and rhinoscopic features of nasal aspergillosis in dogs. Journal of American Veterinary Association. v. 225, p. 1703-12, 2004.

SAUNDERS, J.; VAN BREE, H. Comparsion of radiography and computed tomography for the diagnosis of canine nasal aspergillosis. Veterinary Radiology Ultrassond, v. 44, n. 4 p. 414-19, 2003.

SAUNDERS, J.; VAN BREE, H.; GIELEN, I.; DE ROOSTER, H. Diagnostic value of computed tomography in dogs with chronic nasal disease. Veterinary Radiology Ultrassond, v. 44, n. 4, p. 409-13, 2003.

SCHWARZ, T. Comparision of sensitivity and specificity of conventional radiography and computed tomographic in nasal tumors and fungal rhinitis in dogs. Veterinary Radiology Ultrassond, v. 36, n. 4, p. 428, 1995.

SCHWARZ, T., SULLIVAN, M., HARTUNG, K. Radiographic of the cribriforme plate (lamina cribrosa). Veterinary Radiology, v. 41, n. 2, p. 220-30. 2000.

SHARP, N. J. H.; McENTEE, M.; GILSON, S.; THRALL, D. Nasal cavity and frontal sinuses. Problems in Veterinary Medicine. v. 3, n. 2, p. 170-87, 1991.

SONNTAG, F.; MIHALJEVIC, M.; KLUMPP, S.; KRAMER, M.; JAWINSKI, S. Kopf. In: MIHALJEVIC, M.; KRAMER, M.; GOMERCIC, H. CT und MRT-ATLAS.

Transversalanotomie des hundes. Sttuttgart:Parey 2009. p. 20-58.

TASKER, S.; KNOTTENBELT, C.M.; MUNRO, E.A.C., STONEHEWER, J., SIMPSON, J.W., MACKIN, A.J. Aetiology and diagnosis of persistent nasal disease in the dog: a retrospective study of 42 cases. Journal of Small Animal Practice, v. 40, p. 473-78, 1999.

THRALL, D. E.; ROBERTSON, I.A.; McLEOD, D. A.; HEIDNER, G. L.; HOPPES, P. J.; PAGE, R. L. A comparsion of radiographic and computed tomographic findings in 31 dogs with malignant nasal cavity tumors. Veterinary Radiology, v. 30, p. 59-65, 1989.

VENKERVAN HAAGEN, A. The nose and nasal sinuses. In: Ear, nose throat, and tracheobronchial diseases in dogs and cats. Hannover: Schlütersche, 2005. p. 51-81.

WILLARD, M. D.; RADLINSKY, M. A. Endoscopy examination of choanae in dogs and cats: 118 cases. Journal of American Veterinary Association, v. 215, n. 9, p. 1301-05, 1999.

WINDSOR, R. C.; JOHNSON, L.R. Canine chronic inflamatory rhinits. Clinical Techiniques in Small Animal Practice. v. 21, n. 2, p. 76-81, may 2006. 
WINDSOR, R. C.; JOHNSON, L.R.; HERGESELL, E.J.; DE COCK , H. Idiopathic linfoplasmocytic rhinits in 37 dogs: 1997-2002. Journal of American Veterinary Medical Association. v. 224, n. 12, p. 1952-57, 2004.

WITHROW, S. J. Tumors of the respiratory system. In: ; MACEWEN, G. Clinical veterinary oncology. Philadelphia: J.B.Lippincott. 1989. p. 215-33.

YOSHITOSHI, F. N. Contribuição ao estudo da rinoscopia na avaliação de afecções nasais no cão (Canis familiaris). 2001. 135f. Dissertação (Mestrado em Medicina Veterinária) - Faculdade de Medicina Veterinária e Zootecnia, Universidade de São Paulo, São Paulo, 2003. 


\section{APÊNDICES}

\section{APÊNDICE A}

Tabela 26 - Escore exame radiográfico

\section{RADIOGRAFIA}

\begin{tabular}{cccc}
\hline Casos & Presença de lesão & Extensão da lesão & Suspeita diagnóstica \\
\hline 01 & 1 & 0 & 0 \\
\hline 02 & 3 & 1 & 2 \\
\hline 03 & 3 & 1 & 2 \\
\hline 04 & 2 & 1 & 2 \\
\hline 05 & 3 & 1 & 2 \\
\hline 06 & 2 & 1 & 1 \\
\hline 07 & 2 & 1 & 1 \\
\hline 08 & 1 & 0 & 0 \\
\hline 09 & 1 & 1 & 1 \\
\hline 10 & 1 & 2 & 0 \\
\hline 11 & 1 & 1 & 2 \\
\hline 12 & 1 & 0 & 2 \\
\hline 13 & 1 & 0 & 0 \\
\hline 14 & 1 & 0 & 1 \\
\hline 15 & 1 & 0 & 1 \\
\hline 16 & 1 & 0 & 1 \\
\hline 17 & 3 & 1 & 2 \\
\hline 18 & 1 & 0 & 0 \\
\hline 19 & 1 & 1 & 1 \\
\hline 20 & 1 & 1 & 1 \\
\hline
\end{tabular}

- Escore presença de lesão: 0- Não sugere; 1-Sugere; 2- Provável lesão; 3-Confirma existência da lesão.

- Escore extensão da lesão: 0- Não limita 1-Limite impreciso; 2- Limite preciso; 3-Delimita a lesão.

- Escore suspeita diagnóstica: 0- Não Suspeita 1-Suspeita; 2- Forte suspeita; 3-Confirma. 


\section{APÊNDICE B}

Tabela 27 - Escore exame tomográfico

TOMOGRAFIA

\begin{tabular}{cccc}
\hline Casos & Presença de lesão & Extensão da lesão & Suspeita diagnóstica \\
\hline 01 & 2 & 2 & 2 \\
\hline 02 & 3 & 2 & 3 \\
\hline 03 & 3 & 2 & 3 \\
\hline 04 & 3 & 2 & 2 \\
\hline 05 & 3 & 2 & 2 \\
\hline 06 & 2 & 2 & 2 \\
\hline 07 & 3 & 2 & 2 \\
\hline 08 & 1 & 0 & 0 \\
\hline 09 & 2 & 2 & 2 \\
\hline 10 & 2 & 2 & 2 \\
\hline 11 & 1 & 1 & 1 \\
\hline 12 & 2 & 2 & 1 \\
\hline 13 & 2 & 2 & 2 \\
\hline 14 & 2 & 2 & 1 \\
\hline 15 & 2 & 2 & 1 \\
\hline 16 & 2 & 2 & 1 \\
\hline 17 & 3 & 2 & 3 \\
\hline 18 & 2 & 2 & 0 \\
\hline 19 & 2 & 2 & 2 \\
\hline 20 & 2 & 2 & 1 \\
\hline & & &
\end{tabular}

- Escore presença de lesão: 0- Não sugere; 1-Sugere; 2- Provável lesão; 3-Confirma existência da lesão.

- Escore extensão da lesão: 0- Não limita 1-Limite impreciso; 2- Limite preciso; 3-Delimita a lesão.

- Escore suspeita diagnóstica: 0- Não Suspeita 1-Suspeita; 2- Forte suspeita; 3-Confirma. 


\section{APÊNDICE C}

Tabela 28 - Escore rinoscopia

\begin{tabular}{|c|c|c|c|}
\hline & & & \\
\hline Casos & Presença de lesão & Extensão da lesão & Suspeita diagnóstica \\
\hline 01 & 3 & 1 & 2 \\
\hline 02 & 3 & 1 & 2 \\
\hline 03 & 3 & 1 & 2 \\
\hline 04 & 3 & 1 & 1 \\
\hline 05 & 3 & 1 & 1 \\
\hline 06 & 3 & 1 & 2 \\
\hline 07 & 3 & 1 & 2 \\
\hline 08 & 3 & 2 & 2 \\
\hline 09 & 3 & 1 & 2 \\
\hline 10 & 3 & 3 & 3 \\
\hline 11 & 3 & 2 & 2 \\
\hline 12 & 3 & 2 & 3 \\
\hline 13 & 3 & 2 & 1 \\
\hline 14 & 3 & 0 & 1 \\
\hline 15 & 3 & 2 & 3 \\
\hline 16 & 3 & 2 & 2 \\
\hline 17 & 3 & 1 & 2 \\
\hline 18 & 3 & 3 & 3 \\
\hline 19 & 3 & 0 & 1 \\
\hline 20 & 3 & 1 & 3 \\
\hline
\end{tabular}

- Escore presença de lesão: 0- Não sugere; 1-Sugere; 2- Provável lesão; 3-Confirma existência da lesão.

- Escore extensão da lesão: 0- Não limita 1-Limite impreciso; 2- Limite preciso; 3-Delimita a lesão.

- Escore suspeita diagnóstica: 0- Não Suspeita 1-Suspeita; 2- Forte suspeita; 3-Confirma. 


\section{HOSPITAL VETERINÁRIO}

\section{DA \\ FACULDADE DE MEDICINA VETERINÁRIA E ZOOTECNIA DA USP}

\section{TERMO DE CIÊNCIA E AUTORIZAÇÃO}

EU, , responsável pelo animal da espécie raça sexo , com

(De Idade), registrado no Hospital Veterinário da FMVZ sob $n^{\circ}$ ESTOU CIENTE de que o animal de minha propriedade fará parte do protocolo de pesquisa intitulado:

, em desenvolvimento no Serviço de Faculdade, sob a responsabilidade do Professor Doutor Departamento de da desta , do procedimentos que serão aplicados nesse animal.

Por estar plenamente concorde firmo o presente.

São Paulo, de de

NOME: ASSINATURA

RG 